UNIVERSIDADE DE SÃO PAULO

INSTITUTO DE ASTRONOMIA, GEOFÍSICA E CIÊNCIAS ATMOSFÉRICAS

DEPARTAMENTO DE GEOFÍSICA

DIONÍSIO UENDRO CARLOS

DESENVOLVIMENTO E CONSTRUÇÃO DE BLOCOS DE CONCRETO RADIOATIVO PARA A CALIBRAÇÃ̃O DE ESPECTRÔMETROS GAMA PORTÁTEIS E AEROTRANSPORTADOS, UTILIZADOS EM EXPLORAÇÃO MINERAL E DE HIDROCARBONETOS

SÃO PAULO

2006 
DIONÍSIO UENDRO CARLOS

DESENVOLVIMENTO E CONSTRUÇÃO DE BLOCOS DE CONCRETO RADIOATIVO PARA A CALIBRAÇÃ̃O DE ESPECTRÔMETROS GAMA PORTÁTEIS E AEROTRANSPORTADOS, UTILIZADOS EM EXPLORAÇÃO MINERAL E DE HIDROCARBONETOS

Dissertação apresentada ao Instituto de Astronomia, Geofísica e Ciências Atmosféricas da Universidade de São Paulo para obtenção do Grau de Mestre em Ciências Geofísicas.

Área de Concentração: Geofísica

Orientador: Prof. Dr. Fernando Brenha Ribeiro

SÃO PAULO

2006 


\section{Índice Remissivo}

1. Introdução ............................................................................................................................. 1

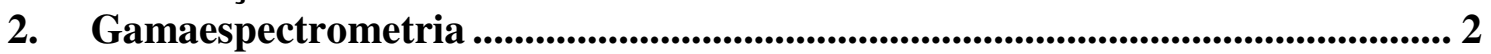

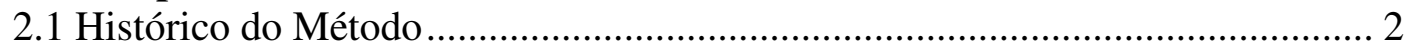

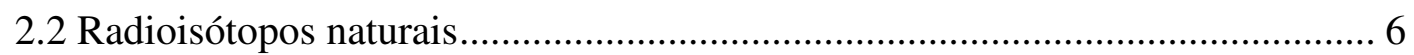

2.2.1 Desequilíbrio Radioativo ......................................................................... 7

2.3 Instrumentação de Campo .................................................................. 9

2.3.1 Espectrômetros Gama Aerotransportados ................................................... 9

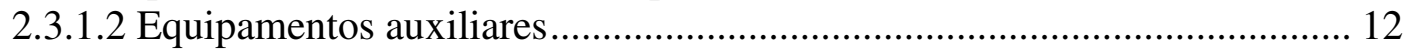

2.3.2 Espectrômetros Gama Portáteis.................................................................... 13

2.4 Padrões e Instalações para calibração dos instrumentos aerotransportados e

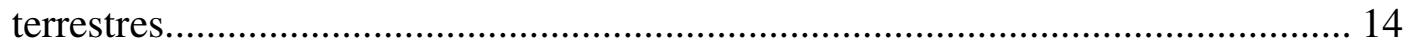

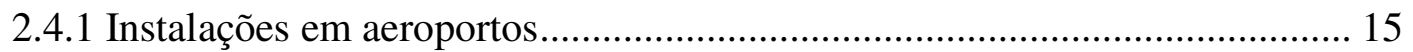

2.4.2 Instalações em centros de pesquisa ............................................................... 17

2.4.3 Blocos de calibração transportáveis ........................................................... 20

2.5 Aquisição e Processamento dos Dados ........................................................... 22

2.5.1 Correção do Efeito Compton ...................................................................... 23

3.Construção das Fontes de Calibração ................................................................................. 25

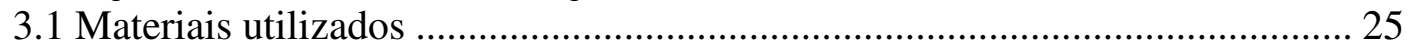

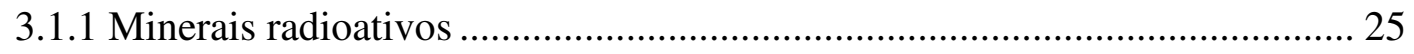

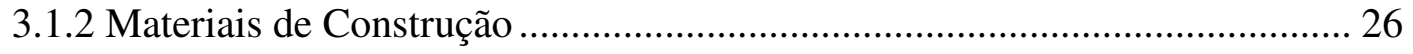

3.1.3 Projeto dos Blocos de Calibração .................................................................. 26

3.2 Montagem do Suporte de Madeira ................................................................ 27

3.2.1 Montagem do molde para cura do concreto ................................................. 29

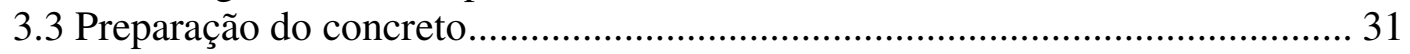

3.4 Envasamento, retirada de amostras e cura do concreto ................................... 34

4. Características Físicas dos Blocos Construídos ............................................... 36

4.1 Densidade do Concreto em cada bloco........................................................ 36

4.2 Distribuição do Fluxo de radiação gama proveniente dos blocos de

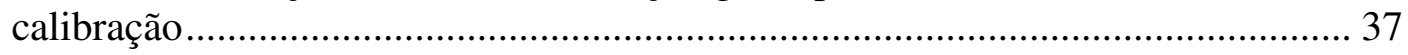

4.2.1 A blindagem lateral do detector................................................................. 41

4.2.2 Verificação da homogeneidade da distribuição da intensidade do fluxo de radiação gama proveniente da superfície do concreto............................................ 44 4.2.3 Uma segunda forma de verificar a homogeneidade da distribuição da intensidade do fluxo de radiação gama proveniente da superfície do concreto ..... 50

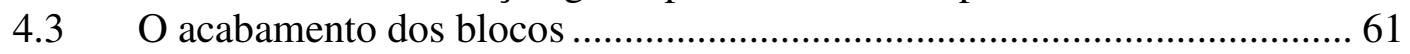
4.3.1 O efeito do acabamento sobre o fluxo de radiação gama proveniente da

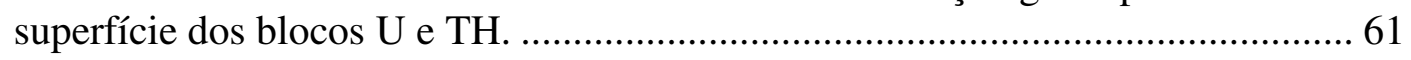
4.4 Determinação das concentrações de potássio, urânio e tório nas amostras de

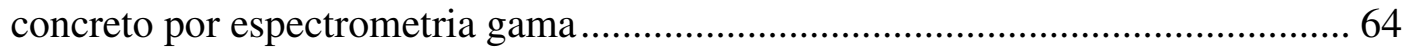

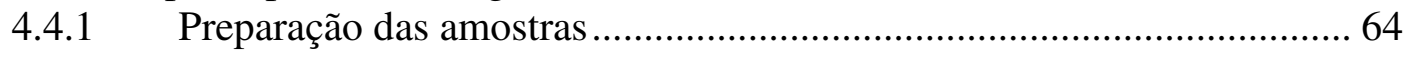

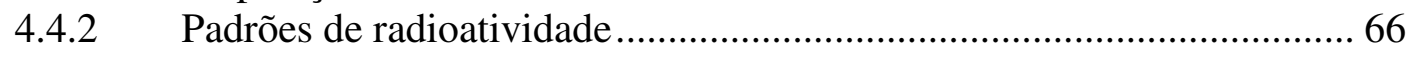

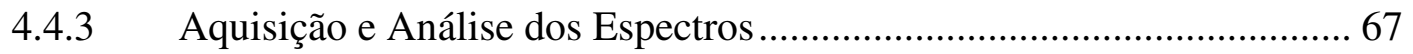

4.5 Concentrações de potássio, urânio e tório nas amostras de concreto ............... 75

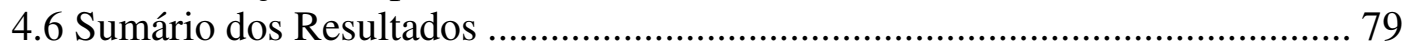

5. Calibração de Espectrômetros Gama Portáteis e Aerotransportados ................. 80

5.1 Calibração de Espectrômetros Portáteis ........................................................ 80

5.2 Calibração de Espectrômetros Aerotransportados.......................................... 86

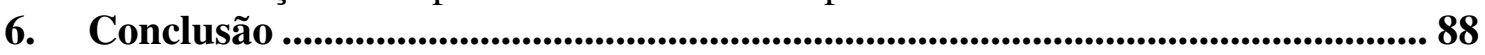


7. Referências Bibliográficas . 


\section{Índice de Tabelas}

Tabela 2.3.1.1 Janelas espectrais e o intervalo de energia para cada uma das janelas de interesse seguindo indicação da IAEA (1991).

Tabela 2.3.2.1 Janelas espectrais e o intervalo de energia para cada uma das janelas segundo indicação da IAEA (1991)

Tabela 2.4.1.1 Valores das concentrações dos blocos de calibração localizados no aeroporto de Vantaa, Finlândia, conforme Multala(1981).................................... 15

Tabela 2.4.1.2.Valores das concentrações dos blocos da Grand Junction (USA), conforme Ward (1978).

Tabela 2.4.1.3 Valores das concentrações dos blocos da Tailândia................................. 16

Tabela 2.4.2.1 Valores das concentrações dos blocos do Instituto Ris $\phi$, Dinamarca. Conforme Lфvborg colaboradores (1978).

Tabela 2.4.2.2 Valores das concentrações dos blocos localizados no IRD/CNEN (RJ). 18

Tabela 2.4.2.3 Concentrações ideais para os blocos de calibração de detectores aerotransportados.

Tabela 2.4.2.4 Concentrações ideais para os blocos de calibração de detectores portáteis.

Tabela 2.4.3.1 Valores das concentrações dos blocos transportáveis para calibração de detectores gama aerotransportados e terrestres, conforme Grasty (1991).............. 20

Tabela 2.4.3.2 Valores das concentrações dos blocos transportáveis para calibração de detectores gama aerotransportados e terrestres da AGSO, conforme AGSO (1995).

Tabela 2.4.3.3 Valores das concentrações dos blocos transportáveis para calibração de detectores gama aerotransportados e terrestres do CSIRO, conforme AGSO (1995). .

Tabela 2.5.1.1 Coeficientes de espalhamento Compton e seus significados................... 23

Tabela 3.1.3.1 Valores das concentrações nominais de potássio, urânio e tório para os diferentes blocos de calibração.

Tabela 3.3.1 Valores das massas dos diversos constituintes utilizados na preparação do concreto de cada bloco.

Tabela 4.1.1 Valores das densidades de cada bloco. Com a utilização dos valores de densidade foi possível estimar a massa de cada bloco, adotando-se um volume nominal de $0,3 \mathrm{~m}^{3}$ para todos os blocos. Obs. D1=primeira medida de densidade e assim por diante.

Tabela 4.2.2.1 Valores das medidas da radiação de fundo para cada bloco de calibração.

Tabela 4.2.2.2 Valores das medidas das taxas de contagens do canal de contagem total para os blocos de calibração.

Tabela 4.2.3.1 Valores dos coeficientes ajustados com base nos dados da Tabela 4.2.2.2.

Tabela 4.2.3.2 Valores dos coeficientes ajustados para uma biquadrática para os blocos $\mathrm{U}$ e $\mathrm{TH}$

Tabela 4.3.1.1 Valores da radiação de fundo do canal de contagem total, medido sobre a superfície dos blocos U e TH, após a impermeabilização dos mesmos.

Tabela 4.3.1.2 Valores do canal de contagem total dos blocos U e TH, após a impermeabilização da superfície.

Tabela 4.3.1.3 Valores dos ajustes para os blocos $\mathrm{U}$ e TH, de uma função do primeiro grau. 
Tabela 4.4.1.1 Massas das alíquotas, que foram quarteadas e massas das amostras que foram seladas em porta-amostras, para medida da atividade.

Tabela 4.4.3.2.1 Radioelementos utilizados para cálculo das atividades do potássio, urânio e tório.

Tabela 4.4.3.4.1 Valores dos níveis de decisão e dos limites de detecção para o padrão estéril com matriz de $\mathrm{SiO}_{2}$

Tabela 4.4.3.5.1 Valores das atividades dos radioelementos da série do urânio............. 72

Tabela 4.4.3.5.2 Valores das atividades dos radioelementos da série do tório. .............. 74

Tabela 4.5.1 Valores de concentração de cada amostra do bloco K1 ............................. 76

Tabela 4.5.2 Valores de concentração de cada amostra do bloco U. ............................... 76

Tabela 4.5.3 Valores de concentração de cada amostra do bloco TH............................. 76

Tabela 4.5.4 Valores de concentração de cada amostra do bloco M1 ............................. 77

Tabela 4.5.5 Valores de concentração de cada amostra do bloco M2 ........................... 77

Tabela 4.5.6 Valores de concentração de cada amostra do bloco M3 ................................ 77

Tabela 4.5.7 Valores de concentração de cada amostra do bloco BKG1....................... 78

Tabela 4.5.8 Valores de concentração de cada amostra do bloco BKG2 ....................... 78

Tabela 4.5.9 Valores das concentrações dos blocos obtidas das atividades determinadas por espectrômetro gama semicondutor de HPGe. ............................................... 78

Tabela 5.1.1.1 Valores das concentrações líquidas dos blocos, medidos por espectrometria gama de alta resolução.

Tabela 5.1.1.2 Valores das taxas de contagens (cpm) líquidas dos blocos, medidas com espectrômetro gama portátil.

Tabela 5.1.1.3 Valores das constantes de espalhamento Compton e janelas de sensibilidades do espectrômetro gama portátil do IAG/USP.

Tabela 5.2.1 Exemplos de valores de coeficientes de espalhamento Compton para dois sistemas de detecção gamaespectrométricos. 


\section{Índice de Figuras}

Figura 2.1.1 Janela de contagem total (a) e razão entre alta e baixa energia (b) apresentando a detecção da radiação artificial dos fragmentos da Cosmos-954 no norte do Canadá. Retirado de IAEA (1991).

Figura 2.3.1.1 Espectro característico de aerolevantamento, apresentando as janelas de energia. Retirado IAEA (2003).

Figura 2.3.1.2 Espectro de tório, mostrando o procedimento para determinação da resolução. Retirado de AGSO (1995).

Figura 2.3.2.1 Representação gráfica das janelas de energia utilizadas em espectrometria gama terrestre. Retirado de L $\phi$ vborg \& Mose(1987).

Figura 2.4.1.1 Representação esquemática dos blocos de calibração localizados no aeroporto de Vantaa, Finlândia. Adaptado de Multala (1981).

Figura 2.4.1.2 Representação esquemática dos blocos de calibração localizados no aeroporto de Walker Field, Grand Junction, Colorado, Estados Unidos. Adaptado de Ward (1978).

Figura 2.4.1.3 Representação esquemática dos blocos de calibração localizados no aeroporto de U-Tapao, Tailândia. Adaptado de Grasty (1987).

Figura 2.4.2.1 Representação esquemática dos blocos de calibração para detectores gama portáteis do Ris $\phi$ National Laboratory, Dinamarca. Adaptado de L $\phi$ vborg e colaboradores (1978).

Figura 2.4.2.2 Representação esquemática dos blocos de calibração para detectores gama portáteis do IRD/CNEN/RJ. Adaptado de Barreto e colaboradores (1986). 18

Figura 2.4.3.1 Calibração conjunto de detector gama aerotransportado. No detalhe, bloco de urânio. Figura retirada do Geological Survey of Canada. ....................... 20

Figura 2.5.1.1 Representação esquemática da interação entre as janelas de energia do potássio (K), urânio (U) e Tório (Th). Os coeficientes comumente utilizados são $(\alpha, \beta, \gamma)$. Adaptado de Killeen (1979).

Figura 3.2.1 Desenho esquemático das placas de madeira para obtenção do tablado.... 28

Figura 3.2.2 Distribuição das vigas de madeira na base do molde................................. 28

Figura 3.2.3 Aspecto final da base madeira. Observar a distribuição dos parafusos na base de madeira.

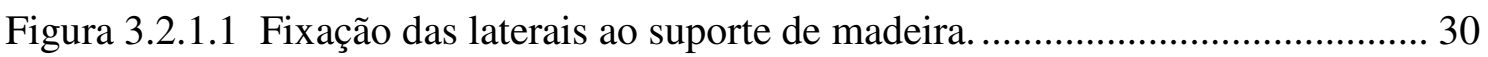

Figura 3.2.1.2 Aspecto final do molde de madeira inteiramente montado...................... 30

Figura 3.4.1 Distribuição espacial dos pontos de amostragem dos blocos.................... 35

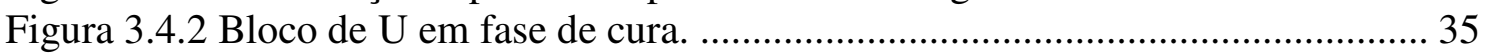

Figura 4.2.1.1 Anel de chumbo utilizado como blindagem lateral............................... 41

Figura 4.2.1.2 As folhas de alumínio foram introduzidas nos diâmetros internos dos

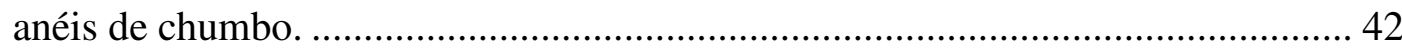

Figura 4.1.2.3 As várias camadas de alumínio foram montadas aos anéis de chumbo de modo a obter-se uma blindagem mais efetiva da radiação................................... 42

Figura 4.2.1.4 Apresenta a montagem da blindagem durante as medidas sobre a superfície dos blocos de calibração. .................................................................... 43

Figura 4.2.2.1. Pontos de medidas da radiação gama..................................................... 44

Figura 4.2.3.1 Medidas do bloco de background 2 - BKG2. Os dados foram ajustados a uma superfície planar. Note a variação percentual das medidas na escala de cores (aproximadamente $\pm 0,6 \%$ ).

Figura 4.2.3.2 Medidas do bloco de potássio - K1. Os dados foram ajustados a uma superfície planar. Note a variação percentual das medidas na escala de cores (aproximadamente $\pm 6 \%$ ). 
Figura 4.2.3.3 Medidas do bloco mista 2 - M2. Os dados foram ajustados a uma superfície planar. Note a variação percentual das medidas na escala de cores (aproximadamente +3 e $-1 \%$ ).

Figura 4.2.3.4. Medidas do bloco de background 1 - BKG1. Os dados foram ajustados a uma superfície planar. Note a variação percentual das medidas na escala de cores (aproximadamente +3 e -2 ).

Figura 4.2.3.5 Medidas do bloco mista 1 - M1. Os dados foram ajustados a uma superfície planar. Note a variação percentual das medidas na escala de cores (aproximadamente $\pm 5 \%$ ).

Figura 4.2.3.6 Medidas do bloco mista 3 - M3. Os dados foram ajustados a uma superfície planar. Note a variação percentual das medidas na escala de cores (aproximadamente $\pm 3 \%$ ).

Figura 4.2.3.7. Medidas do bloco de urânio - U. Os dados foram ajustados a uma superfície biquadrática. Note que o mapa de isolinhas não está centralizado, sugerindo um escape preferencial de radônio para a direita do eixo $\mathrm{X}$.

Figura 4.2.3.8. Medidas do bloco de tório - TH. Os dados foram ajustados a uma superfície biquadrática. Note que o mapa de isolinhas não está centralizado, sugerindo um escape preferencial de radônio obliquamente e a esquerda do eixo $\mathrm{X}$. 


\section{Resumo}

Oito blocos transportáveis para calibração foram construídos para serem utilizados como padrões de concentração na calibração de espectrômetros gama portáteis e aerotransportados. Todo o procedimento de construção é descrito em detalhe.

Os blocos, com dimensões de $1 \mathrm{~m}$ x $1 \mathrm{~m}$ x 0,30 m e massas variando entre $593 \mathrm{~kg}$ e 673 $\mathrm{kg}$, devem a sua radioatividade à adição de diferentes quantidades de feldspato potássico (ortoclásio), caldasito e areia monazítica à massa de concreto. As concentrações de potássio, urânio e tório variam significativamente de um bloco para outro atingindo valores máximos de 5,7\% de K, 45,6 ppm eU e 137 ppm eTh.

A distribuição do fluxo de radiação gama proveniente da superfície dos blocos de concreto e a magnitude das heterogeneidades na concentração dos elementos radioativos foi determinada experimentalmente.

Como exemplo de aplicação apresenta-se o resultado da calibração de um espectrômetro gama portátil. 


\begin{abstract}
Eight transportable calibration pads were built in to be used as concentration standards for portable and airborne gamma-ray spectrometers calibrations. The pads construction procedure is described in full detail. The pads, with dimensions of $1 \mathrm{~m} \times 1 \mathrm{~m} \times 0,30 \mathrm{~m}$ and masses between $593 \mathrm{~kg}$ and $673 \mathrm{~kg}$ were made radioactive by the addition of different amounts of k-feldspar, caldasite and monazitic sand to the concrete masses. The potassium, uranium and thorium concentration vary significantly in the pads, reaching maximum values of 5,7\% of $\mathrm{K}, 45,6 \mathrm{ppm} e U$ and $137 \mathrm{ppm}$ eTh.

The distribution of the gamma radiation flux from the pads surfaces and the heterogeneity magnitudes of the radioactive elements concentration were experimentally established.
\end{abstract}

An example of gamma-ray spectrometer calibration is presented. 


\section{Agradecimentos}

Gostaria, em primeiro lugar, de agradecer a Deus pelo dom sublime da vida. Tantas pessoas deveriam ser lembradas nesse momento e eventualmente, se alguma for omitida, tenham certeza que não foi um ato proposital do autor. Agradecimentos ao Convênio ANP/Escola Politécnica da USP e a AGP-LA (Aerogeophysica Latinoamerica), pela compra de materiais e ferramentas para elaboração do trabalho. Agradeço a meu orientador professor Dr. Fernando Brenha Ribeiro por acreditar que seriam possíveis o desenvolvimento, construção e certificação dos blocos. Ao professor Dr. Francisco Y. Hiodo, pelas discussões sobre algumas abordagens teóricas e experimentais. Agradecimentos especiais são devidos a toda a equipe de serviços gerais e manutenção deste instituto, pessoas como: Sr. Lázaro e Sr. Dario que propiciaram a utilização do local e ferramentas para o desenvolvimento e construção dos blocos. Na fase de preparação do concreto o autor recebeu ajuda inestimável do Sr. João e também durante o acabamento dos mesmos. Durante o envasamento dos blocos ao Sr. Mário Gonçalves, também, reitero meus agradecimentos.

Impossível não citar os amigos de sempre, meu companheiro Gilmar Rodrigues do Carmo, a quem as reclamações, alegrias e novas conquistas, eram sempre partilhadas, valeu camarada. Ao amigo Luiz Gustavo Rodrigues Pinto, por proporcionar retorno seguro e tranqüilo quando íamos e voltávamos da maravilhosa cidade de Limeira. Ao amigo Danillo, por colocar algumas amostras nos finais de semana. A todos os amigos da pós-graduação: Slot, Tom, Alanna, Deborah, Alexandre Maia, Francisca, Alexandre Lopes, Alexandre Lago, Gelvam, Fábio Lucas, Érika, Rosana, Marcelo Peres, Lívia, Rodrigo Nunes. Ao químico do laboratório de Geoquímica: Roberto.

A pesquisadora do Laboratório de Poços de Caldas, Maria Helena Tirollo Taddei pela concessão dos materiais para construção dos blocos. Ao Sr. Fernando Taddei das 
Indústrias Nucleares do Brasil, pela autorização e permissão para a pulverização das amostras, no caso, o Sr. José Antônio de Siqueira, pela execução do trabalho.

A Dr. Elisabeth Yoshimura pela utilização do microscópio do Laboratório de Dosimetria do Instituto de Física da Universidade de São Paulo e a seu aluno de pósgraduação Tiago, que me deu o treinamento inicial a Técnica dos Detectores Nucleares de Traço Sólido (SSNTD).

Aos meus pais Dionísio e Olga, pessoas humildes a quem devo todas as minhas conquistas e formação. Aos meus irmãos, Enéas, Zilda e Luzia, exemplos constantes de pessoas trabalhadoras e honestas. A minha sobrinha Lívia, motivo de momentos alegres nesses dois anos. A minha noiva Milena, companheira nos momentos de conquistas e também reclamações. A Dr. Silvia H. Nicolai, pelo incentivo durante todo o trabalho. Ao Sr. Carlos da mecânica de automóveis, sempre solícito aos pedidos de empréstimo de ferramentas. A todo pessoal da minha querida cidade de Limeira: Pedro Valdecir, Agostinho, Zezé, Chico, Rosana, Sônia, Zé, a quem nesse momento ofereço um pouco daquilo que conquistei. Ao pessoal da república: Jovino, João, Berto, Pedrão e Henrique Dal Pozzo.

Finalmente aos grandes pesquisadores: Stromswold, Killeen, Koizumi, Multala e Brian S. Minty e ao Ris $\phi$ Establishment (Dinamarca) pelas motivações de continuar com o trabalho. Não poderia deixar de lembrar a motivação de grandes expoentes da física nuclear experimental, principalmente E. O. Lawrence e M. S. Livingston - no desenvolvido dos aceleradores de partículas - cujo exemplo de dedicação, competência e conhecimento proporcionaram a descoberta de novos horizontes da física experimental e teórica. 
A pedra que os pedreiros rejeitaram, tornou-se agora a pedra angular.

Sl $118(117)$

xiii 


\section{Introdução}

A partir da década de 70 a indústria do aerolevantamento, especificamente a espectrometria gama aerotransportada iniciou a utilização de procedimentos para padronização do método.

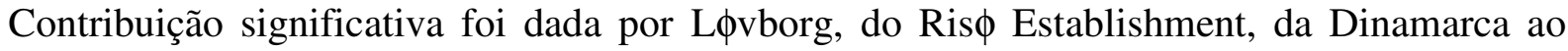
construir os primeiros blocos de calibração para espectrômetros gama portáteis. Através da elaboração de blocos de concreto circulares com material radioativo misturado a matriz de concreto foi possível estabelecer a relação entre as contagens fornecidas pelo equipamento e as concentrações de $\mathrm{K}$, U, Th e Contagem Total.

Finalmente no início da década de 90, Grasty e colaboradores (1991), desenvolveram blocos transportáveis para calibração (transportable calibration pads) de detectores tanto portáteis quanto aerotransportados.

A prática da utilização de blocos transportáveis tem sido adotada como procedimento padrão para determinação das constantes de espalhamento Compton por diversas companhias de aerolevantamento e órgãos governamentais como, por exemplo, o Serviço Geológico do Canadá, o Serviço Geológico Australiano e uma série de outras instituições públicas pelo mundo.

Neste trabalho, oito blocos de concreto, para calibração de espectrômetros gama portáteis e aerotransportados, foram construídos, seguindo o modelo proposto por Grasty e colaboradores (1991). 


\section{Gamaespectrometria}

\subsection{Histórico do Método}

A aerogamaespectrometria é uma técnica utilizada para mapeamento geológico, exploração mineral e monitoramento ambiental (Darnley, 1991). Todo o processo de desenvolvimento desta metodologia não envolveu apenas física nuclear, instrumentação nuclear e computação científica, mas geologia, geoquímica, mineralogia, ciência do solo, meteorologia e aviação.

A primeira geração de instrumentação para levantamentos aero-radiométricos foi concebida e desenhada antes que a discriminação da energia da radiação gama em operações de vôo fosse uma prática possível. Em função disso, pode-se dizer que o levantamento aero-radiométrico desenvolvido durante a década de 50 era de valor limitado.

Em 1943 foram feitas as primeiras propostas para utilização dos detectores de radiação em aeronaves para exploração de urânio. No final da década de 60, mapeamentos radiométricos quantitativos da superfície tornaram-se o objetivo principal dos levantamentos aéreos, suprimindo a pesquisa qualitativa por anomalias radioativas isoladas que caracterizaram a primeira fase da exploração radiométrica (Darnley e Fleet, 1968, apud Darnley, 1991). Com esta mudança na filosofia todos os pontos de dados tornaram-se significantes, incluindo aqueles feitos sobre área previamente denominadas "background". Isso necessitou muito aperfeiçoamento na estatística de contagem forçando um maior avanço na sensibilidade e estabilidade espectral da instrumentação. Novas convenções para relatórios dos dados, com instalações e procedimentos de calibração foram estabelecidas (Darnley, 1991).

A pesquisa e desenvolvimento necessários para trazer mudanças ocorreram no Canadá entre 1966-1970, com financiamento fornecido pelo Geological Survey of Canada.

Nesse primeiro estágio participaram físicos do Atomic Energy of Canada Ltd, cada um responsável por tópicos específicos. Q. Bristow foi responsável pelo desenvolvimento da 
instrumentação radiométrica, D. K. Donhoffer por estudos de espalhamento atmosférico e atenuação e C. J. Thompson pelo tratamento dos dados.

Em 1968 R.L. Grasty juntou-se ao grupo para continuar o trabalho de tratamento dos dados e atenuação atmosférica e estender o entendimento da física envolvida na AGRS (Airborne Gamma-Ray Spectrometry).

Em 1969 foi apresentado o primeiro trabalho que constou de um mapeamento das concentrações de radioelementos naturais no solo, cobrindo uma área de $750 \mathrm{~km}^{2}$ da região aos arredores de Brancoft, Ontário. Mapas com coloração cinza foram apresentados, trazendo contornos indicando potássio em \%, ppm eU e ppm eTh (Darnley e Grasty,1971 apud Darnley, 1991).

A crise do petróleo de 1973 sustentou a oportunidade para aplicar esta nova tecnologia em uma sistemática pesquisa por regiões contendo mineralização de urânio. Dessa época são os grandes mapeamentos gamaespectrométricos governamentais como o programa NURE (National Uranium Resource Evaluation) dos EUA e também programas de exploração governamental do Canadá.

Além do mapeamento geológico a gamaespectrometria foi utilizada em outras aplicabilidades. A aplicação que tornou o método conhecido do público leigo foi a localização de pedaços do satélite radioativo russo COSMOS 954 (IAEA, 1991), que continha um pequeno reator nuclear e em sua reentrada na atmosfera terrestre o satélite foi destruído e caiu sobre território canadense em 1978. A Figura 2.1.1 (a) apresenta um perfil do canal de contagem total e a Figura 2.1.1 (b) a razão entre as baixas e altas energias da radiação do satélite. 


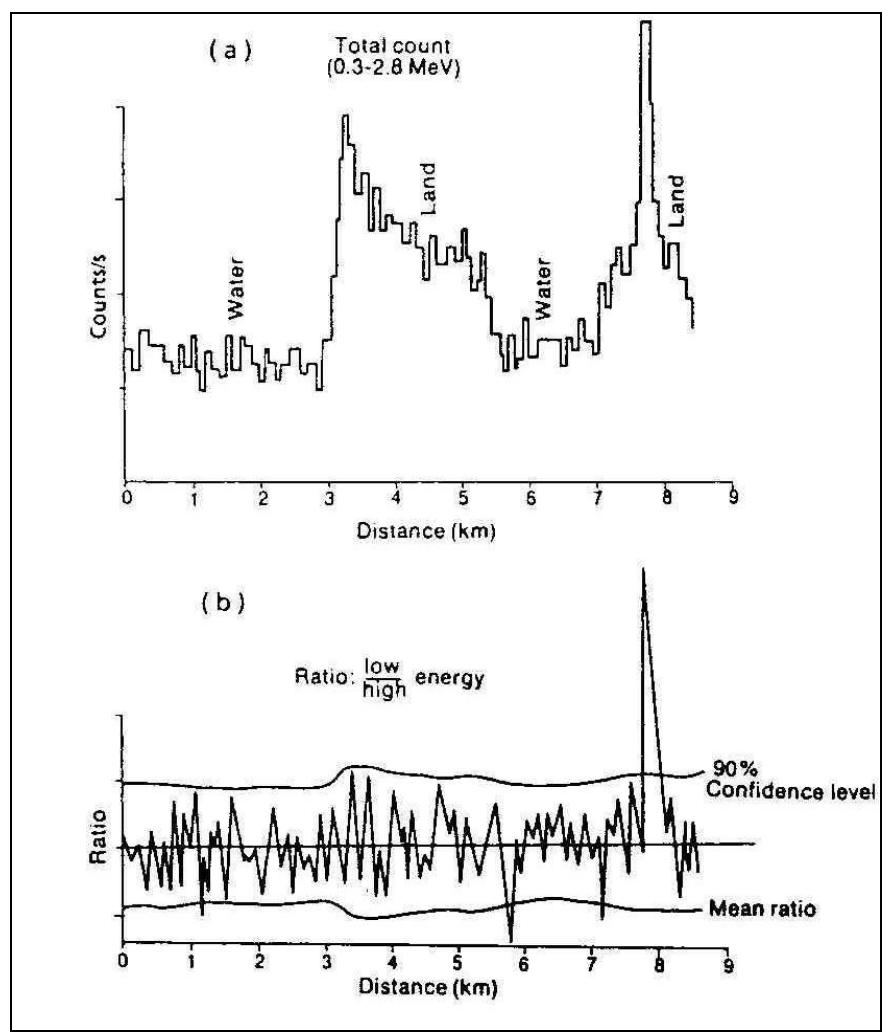

Figura 2.1.1 Janela de contagem total (a) e razão entre alta e baixa energia (b) apresentando a detecção da radiação artificial dos fragmentos da Cosmos-954 no norte do Canadá. Retirado de IAEA (1991).

Durante a década de 80 acumulou-se muita experiência dos levantamentos regionais iniciados na década de 70. O primeiro avanço nessa época foi nas técnicas de computação que permitiram a apresentação dos resultados em mapas coloridos.

Um segundo avanço foi o estabelecimento de uma padronização para a apresentação dos resultados dos aerolevantamentos gamaespectrométricos. Inicialmente os dados eram apresentados na escala em que os equipamentos faziam as medidas, geralmente cps (contagem por segundo) ou cpm (contagem por minuto).

O inconveniente da utilização dessas unidades é que não poderia haver uma concatenação dos dados adquiridos por diferentes sistemas de aquisição dos dados radiométricos. Procedimentos padronizados para conversão de medidas aerogamaespectrométricas para concentração em solo de potássio, urânio e tório, foram desenvolvidas no final da década de 
70 nos programas governamentais acima citados, devido a muitas aeronaves com diferentes volumes de detectores estarem envolvidas nesses programas (Grasty, 1999).

Grandes blocos de concreto para calibração, geralmente com $8 \mathrm{~m}$ de seção longitudinal (Ward, 1978; Multala, 1981; Grasty 1987), com concentração conhecida dos três elementos radioativos foram utilizados para estabelecer a interferência mútua (razões de stripping) entre as três janelas dos radioelementos. A partir de 1991, uma prática foi adotada como padrão para determinação das razões de stripping (Grasty e colaboradores, 1991), a utilização de blocos transportáveis para calibração de detectores gama aerotransportados e terrestres $(1 \mathrm{~m} \mathrm{x}$ $1 \mathrm{~m} \times 0,3 \mathrm{~m})$.

A gamaespectrometria terrestre também necessita de muitas correções (praticamente as mesmas de levantamentos aerotransportados), mas não apresenta uma série de variáveis encontradas na aerotransportada, devido à altitude de vôo.

O propósito desse trabalho de mestrado foi a construção e o desenvolvimento de todas as etapas necessárias para construção de blocos de concreto radioativo para calibração de detectores gama aerotransportados e terrestres. No Brasil este é o primeiro trabalho com aplicação a área de aerogamaespectrometria. Barreto e colaboradores (1986) desenvolveram blocos de calibração, seguindo o modelo proposto por Lфvborg e colaboradores (1981), para calibração de detectores gama portáteis. 


\subsection{Radioisótopos naturais}

Na natureza existem apenas três elementos radioativos que apresentam radioisótopos e podem ser encontrados em concentrações significantes no material da crosta terrestre, esses são o potássio, o urânio e o tório. A média crustral das abundâncias são $K-2 \%, U-2,7$ ppm e Th 8,5 ppm (Minty, 1997).

O ${ }^{40} \mathrm{~K}$ é o isótopo radioativo do potássio e constitui aproximadamente $0,012 \%$ de todo o potássio natural. Apresenta uma meia-vida de $1,3 \times 10^{9}$ anos. Uma fração de $89 \%$ dos átomos de ${ }^{40} \mathrm{~K}$ decaem pela emissão de partículas beta formando átomos de ${ }^{40} \mathrm{Ca}$, os $11 \%$ restantes desintegram-se por captura eletrônica para formar átomos de ${ }^{40} \mathrm{Ar}$ com a emissão de um único fóton gama na energia de 1,46 MeV (Bristow, 1983).

O urânio ocorre naturalmente em dois isótopos: ${ }^{235} \mathrm{U}$ e ${ }^{238} \mathrm{U}$. As meias-vidas dos elementos das séries de ambos variam de frações de milisegundos a dezenas e centenas de milhares de anos. Ambos terminam suas séries com o $\mathrm{Pb}$, sendo a série do ${ }^{235} \mathrm{U}$ com o ${ }^{207} \mathrm{~Pb}$ e a série do ${ }^{238} \mathrm{U}$ com o ${ }^{206} \mathrm{~Pb}$. O ${ }^{238} \mathrm{U}$ é mais abundante, com $99,73 \%$, devido a essa abundância seus elementos filhos são utilizados para exploração, seja mineral ou geológica.

O tório ocorre naturalmente como o isótopo ${ }^{232} \mathrm{Th}$ e sua série de decaimentos radioativos termina com o ${ }^{208} \mathrm{~Pb}$. 


\subsubsection{Desequilíbrio Radioativo}

O desequilíbrio na série do urânio é uma fonte importante de erros em levantamentos aerogama transportados. Quando o decaimento radioativo resulta em produto filho instável com uma meia-vida muito menor que a do pai da série, uma situação eventualmente será alcançada onde o produto filho está decaindo tão rapidamente quanto está sendo produzido. Se isto for verdadeiro para todos os filhos da série, então a série é dita em equilíbrio radioativo secular e a atividade total diminui na mesma taxa como o elemento que originou a série. A atividade igual sob as condições de equilíbrio não implica em igual concentração já que meias-vidas diferentes devem ser consideradas quando calculada a concentração relativa dos membros de cada série (Minty, 1997).

O desequilíbrio ocorre quando um ou mais produtos do decaimento são completamente ou parcialmente removidos ou adicionados ao sistema e este processo pode levar dias, semanas ou milhões de anos para restabelecer o equilíbrio, dependendo das meias-vidas dos radioisótopos envolvidos.

A série que está mais susceptível a ocorrência do desequilíbrio é a série do urânio, devido ao fracionamento do mesmo. O fracionamento é provocado por dois mecanismos, o químico e o físico. Exemplo de mecanismos químicos é a co-precipitação, adsorção e absorção biológica. O mecanismo físico envolve o recuo nuclear.

O desequilíbrio radioativo pode resultar no fracionamento das cinco últimas posições da série do ${ }^{238} \mathrm{U}$ (Minty, 1997):

a. $\mathrm{O}{ }^{238} \mathrm{U}$ pode ser seletivamente lixiviado relativamnete ao ${ }^{234} \mathrm{U}$, particularmente em matriz argilosa

b. $\mathrm{O}{ }^{234} \mathrm{U}$ poder ser seletivamente lixiviado relativamente ao ${ }^{238} \mathrm{U}$

c. $\mathrm{O}{ }^{230} \mathrm{Th}$ pode ser seletivamente lixiviado relativamente a outro radioisótopo da cadeia de decaimentos 
d. fracionamento do ${ }^{226} \mathrm{Ra}$

e. O gás radônio $\left({ }^{222} \mathrm{Rn}\right)$ é muito móvel e escapa para atmosfera oriundo de solos e físsuras de rochas.

Em análises laboratoriais para medida da atividade gama de amostras coletadas em campo é regra estabelecer um período de 10 meias-vidas do elemento intermediário de maior meiavida da série de decaimentos, no caso do urânio, o ${ }^{222} \mathrm{Rn}$, possui uma meia-vida de 3,8 dias, adota-se 40 dias para que determinada amostra atinja o equilíbrio radioativo. 


\subsection{Instrumentação de Campo}

\subsubsection{Espectrômetros Gama Aerotransportados}

Os levantamentos aerogamaespectrométricos utilizam detectores de iodeto de sódio dopado com tálio - $\mathrm{NaI}(\mathrm{Tl})$, montados em aeronaves de asa fixa ou helicópteros. Atualmente nos levantamentos aéreos utilizam-se seis detectores (dois detectores apontados para cima upward looking e quatro apontados para baixo - downward looking) prismáticos de 4"x 4" x 16" (10 cm x $10 \mathrm{~cm}$ x $40 \mathrm{~cm}$ ) acoplados a tubos fotomultiplicadores e estes por sua vez estão ligados ao pré-amplificador. A saída do pré-amplificador está ligada ao amplificador espectroscópico. Quanto maior o volume do conjunto de detectores, maior será a capacidade de resolução da área estudada. Para mapeamentos regionais são utilizados modernos espectrômetros gama multicanal e o volume do detector pode variar de 16 - 50L e o intervalo de amostragem é de 1 amostra por segundo. Como exemplo, uma aeronave voando a 250 $\mathrm{km} / \mathrm{h}$ apresentará uma medida a cada $70 \mathrm{~m}$ no solo.

Os modernos espectrômetros gama armazenam dados em 512 canais numa faixa de energia de $0-3 \mathrm{MeV}$ e apresentam detectores para estabilizar a temperatura, visando a minimização da deriva espectral ou apresentam ainda auto-estabilização.

Os espectrômetros gama armazenam as medidas dos raios gama nas janelas do ${ }^{40} \mathrm{~K}$ em 1460 $\mathrm{keV}$, do ${ }^{214} \mathrm{Bi}$ em $1760 \mathrm{keV}$ e do ${ }^{208} \mathrm{Tl}$ em $2615 \mathrm{keV}$. A janela de contagem total (CT) é armazenada para monitorar os níveis de radioatividade geral. A Figura 2.3.1.1 abaixo apresenta um espectro típico de aerolevantamento. 


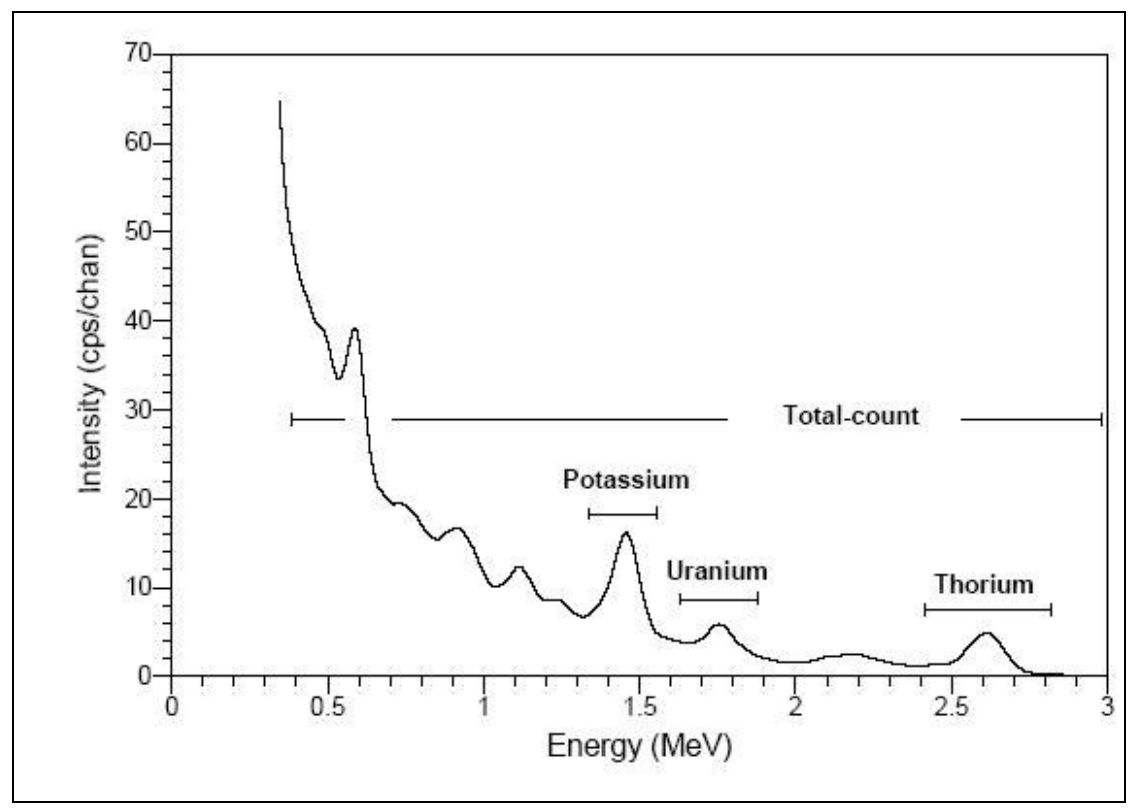

Figura 2.3.1.1 Espectro característico de aerolevantamento, apresentando as janelas de energia. Retirado IAEA (2003).

As taxas de contagem do detector devido à radiação cósmica aumentam exponencialmente com a altitude acima do nível médio do mar. A janela de radiação cósmica, que armazena todas as contagens produzidas por radiação gama com energia superior a $3 \mathrm{MeV}$, é utilizada para monitorar esse incremento (AGSO, 1995).

Antes do início de levantamentos aéreos ou qualquer procedimento de calibração a resolução do sistema deve ser melhor que $7 \%$ baseado na largura máxima a meia altura (FWHM) do pico do ${ }^{208} \mathrm{Tl}$ em $2615 \mathrm{keV}$. A Figura 2.3.1.2 apresenta graficamente a definição de FWHM. 


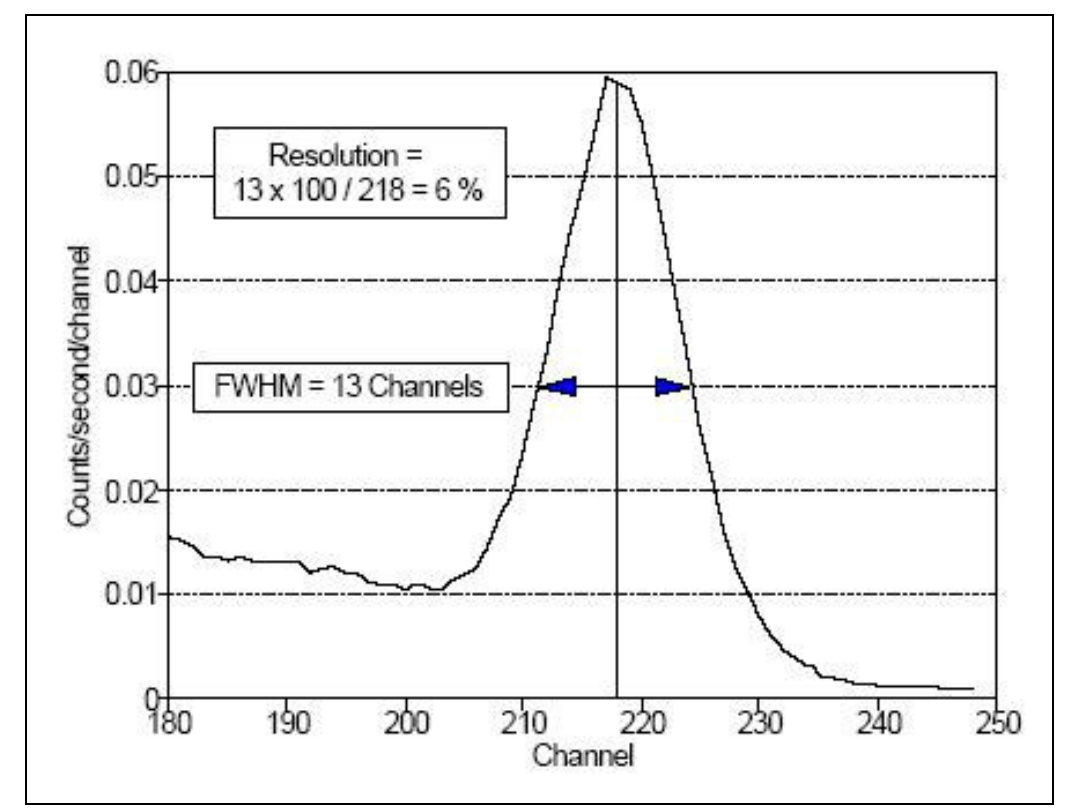

Figura 2.3.1.2 Espectro de tório, mostrando o procedimento para determinação da resolução. Retirado de AGSO (1995).

A resolução é calculada pela Equação 2.3.1.1:

$$
R(\%)=\frac{F W H M(\text { canais }) \cdot 100}{\text { pico }(\text { canais })}
$$

As janelas de interesse (ROI - region of interest) foram definidas pela IAEA (1991) e estão nas faixas de energia, conforme Tabela 2.3.1.1, abaixo:

\begin{tabular}{|c|c|c|c|}
\hline Janela & Isótopo & Energia dos Raios Gama (keV) & Janela de Energia(keV) \\
\hline Potássio $($ K) & ${ }^{40} \mathbf{K}$ & 1460 & $1370-1570$ \\
\hline Urânio $(\boldsymbol{U})$ & ${ }^{214} \mathbf{B i}$ & 1760 & $1660-1860$ \\
\hline Tório $($ Th $)$ & ${ }^{208} \mathbf{T l}$ & 2615 & $2410-2810$ \\
\hline Contagem Total & - & - & $410-2810$ \\
\hline Cósmica & - & - & $3000-\infty$ \\
\hline
\end{tabular}

Tabela 2.3.1.1 Janelas espectrais e o intervalo de energia para cada uma das janelas de interesse seguindo indicação da IAEA (1991). 


\subsubsection{Equipamentos auxiliares}

Como a radiação gama varia exponencialmente com a altitude um equipamento de extrema importância é o radar altímetro. As taxas de contagem dependem da densidade do ar entre o detector e o solo e em consequiência da temperatura e pressão. Para levantamentos a aproximadamente altura constante, acima do nível do mar, os efeitos das mudanças de pressão nas taxas de contagens é relativamente pequeno (AGSO, 1995).

A correção para variações de temperatura é um cuidado muito importante como parte dos procedimentos de processamento. Variações anuais de temperatura podem modificar significativamente sobre a mesma fonte radioativa. A importância das correções de temperatura e pressão está relacionada a áreas topográficas irregulares onde altura de vôo pode apresentar variações marcantes. 


\subsubsection{Espectrômetros Gama Portáteis}

O equipamento utilizado é composto de um detector de $\mathrm{NaI}(\mathrm{Tl})$ de 3" x 3". Os espectrômetros gama portáteis são utilizados em regiões de radioatividade conhecida para localizar e mapear geoquimicamente diferenciadas ocorrências de urânio e tório. A Figura 2.3.2.1 apresenta as janelas padrões utilizadas em espectrometria gama terrestre (L $\phi$ vborg \& Mose, 1987).

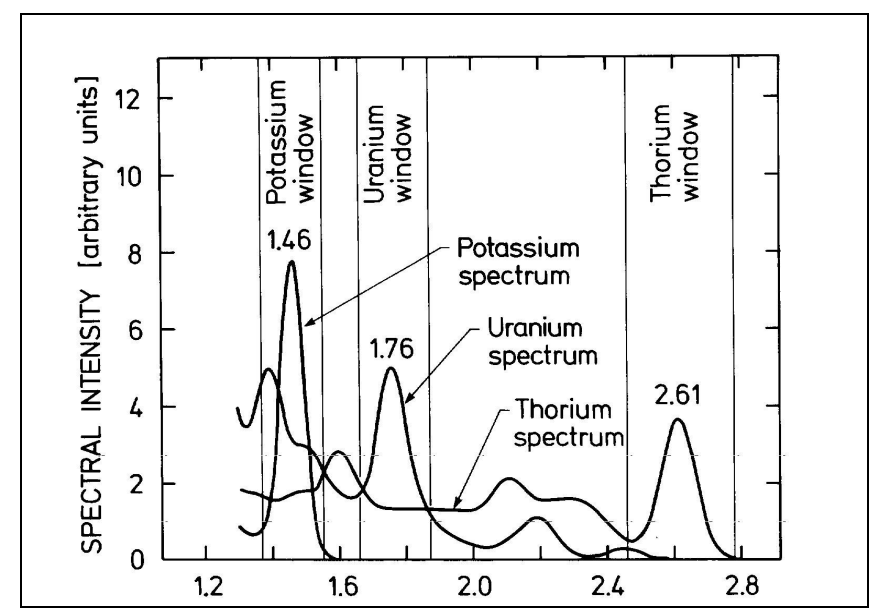

Figura 2.3.2.1 Representação gráfica das janelas de energia utilizadas em espectrometria gama terrestre. Retirado de L $\phi$ vborg \& Mose(1987).

Esse tipo de detector mede diretamente os elementos de interesse (K, U, Th) não necessitando de coleta de amostras evitando desta maneira o transporte de amostras para posterior análise em laboratório analítico. Com as medidas in situ os dados podem ser imediatamente avaliados.

Algumas desvantagens como calibração periódica, pequeno número de medidas por dia de trabalho e curto tempo de vida da bateria podem ser assinalados. A Tabela 2.3.2.1 abaixo apresenta os intervalos característicos das janelas de energia conforme IAEA (1991).

\begin{tabular}{|c|c|c|c|}
\hline Janela & Isótopo & Intervalo (Canais) & Janela de Energia(keV) \\
\hline Potássio $($ K) & ${ }^{40} \mathbf{K}$ & $224-254$ & $1344-1524$ \\
\hline Urânio $(\boldsymbol{U})$ & ${ }^{214} \mathbf{B i}$ & $267-305$ & $1602-1830$ \\
\hline Tório $(\boldsymbol{T h})$ & ${ }^{208} \mathbf{T l}$ & $396-450$ & $2376-2700$ \\
\hline Contagem Total & - & $140-511$ & $840-3066$ \\
\hline
\end{tabular}

Tabela 2.3.2.1 Janelas espectrais e 0 intervalo de energia para cada uma das janelas segundo indicação da IAEA (1991). 


\subsection{Padrões e Instalações para calibração dos instrumentos aerotransportados e terrestres}

Basicamente as fontes para calibração de detectores gama constam de blocos de concreto com concentrações muito bem determinadas de material radioativo misturado a esse bloco. As instalações para calibração podem ser classificadas em fixas e móveis.

Nas instalações fixas encontramos conjuntos de blocos para calibração localizados em aeroportos com grandes dimensões (Multala, 1981; Ward, 1978; Grasty, 1987) e blocos localizados em centros de pesquisa ou órgãos governamentais, como o de Ris $\phi$ na Dinamarca, do Instituto de Radioproteção e Dosimetria da Comissão Nacional de Energia Nuclear, Rio de Janeiro (Barreto e colaboradores, 1986) e Pelindaba na África do Sul. A seguir serão apresentados os principais trabalhos relacionados ao desenvolvimento de instalações para calibração de detectores gama. 


\subsubsection{Instalações em aeroportos}

Utilizados para calibração de detectores gama aerotransportados. Nesse tipo de instalação a aeronave, o veículo motorizado ou mesmo o detector portátil é deslocado sobre cada bloco e os espectros e medidas armazenados. Multala (1981), Figura 2.4.1.1, construiu quatro blocos quadrados de $8 \mathrm{~m}$ x $8 \mathrm{~m}$ e $0,50 \mathrm{~m}$ de espessura. Estão localizados no aeroporto de Vantaa, Finlândia. Consta dos blocos de K, U, Th e um bloco para medida da radiação de fundo (background), os valores das concentrações estão apresentados na Tabela 2.4.1.1. Outro trabalho do gênero, Figura 2.4.1.2, está localizado no Colorado, EUA, os blocos do aeroporto da Grand Junction (Ward, 1978; Stromswold, 1978), compostos de K, Ra, Th e um bloco para medida da radiação de fundo. A Tabela 2.4.1.2, apresenta os valores das concentrações dos mesmos. Grasty (1987) desenvolveu e construiu sob encomenda do Departamento de Recursos Minerais da Tailândia quatro blocos para calibração de detectores gama aerotransportados para aplicação a mapeamentos minerais. A Figura 2.4.1.3 apresenta a geometria dos mesmos e a Tabela 2.4.1.3, as concentrações de cada bloco de calibração da Tailândia.

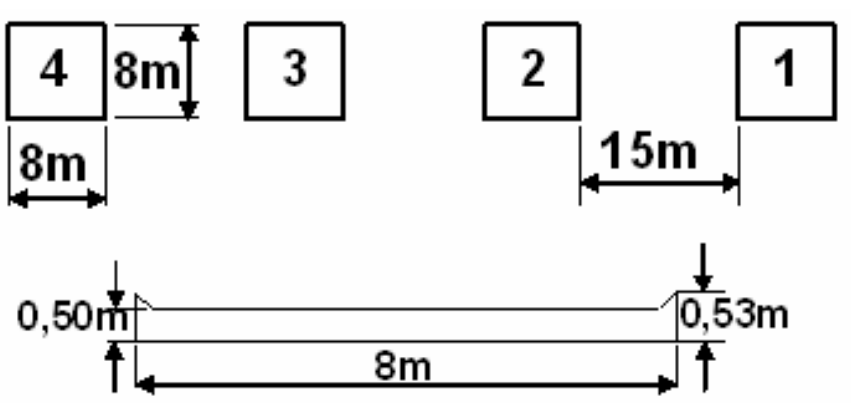

Figura 2.4.1.1 Representação esquemática dos blocos de calibração localizados no aeroporto de Vantaa, Finlândia. Adaptado de Multala (1981).

\begin{tabular}{|c|c|c|c|}
\hline PAD & $\mathbf{K}(\boldsymbol{\%})$ & $\mathbf{U}(\mathbf{p p m})$ & Th (ppm) \\
\hline $\mathbf{1}$ & $2,54 \pm 0,11$ & $4,1 \pm 0,3$ & $9,1 \pm 0,6$ \\
\hline 2 “K” & $3,51 \pm 0,17$ & $2,3 \pm 0,2$ & $2,4 \pm 0,5$ \\
\hline 3 “U” & $2,30 \pm 0,15$ & $53,2 \pm 3,7$ & $7,7 \pm 0,6$ \\
\hline 4 “Th" & $2,55 \pm 0,13$ & $11,3 \pm 0,8$ & $104 \pm 9$ \\
\hline
\end{tabular}

Tabela 2.4.1.1 Valores das concentrações dos blocos de calibração localizados no aeroporto de Vantaa, Finlândia, conforme Multala(1981). 


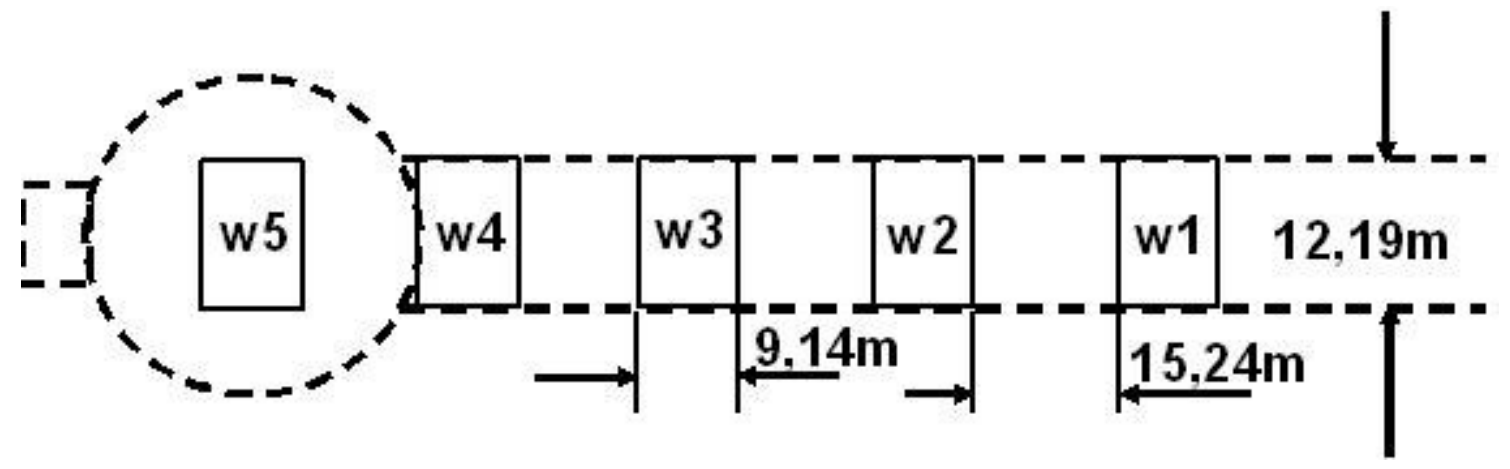

Figura 2.4.1.2 Representação esquemática dos blocos de calibração localizados no aeroporto de Walker Field, Grand Junction, Colorado, Estados Unidos. Adaptado de Ward (1978).

\begin{tabular}{|c|c|c|c|}
\hline Pad & K (\%) & U (ppm) & Th (ppm) \\
\hline w1 (BKG) & $1,45 \pm 0,01$ & $2,2 \pm 0,1$ & $6,3 \pm 0,1$ \\
\hline w2 (K) & $5,14 \pm 0,09$ & $5,1 \pm 0,3$ & $8,5 \pm 0,3$ \\
\hline w3 (Th) & $2,01 \pm 0,04$ & $5,1 \pm 0,2$ & $45,3 \pm 0,7$ \\
\hline w4 (Ra) & $2,03 \pm 0,05$ & $30,3 \pm 1,6$ & $9,2 \pm 0,3$ \\
\hline w5 (Mix) & $4,11 \pm 0,06$ & $20,4 \pm 1,3$ & $17,5 \pm 0,3$ \\
\hline
\end{tabular}

Tabela 2.4.1.2. Valores das concentrações dos blocos da Grand Junction (USA), conforme Ward (1978).

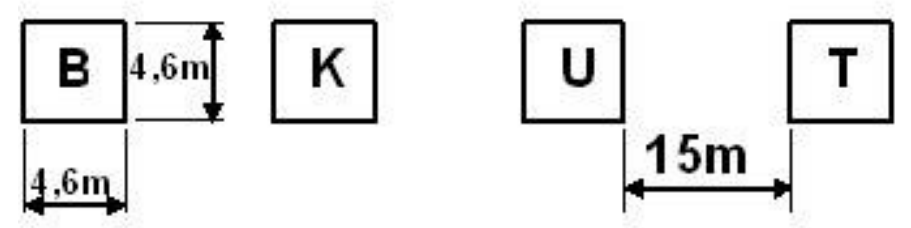

Figura 2.4.1.3 Representação esquemática dos blocos de calibração localizados no aeroporto de U-Tapao, Tailândia. Adaptado de Grasty (1987).

\begin{tabular}{|c|c|c|c|}
\hline Pad & K (\%) & U (ppm) & Th (ppm) \\
\hline Backg. & $0,25 \pm 0,02$ & $0,91 \pm 0,16$ & $2,86 \pm 0,26$ \\
\hline K & $6,18 \pm 0,10$ & $1,46 \pm 0,24$ & $1,16 \pm 0,34$ \\
\hline $\mathbf{U}$ & $0,33 \pm 0,04$ & $16,21 \pm 1,01$ & $2,80 \pm 0,41$ \\
\hline Th & $0,22 \pm 0,04$ & $2,54 \pm 0,28$ & $37,31 \pm 1,64$ \\
\hline
\end{tabular}

Tabela 2.4.1.3 Valores das concentrações dos blocos da Tailândia. 


\subsubsection{Instalações em centros de pesquisa}

Utilizados para calibração de detectores gama portáteis. Lфvborg e colaboradores (1978) construíram um conjunto composto por K, U, Th e Z (background). Estes blocos estão localizados no Ris $\phi$ Establishment, Dinamarca. A geometria nesse caso é circular, com 3 m de diâmetro por 0,50 m de profundidade e os blocos estão separados por uma distância de $5 \mathrm{~m}$ (Figura 2.4.2.1). As concentrações dos blocos estão apresentadas na Tabela 2.4.2.1.
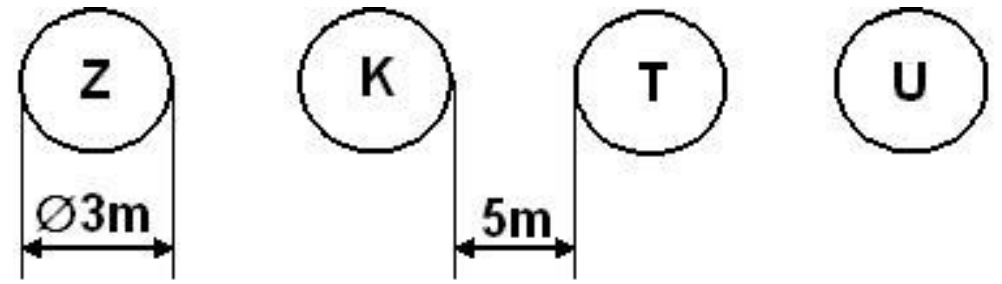

Figura 2.4.2.1 Representação esquemática dos blocos de calibração para detectores gama portáteis do Ris $\phi$ National Laboratory, Dinamarca. Adaptado de L $\phi$ vborg e colaboradores (1978).

\begin{tabular}{|c||c|c|c|}
\hline Pad & K(\%) & eU(ppm) & eTh(ppm) \\
\hline $\mathbf{Z}$ & $1,0 \pm 0,1$ & $0,8 \pm 0,1$ & $2,3 \pm 0,2$ \\
\hline $\mathbf{K}$ & $6,85 \pm 0,30$ & $3,5 \pm 0,4$ & $2,7 \pm 0,3$ \\
\hline $\mathbf{T}$ & $0,8 \pm 0,1$ & $6,0 \pm 0,6$ & $150 \pm 5$ \\
\hline $\mathbf{U}$ & $1,0 \pm 0,2$ & $190 \pm 8$ & $8 \pm 3$ \\
\hline
\end{tabular}

Tabela 2.4.2.1 Valores das concentrações dos blocos do Instituto Ris $\phi$, Dinamarca. Conforme L $\phi$ vborg colaboradores (1978).

Barreto e colaboradores (1986) foram responsáveis pelo primeiro trabalho desenvolvido no Brasil para calibração de detectores gama portáteis, seguindo o modelo proposto por L $\phi v b o r g$ e colaboradores (1978). Os conjuntos constam de blocos circulares de $3 \mathrm{~m}$ de diâmetro por 0,50 m de profundidade. O sistema de calibração é composto por oito blocos de calibração sendo os mesmos de $\mathrm{K} 1, \mathrm{~K} 2$, U1, U2, Th1, Uth1, Uth2, BKG, além de um tanque de água, circular, com 4 metros de diâmetro e 0,7 metro de profundidade, no centro do conjunto, para correções da radiação cósmica e de ruídos instrumentais. A Figura 2.4.2.2 e a Tabela 2.4.2.2 apresentam as principais características dessa instalação para calibração de detectores gama portáteis. 


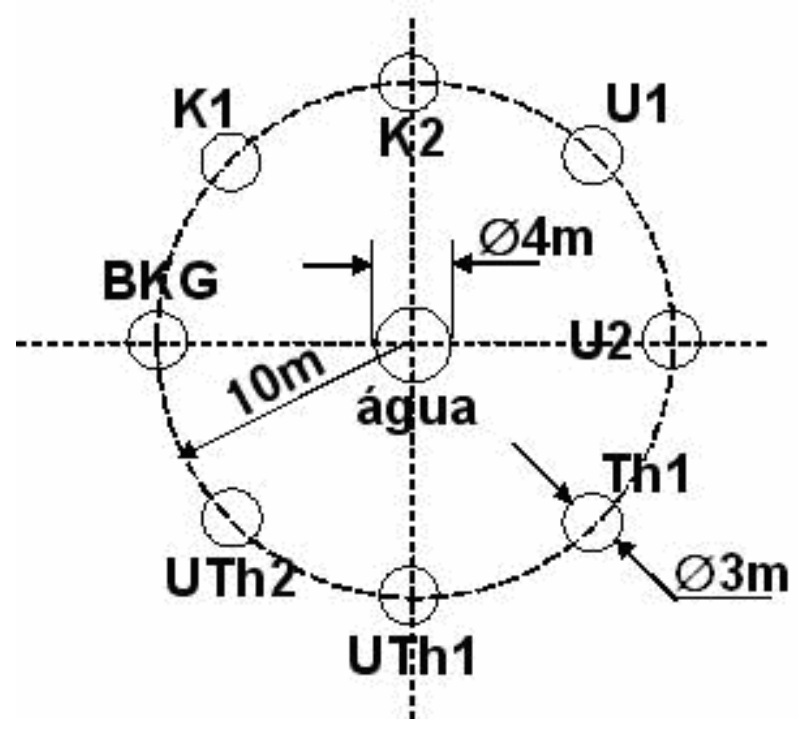

Figura 2.4.2.2 Representação esquemática dos blocos de calibração para detectores gama portáteis do IRD/CNEN/RJ. Adaptado de Barreto e colaboradores (1986).

\begin{tabular}{|c|c||c|c|}
\hline Pad & K(\%) & eU(ppm) & eTh(ppm) \\
\hline BKG & $0,08 \pm 0,10$ & $0,82 \pm 0,01$ & $1,75 \pm 0,12$ \\
\hline K1 & $6,71 \pm 0,06$ & $2,00 \pm 0,07$ & $20,90 \pm 0,81$ \\
\hline K2 & $4,43 \pm 0,08$ & $2,97 \pm 0,06$ & $29,72 \pm 1,39$ \\
\hline U1 & $3,47 \pm 0,07$ & $69,92 \pm 0,67$ & $50,13 \pm 0,99$ \\
\hline U2 & $3,43 \pm 0,08$ & $19,45 \pm 0,14$ & $53,06 \pm 1,68$ \\
\hline Th1 & $3,54 \pm 0,07$ & $11,63 \pm 0,15$ & $255,97 \pm 5,25$ \\
\hline UTh1 & $3,64 \pm 0,03$ & $12,10 \pm 0,24$ & $71,59 \pm 1,76$ \\
\hline UTh2 & $3,65 \pm 0,03$ & $44,47 \pm 0,63$ & $152,39 \pm 4,76$ \\
\hline
\end{tabular}

Tabela 2.4.2.2 Valores das concentrações dos blocos localizados no IRD/CNEN (RJ).

IAEA (1989) apresentou um trabalho cujo objetivo principal foi a padronização para construção dos blocos de calibração das instalações. Alguns valores de concentração foram sugeridos como concentrações ideais para espectrômetros gama aerotransportados e terrestres. As Tabelas 2.4.2.3 e 2.4.2.4 apresentam os valores ideais sugeridos de concentração para calibração dos tipos de detectores aerotransportados e terrestres.

\begin{tabular}{|c|c|c|c|}
\hline PAD & K (\%) & $\mathbf{U}(\mathbf{p p m})$ & Th (ppm) \\
\hline Branco & 0 & 0 & 0 \\
\hline K & 8 & 0 & 0 \\
\hline U & 0 & 20 & 0 \\
\hline Th & 0 & 0 & 40 \\
\hline
\end{tabular}

Tabela 2.4.2.3 Concentrações ideais para os blocos de calibração de detectores aerotransportados. 


\begin{tabular}{|c|c|c|c|}
\hline PAD & K (\%) & $\mathbf{U}(\mathbf{p p m})$ & Th (ppm) \\
\hline Branco & 0 & 0 & 0 \\
\hline K & 8 & 0 & 0 \\
\hline U & 0 & 50 & 0 \\
\hline Th & 0 & 0 & 125 \\
\hline
\end{tabular}

Tabela 2.4.2.4 Concentrações ideais para os blocos de calibração de detectores portáteis. 


\subsubsection{Blocos de calibração transportáveis}

Os blocos transportáveis de calibração (Transportable Calibration Pads) - utilizados para calibração de detectores gama aerotransportados e portáteis foram desenvolvidos por Grasty e colaboradores (1991) e são compostos de um conjunto de quatro blocos quadrados de $1 \mathrm{~m} \mathrm{x}$ $1 \mathrm{~m}$ x 0,30 m. Esse conjunto consta dos blocos de K, U, Th e radiação de fundo. Atualmente o padrão de calibração para aerolevantamentos está baseado na utilização desses blocos transportáveis. Um a um os blocos são colocados sob a aeronave e medidas das contagens são armazenadas para posterior cálculo dos valores das constantes de stripping. A Figura 2.4.3.1 apresenta a etapa de calibração com a utilização de um bloco de urânio (detalhe em amarelo).

A Tabela 2.4.3.1 apresenta os valores de concentração dos blocos canadenses.

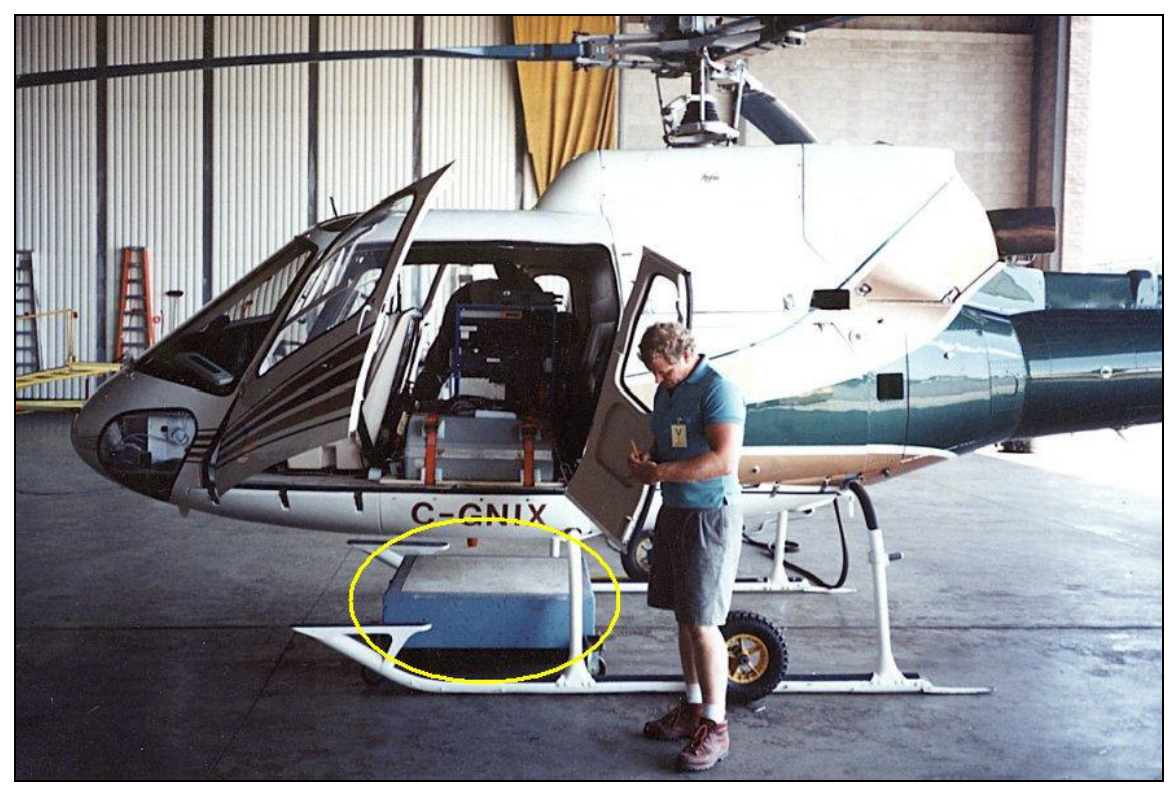

Figura 2.4.3.1 Calibração conjunto de detector gama aerotransportado. No detalhe, bloco de urânio. Figura retirada do Geological Survey of Canada.

\begin{tabular}{|c|c|c|c|}
\hline PAD & $\mathbf{K}(\boldsymbol{\%})$ & $\mathbf{U}(\mathbf{p p m})$ & $\mathbf{T h}(\mathbf{p p m})$ \\
\hline $\mathbf{B}$ & $1,43 \pm 0,01$ & $0,94 \pm 0,02$ & $2,32 \pm 0,06$ \\
\hline $\mathbf{K}$ & $7,57 \pm 0,05$ & $1,22 \pm 0,09$ & $1,40 \pm 0,12$ \\
\hline $\mathbf{U}$ & $1,07 \pm 0,01$ & $46,93 \pm 0,32$ & $2,75 \pm 0,07$ \\
\hline $\mathbf{T}$ & $1,43 \pm 0,02$ & $1,74 \pm 0,16$ & $121,5 \pm 1,66$ \\
\hline
\end{tabular}

Tabela 2.4.3.1 Valores das concentrações dos blocos transportáveis para calibração de detectores gama aerotransportados e terrestres, conforme Grasty (1991). 
Na Austrália existem cinco conjuntos de blocos de calibração transportáveis construídos em duas épocas diferentes. Um conjunto de $1 \mathrm{~m} \times 1 \mathrm{~m}$ x $0,3 \mathrm{~m}$ de blocos transportáveis da World Geoscience, foi construído no Canadá por Grasty e colaboradores (1991). Quatro conjuntos semelhantes foram construídos por Bruce Dickson no CSIRO (Australian Commonwealth Scientific and Industrial Research Organisation) e pertencem a AGSO (Australian Geological Survey Organisation) (AGSO, 1995).

As Tabelas 2.4.3.2 e 2.4.3.3 apresentam os valores das concentrações dos blocos transportáveis da AGSO e CSIRO, respectivamente.

\begin{tabular}{|c|c|c|c|}
\hline PAD & K (\%) & U (ppm) & Th (ppm) \\
\hline Branco & $0,24 \pm 0,02$ & $0,48 \pm 0,06$ & $2,28 \pm 0,12$ \\
\hline Potássio & $6,64 \pm 0,06$ & $1,20 \pm 0,12$ & $2,27 \pm 0,20$ \\
\hline Urânio & $0,52 \pm 0,02$ & $43,67 \pm 1,60$ & $2,44 \pm 0,19$ \\
\hline Tório & $0,04 \pm 0,02$ & $7,05 \pm 0,12$ & $123,9 \pm 2,0$ \\
\hline
\end{tabular}

Tabela 2.4.3.2 Valores das concentrações dos blocos transportáveis para calibração de detectores gama aerotransportados e terrestres da AGSO, conforme AGSO (1995).

\begin{tabular}{|c|c|c|c|}
\hline PAD & K (\%) & U (ppm) & Th (ppm) \\
\hline Branco & $0,19 \pm 0,07$ & $0,77 \pm 0,06$ & $2,26 \pm 1,21$ \\
\hline Potássio & $3,87 \pm 0,04$ & $1,01 \pm 0,10$ & $1,24 \pm 0,19$ \\
\hline Urânio & $0,39 \pm 0,06$ & $88,2 \pm 1,8$ & $1,40 \pm 0,34$ \\
\hline Mista & $0,17 \pm 0,04$ & $39,9 \pm 0,9$ & $91,1 \pm 1,3$ \\
\hline Tório & $0,07 \pm 0,04$ & $10,3 \pm 0,5$ & $160,1 \pm 2,1$ \\
\hline
\end{tabular}

Tabela 2.4.3.3 Valores das concentrações dos blocos transportáveis para calibração de detectores gama aerotransportados e terrestres do CSIRO, conforme AGSO (1995). 


\subsection{Aquisição e Processamento dos Dados}

A aquisição dos dados aerogamaespectrométricos é feita com a aeronave em movimento e a freqüência de aquisição dos dados é de uma amostra por segundo. Algumas correções devem ser aplicadas aos dados gamaespectrométricos, correções como: tempo morto, stripping, altitude, backgrounds cósmico, da aeronave e radônio. Após todas essas correções os dados são transformados em concentrações dos três elementos de interesse - K (\%), U (ppm eU) e Th (ppm eTh). A janela de contagem total também é utilizada e seus valores são transformados em $\mu R / h$, o que corresponde a taxa de dose. As etapas de processamento dos dados radiométricos são as seguintes:

1. Banco de Dados Radiométricos

2. Correção do tempo morto

3. Filtragem altura, radiação cósmica e canais upward

4. Cálculo da Altura Efetiva de Vôo

5. Remoção do Background Cósmico e da Aeronave

6. Remoção do Background do Radônio

7. Correção do Efeito Compton

8. Correção da Atenuação Atmosférica

9. Conversão para Concentração dos elementos de interesse

10. Dados radiométricos corrigidos

11. Geração dos mapas

Nossa análise será apenas em relação ao item 7, objetivo deste trabalho. 


\subsubsection{Correção do Efeito Compton}

O objetivo da construção dos blocos é através de medidas tomadas por espectrômetros gama aerotransportados ou terrestres encontrar os vários coeficientes que definem a influência de um elemento na janela do outro elemento.

A Figura 2.5.1.1 abaixo apresenta de forma esquemática a influência de um elemento na janela do outro elemento (Killeen, 1979). Observe que a influência das janelas de maior energia nas janelas de menor energia são representadas pelos coeficientes $\alpha, \beta$ e $\gamma$. Já a influência das janelas de menor energia nas janelas de menor energia são representadas pelas letras $a, b$ e $g$. A estrutura dos espectros gama naturais mostra que os coeficientes $b$ e $g$ devem ser nulos, uma vez que não há influência do pico do $\mathrm{K}$ sobre os picos utilizados para identificar e/ou quantificar o U e o Th. Na prática, portanto, são considerados apenas o três coeficientes das janelas de maior energia $(\alpha, \beta, \gamma)$ e o coeficiente $a$.

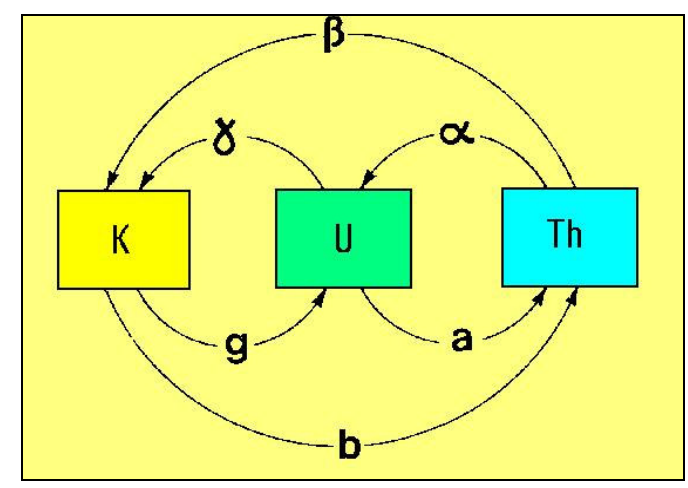

Figura 2.5.1.1 Representação esquemática da interação entre as janelas de energia do potássio (K), urânio (U) e Tório (Th). Os coeficientes comumente utilizados são $(\alpha, \beta, \gamma)$. Adaptado de Killeen (1979).

Dessa maneira temos:

\begin{tabular}{|c|c|}
\hline coeficiente & influência \\
\hline$\alpha$ & raios gama do tório na janela do $\mathrm{U}$ \\
\hline$\beta$ & raios gama do tório na janela do $\mathrm{K}$ \\
\hline$\gamma$ & raios gama do urânio na janela do $\mathrm{K}$ \\
\hline$a$ & raios gama do urânio na janela do Th \\
\hline$b$ & raios gama do potássio na janela do $\mathrm{Th}$ \\
\hline$g$ & raios gama do potássio na janela do $\mathrm{U}$ \\
\hline
\end{tabular}

Tabela 2.5.1.1 Coeficientes de espalhamento Compton e seus significados. 
Então com essa análise estabelecem-se as equações de correção de stripping dadas pelas Equações 2.5.1.1 a 2.5.1.3.

$$
\begin{aligned}
& \left(N_{K}\right)_{c o r r}=N_{K}-\beta \cdot\left(N_{T h}\right)_{c o r r}-\gamma \cdot\left(N_{U}\right)_{c o r r} \\
& \left(N_{U}\right)_{c o r r}=N_{U}-\alpha \cdot\left(N_{T h}\right)_{c o r r}-g \cdot\left(N_{K}\right)_{c o r r} \\
& \left(N_{T h}\right)_{c o r r}=N_{T h}-a \cdot\left(N_{U}\right)_{c o r r}-b \cdot\left(N_{K}\right)_{c o r r}
\end{aligned}
$$

onde:

$\left(N_{K}\right)_{c o r r}=$ valor do potássio corrigido

$\left(N_{U}\right)_{\text {corr }}=$ valor do urânio corrigido

$\left(N_{T h}\right)_{c o r r}=$ valor do tório corrigido

$N_{K}=$ valores brutos de potássio

$N_{U}=$ valores brutos de urânio

$N_{T h}=$ valores brutos de tório

$a, b, g, \alpha, \beta, \gamma$ veja Tabela 2.5.1.1 


\section{Construção das Fontes de Calibração}

\subsection{Materiais utilizados}

\subsubsection{Minerais radioativos}

Três minerais radioativos foram misturados à massa de concreto durante a confecção dos blocos. Como fonte primária de urânio foi utilizado o mineral caldasito, com 0,3\% de urânio e $0,1 \%$ de tório e como fonte primária de tório, a areia monazita com $4,8 \%$ de tório e $0,2 \%$ de urânio natural ${ }^{1}$. Como fonte de potássio radioativo ${ }^{2}$ foi utilizado o mineral ortoclásio (feldspato potássico) com $8 \%$ de potássio.

O caldasito utilizado é essencialmente composto por fragmentos com dimensões variando entre 0,42 $\mathrm{mm}$ até $7 \mathrm{~mm}$, com uma fração pequena de fragmentos com dimensões inferiores a 0,42 mm. Por outro lado, a areia monazita é toda composta por fragmentos inferiores a 0,42 $\mathrm{mm}$.

O ortoclásio utilizado teve duas granulometrias diferentes: a primeira moída com granulação média de 0,25 - 0,5 mm e a segunda na forma de nódulos com dimensões típicas entre $10 \mathrm{~mm}$ e $20 \mathrm{~mm}$.

\footnotetext{
${ }^{1} \mathrm{O}$ termo urânio natural se refere a mistura isotópica contendo $99,3 \%$ do isótopo ${ }^{238} \mathrm{U}$ e $0,7 \%$ do isótopo ${ }^{235} \mathrm{U}$, que representa a composição média observada e praticamente constante, na natureza. $\mathrm{O}$ elemento tório observado na natureza é essencialmente composto pelo isótopo ${ }^{232} \mathrm{Th}$.

${ }^{2} \mathrm{O}{ }^{40} \mathrm{~K}$ é o único isótopo radioativo natural do potássio e corresponde a $0,012 \%$ da composição isotópica natural do elemento.
} 


\subsubsection{Materiais de Construção}

As massas de concreto foram preparadas utilizando-se cimento tipo Portland encontrado no comércio, areia para construção, lavada, com granulação média (grãos com dimensões entre 0,5 mm e 1,0 mm e brita de basalto (brita 1, com dimensões típicas de $10 \mathrm{~mm}$ e $20 \mathrm{~mm}$ ).

\subsubsection{Projeto dos Blocos de Calibração}

A construção dos blocos de concreto radioativo teve início com a confecção dos suportes de madeira para a sustentação dos blocos, seguida da montagem de moldes para receber e sustentar a massa de concreto durante o processo de cura. Em seguida, foram preparadas as massas de concreto com diferentes quantidades de minerais radioativos. Os blocos de concreto foram construídos de forma a se obter, aproximadamente, as concentrações apresentadas na Tabela 3.1.3.1.

\begin{tabular}{|c|c|c|c|}
\hline Bloco & $\boldsymbol{K}(\%)$ & $\boldsymbol{e U}(\mathbf{p p m})$ & $\boldsymbol{e T h}(\mathbf{p p m})$ \\
\hline BKG1 & - & - & - \\
\hline $\boldsymbol{K} \boldsymbol{1}$ & 7 & - & - \\
\hline $\boldsymbol{U}$ & - & 50 & - \\
\hline $\boldsymbol{T H}$ & - & - & 150 \\
\hline $\boldsymbol{B K G 2}$ & - & - & - \\
\hline $\boldsymbol{M 1}$ & 3,5 & 3,4 & 35 \\
\hline $\boldsymbol{M} 2$ & 5,0 & 10 & 70 \\
\hline $\boldsymbol{M 3}$ & 1,5 & 20 & 10 \\
\hline
\end{tabular}

Tabela 3.1.3.1 Valores das concentrações nominais de potássio, urânio e tório para os diferentes blocos de calibração.

O bloco identificado como $\mathrm{K} 1$ deve conter apenas potássio, enquanto que, idealmente os blocos U e TH deveriam conter apenas urânio e tório, respectivamente. No entanto, uma vez que tanto o caldasito quanto a areia monazítica contém ambos os elementos, o resultado final será um bloco de $\mathrm{U}$ enriquecido em urânio, mas contendo também tório e um bloco TH enriquecido em tório, mas contendo também urânio. 
Os blocos identificados como M1, M2 e M3 contêm diferentes quantidades dos três elementos radioativos. Os blocos BKG1 e BKG2 se destinam à observação da radiação de fundo durante o processo de calibração dos instrumentos radiométricos e a eles não foram adicionados minerais radioativos.

Os valores de concentração de potássio, urânio e tório nos blocos a serem construídos foram estabelecidos com base nas concentrações de diferentes instalações de calibração existentes, por exemplo, Barreto e colaboradores (1986). Os valores são suficientemente altos para permitir a aquisição de dados com boa precisão, usando um intervalo de tempo relativamente pequeno para a integração das contagens produzidas pela incidência da radiação sobre os sistemas de detecção a serem calibrados.

\subsection{Montagem do Suporte de Madeira}

O suporte de madeira é um componente permanente dos blocos de concreto. Ele se destina, inicialmente, a formar o fundo do molde para a cura do concreto e, posteriormente, a suportar e permitir a movimentação dos blocos depois de concluída a sua construção.

As dimensões dos blocos de concreto permitem estimar o seu peso entre 600 e $700 \mathrm{~kg}$. Uma vez que a preparação do concreto não prevê o uso de malha interna de ferro, o suporte de madeira deve ser rígido o suficiente para evitar flexão significativa dos blocos durante sua movimentação. A Figura 3.2.1 apresenta o esquema de construção do suporte de madeira. Ele consiste de um tablado de 1,20 m x 1,20 m x 0,05 m, confeccionado com três pranchas de ipê com $0,40 \mathrm{~m}$ de largura e coladas lateralmente. 


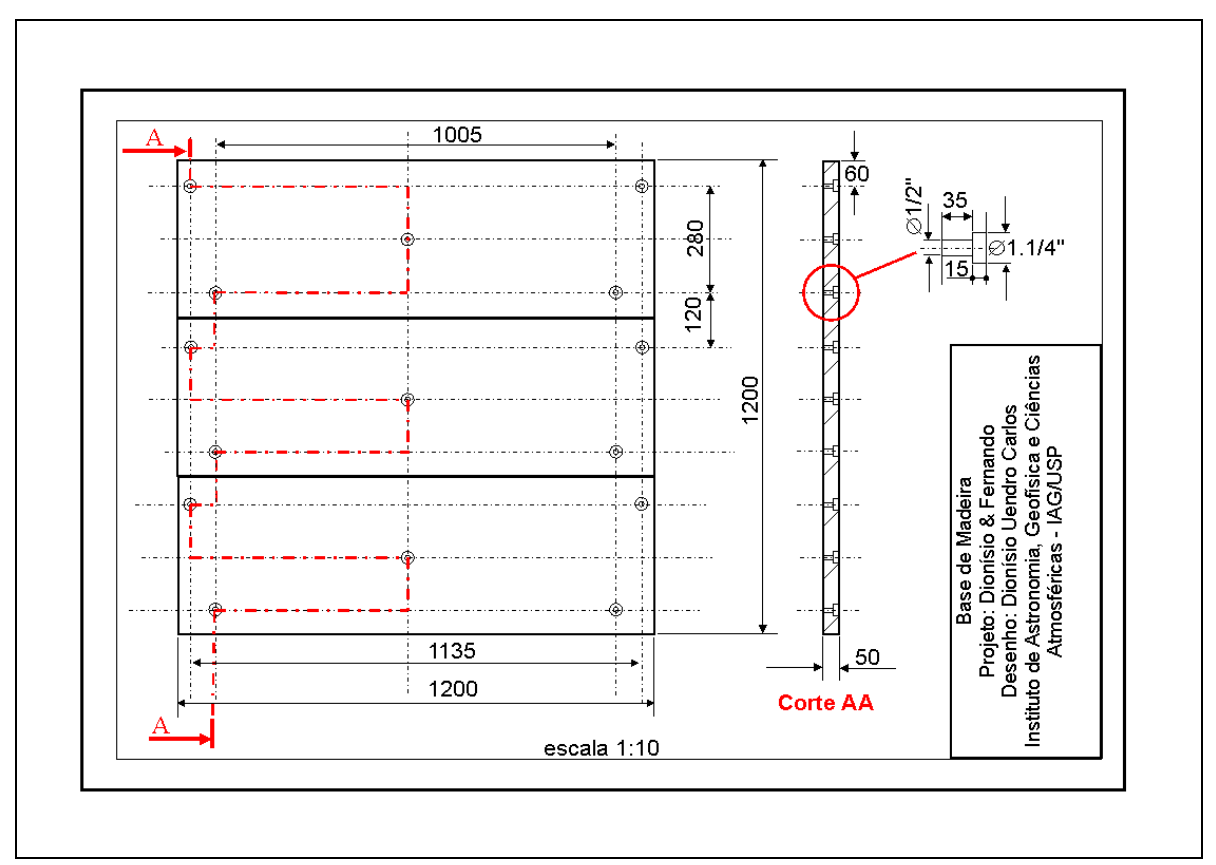

Figura 3.2.1 Desenho esquemático das placas de madeira para obtenção do tablado.

A emenda é feita com alma para garantir uma boa fixação. Sob a prancha, são fixadas no sentido perpendicular as emendas, com parafusos do tipo francês, três vigas de ipê com 1,20 $\mathrm{m} \times 0,15 \mathrm{~m} \times 0,15 \mathrm{~m}$, que servem como apoio do suporte no solo e permitem a aplicação de um macaco hidráulico para a movimentação dos blocos. Duas vigas são fixadas rentes as laterais da prancha e uma no seu centro. A Figura 3.2.2 mostra a distribuição das vigas no tablado.

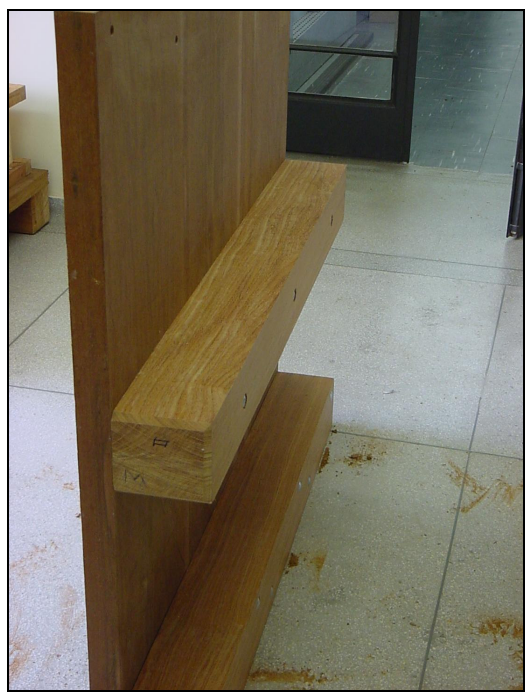

Figura 3.2.2 Distribuição das vigas de madeira na base do molde. 
A Figura 3.2.3 mostra o aspecto final do suporte onde se deve observar a distribuição dos parafusos de fixação. Embora tenham sido coladas lateralmente, cada prancha de ipê é fixa por dois parafusos a cada viga na lateral do suporte e por um parafuso à viga central. Tanto a cabeça do parafuso na viga quanto a porca e arruela de fixação no tablado foram encaixados na madeira.

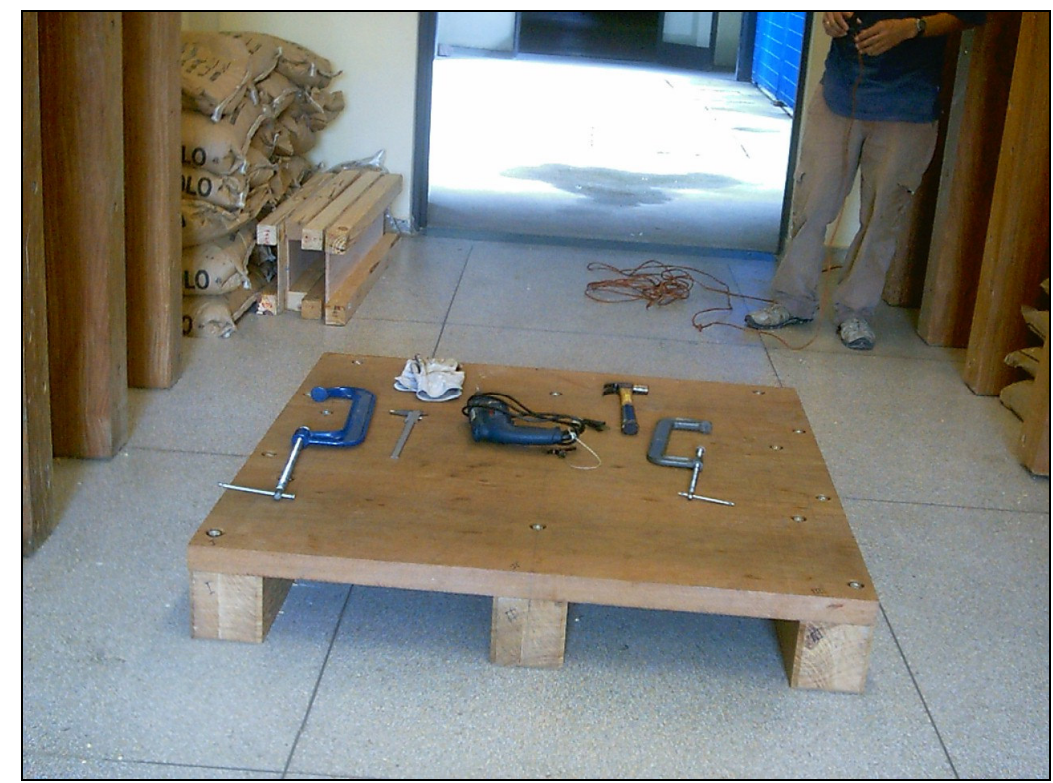

Figura 3.2.3 Aspecto final da base madeira. Observar a distribuição dos parafusos na base de madeira.

\subsubsection{Montagem do molde para cura do concreto}

A Figura 3.2.1.1 apresenta o esquema de montagem dos moldes de madeira. Eles consistem de quatro laterais de madeira compensada com $10 \mathrm{~mm}$ de espessura e 0,30 $\mathrm{m}$ de largura. Duas laterais tem 1,02 $\mathrm{m}$ de comprimento e as outras duas tem $1,00 \mathrm{~m}$ de comprimento. A cada lateral são fixadas, nas bordas ao longo do comprimento, duas vigas de madeira com $60 \mathrm{~mm} \mathrm{x}$ $60 \mathrm{~mm}$ de base. Nas laterais mais curtas as vigas têm 1,02 $\mathrm{m}$ de comprimento, enquanto que nas laterais mais longas as vigas têm um comprimento de $1,14 \mathrm{~m}$.

A montagem é feita de forma que as dimensões internas sejam $1,0 \mathrm{~m} \times 1,0 \mathrm{~m} \times 0,30 \mathrm{~m}$. A fixação do molde é feita por parafusos que unem as extremidades das bordas nas laterais, 
atravessando transversalmente as bordas mais longas e as mais curtas ao longo do seu eixo. A 3.2.1.1 mostra um instante dessa fixação. Parafusos fixam as bordas das laterais do suporte de madeira. A Figura 3.2.1.2 apresenta o aspecto final do molde sobre o suporte.

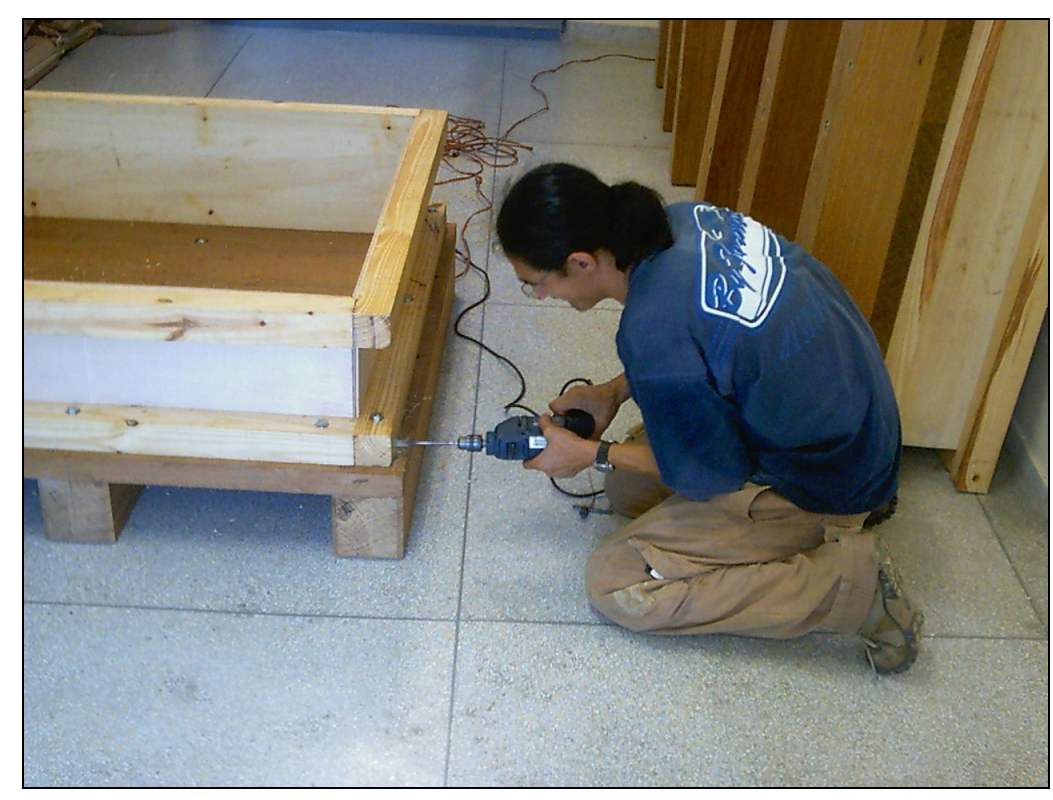

Figura 3.2.1.1 Fixação das laterais ao suporte de madeira.

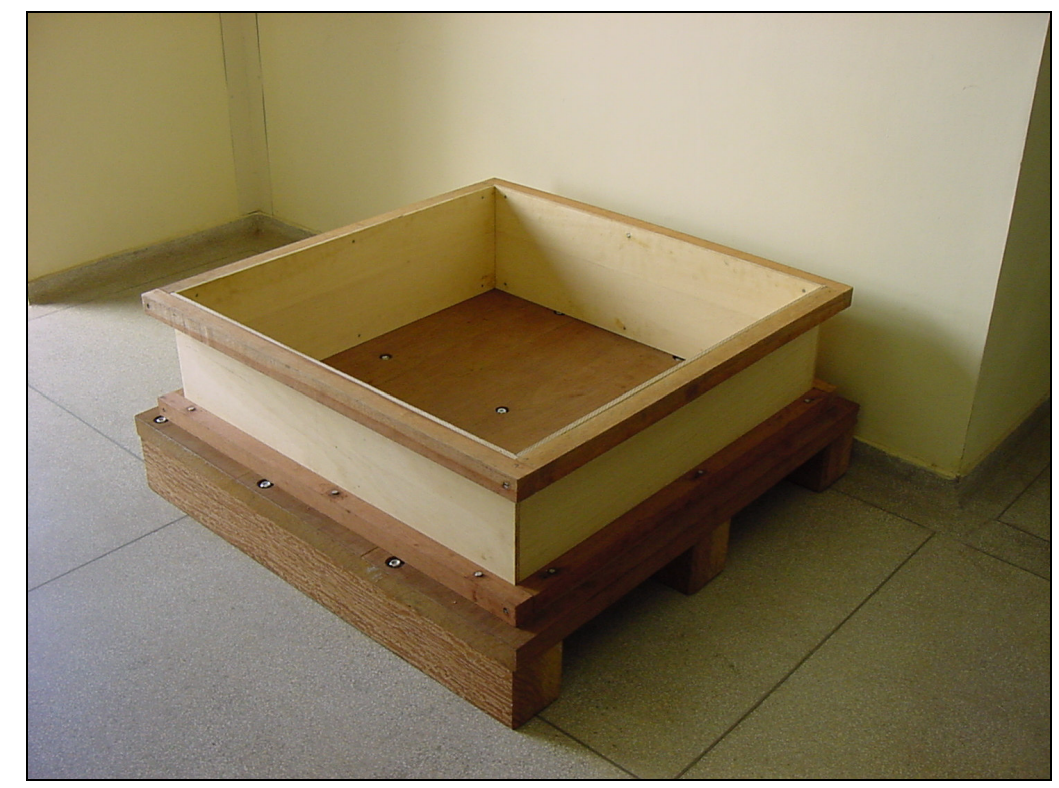

Figura 3.2.1.2 Aspecto final do molde de madeira inteiramente montado.

O acabamento do molde consiste em uma pintura, da sua parte interna, com tinta a base de epoxy para evitar que o concreto fique aderido às laterais e para impermeabilizar a área do suporte em contato com o concreto. Além disso, as juntas das diferentes partes de madeira e os encaixes dos parafusos foram calafetados com borracha de silicone. 


\subsection{Preparação do concreto}

Os blocos destinados à estimativa da radiação de fundo (BKG1 e BKG2) são feitos de concreto na proporção em massa de 1 parte de cimento para 2 partes de brita de basalto para 3 partes de areia de construção. As massas de cada componente, $117 \mathrm{~kg}$ de cimento, $234 \mathrm{~kg}$ de brita e $351 \mathrm{~kg}$ de areia, foram pesadas em uma balança eletrônica com precisão de $20 \mathrm{~g}$.

As massas iniciais de cada componente foram divididas em duas frações iguais de maneira que a betoneira de $400 \mathrm{~L}$, que foi utilizada, não ficasse com seu volume totalmente ocupado, o que dificultaria a homogeneização da mistura. A preparação do concreto foi iniciada adicionando-se água à metade da massa total de cimento, com a betoneira em movimento. A mistura foi homogeneizada por aproximadamente 5 minutos. Em seguida, metade da massa total de brita foi adicionada a mistura homogeneizada por 10-15 minutos. Metade da massa total de areia foi, então, acrescentada aos poucos, junto com mais água, até atingir a consistência desejada para o concreto. Uma vez atingida essa consistência, a mistura foi homogeneizada por mais quarenta e cinco minutos. Em seguida, a massa de concreto foi retirada da betoneira e reservada.

O processo descrito acima foi repetido com o restante do material. Ao final as duas frações foram misturadas juntas na betoneira por mais 45 minutos.

Quanto à consistência pode-se afirmar, que, uma massa muito seca pode levar a uma peça de concreto com pequenas rachaduras e descontinuidades. Uma massa muito úmida pode permitir uma decantação parcial dos componentes do concreto antes do seu endurecimento. Em termos gerais, a massa deve ter um aspecto plástico, sem excesso observável de água. O bloco K1 foi projetado para ter uma concentração de 7\% em massa de potássio. Para atingir esse valor, na sua construção os $351 \mathrm{~kg}$ de areia foram substituídos por feldspato potássico (ortoclásio) moído com granulometria semelhante a da areia. Além disso, a brita de basalto foi substituída por nódulos de feldspato com dimensões equivalentes à da brita. A preparação da 
massa de concreto do bloco K1 seguiu o mesmo procedimento adotado para os blocos BKG1 e BKG2.

Os blocos U e TH têm, essencialmente, a mesma composição dos blocos destinados à observação da radiação de fundo. A essa composição foram adicionados, aproximadamente, $12 \mathrm{~kg}$ de caldasito, no caso do bloco U e $2 \mathrm{~kg}$ de areia monazita, no caso do bloco $\mathrm{TH}$.

A preparação dos blocos U e TH exigiram cuidados devido à heterogeneidade granulométrica do caldasito; e quanto a areia monazítica às pequenas massas envolvidas. De um lado, a granulação do caldasito utilizado é irregular e não corresponde à granulação dos componentes básicos do concreto e de outro, a granulação da areia monazítica utilizada é inferior à da areia de construção. Para evitar heterogeneidades na massa de concreto a areia de construção foi inicialmente seca e a sua massa total dividida em três partes iguais. As massas totais dos minérios, caldasito ou areia monazítica, também foram divididos em três alíquotas de mesma massa.

Cada fração de areia recebeu a fração correspondente dos minerais radioativos e foi homogeneizada na betoneira completamente seca, por uma hora. Em seguida cada uma das frações originais foi dividida em três sub-alíquotas de mesma massa.

Tomando-se uma sub-alíquota de cada uma das alíquotas originais, já homogeneizadas, três novas alíquotas equivalentes a um terço da massa total de areia foram formadas. Cada uma dessas alíquotas foi homogeneizada na betoneira seca por aproximadamente 30 minutos. O processo foi repetido mais uma vez. No final as três frações foram misturadas juntas por 30 minutos.

A areia contendo os minérios de urânio e tório foi então utilizada na preparação da massa de concreto, seguindo o mesmo procedimento utilizado no caso dos blocos BKG1 e BKG2.

Nos blocos M1, M2 e M3, dependendo da concentração de potássio desejada, a areia de construção foi substituída em parte (M1 e M3) ou totalmente (M2) por feldspato potássico 
moído. A cada bloco foram adicionados os minerais contendo urânio e tório. A Tabela 3.3.1 apresenta as massas de caldasito, areia monazítica e ortoclásio utilizadas em cada bloco.

\begin{tabular}{|c|c|c|c|c|c|c|}
\hline Bloco & areia & $\begin{array}{c}\text { Brita } \\
\text { basalto }\end{array}$ & cimento & $\begin{array}{c}\text { Areia } \\
\text { feldspato }\end{array}$ & caldasito & $\begin{array}{c}\text { Areia } \\
\text { monazita }\end{array}$ \\
\hline BKG1 & 351 & 234 & 117 & & & \\
\hline $\boldsymbol{B K G 2}$ & 351 & 234 & 117 & & & \\
\hline $\boldsymbol{K} \mathbf{1}$ & & 234 & 117 & 351 & & \\
\hline $\boldsymbol{U}$ & 351 & 234 & 117 & & & 12 \\
\hline $\boldsymbol{T H}$ & 351 & 234 & 117 & & & 2 \\
\hline $\boldsymbol{M 1}$ & 103 & 234 & 117 & 240 & 0,9 & 0,5 \\
\hline $\boldsymbol{M} 2$ & & 234 & 117 & 351 & 2,7 & 1,0 \\
\hline $\boldsymbol{M 3}$ & 248 & 234 & 117 & 103 & 5,5 & 0,1 \\
\hline
\end{tabular}

Tabela 3.3.1 Valores das massas dos diversos constituintes utilizados na preparação do concreto de cada bloco.

A preparação da massa de concreto dos blocos M1, M2 e M3 seguiu os mesmos cuidados adotados no caso dos blocos de $\mathrm{U}$ e $\mathrm{TH}$. 


\subsection{Envasamento, retirada de amostras e cura do concreto}

Uma vez obtida a massa desejada, o concreto foi introduzido nos moldes de madeira. A transferência da massa de concreto foi sempre feita em duas etapas. Na primeira, o volume equivalente à metade do volume do molde era transferido. A massa de concreto era distribuída e assentada manualmente de forma a preencher completamente o espaço e a evitar, na medida do possível, a formação de vesículas.

No envasamento da massa de concreto não foram utilizados vibradores mecânicos para se evitar, ao máximo, a possibilidade dos minerais caldasito e areia monazita, que são mais densos, migrarem em direção ao fundo do molde.

Nessa primeira fase, cinco amostras do concreto já transferido foram coletadas e armazenadas em porta amostras feitos com tubo de PVC com 15,2 cm de diâmetro e $15 \mathrm{~cm}$ de altura, o volume coletado ocupava metade do porta amostra. A função dessas amostras é a determinação da concentração final dos elementos radioativos naturais. A Figura 3.4.1 mostra a distribuição dos pontos de amostragem na superfície do concreto.

$\mathrm{Na}$ segunda etapa, o restante da massa foi transferida para o molde e acomodada manualmente. Todo cuidado foi tomado para evitar a formação de uma descontinuidade no bloco. Amostras dos 7,5 centímetros superiores do concreto foram retiradas dos mesmos pontos de amostragem e sobrepostas às amostras coletadas anteriormente. As massas totais dessas amostras variaram entre $5 \mathrm{~kg}$ e $12 \mathrm{~kg}$, aproximadamente. Uma amostra final de concreto foi colhida do restante do concreto na betoneira e introduzida em porta amostras de PVC para a determinação da densidade do concreto. Essa amostra foi assentada de forma tão semelhante quanto possível ao concreto contido nos moldes de madeira. 


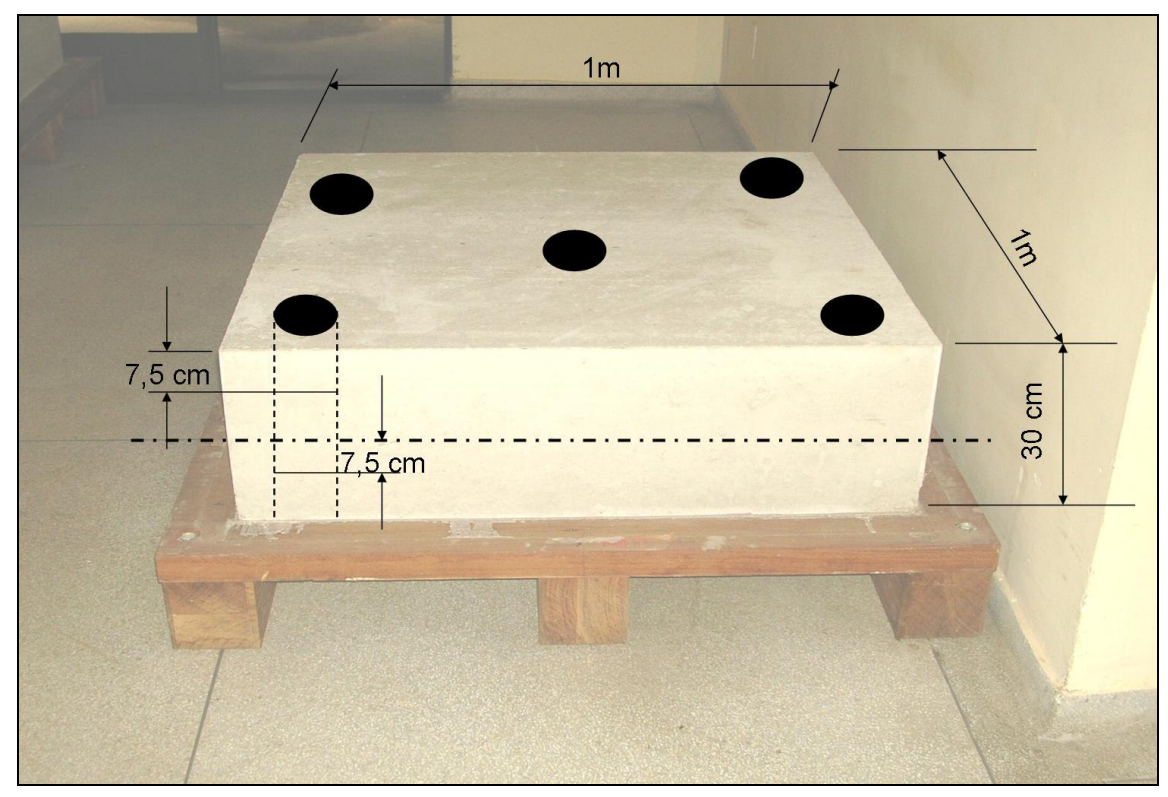

Figura 3.4.1 Distribuição espacial dos pontos de amostragem dos blocos.

O processo de cura do concreto variou entre 30 e 40 dias. Durante esse período o concreto, tanto dos moldes quanto dos porta amostras, foram umedecidos com excesso de água duas vezes ao dia. A função desse procedimento foi evitar a formação de fraturas no concreto durante o processo de cura. A Figura 3.4.2, abaixo, apresenta o bloco U na fase de cura do concreto.

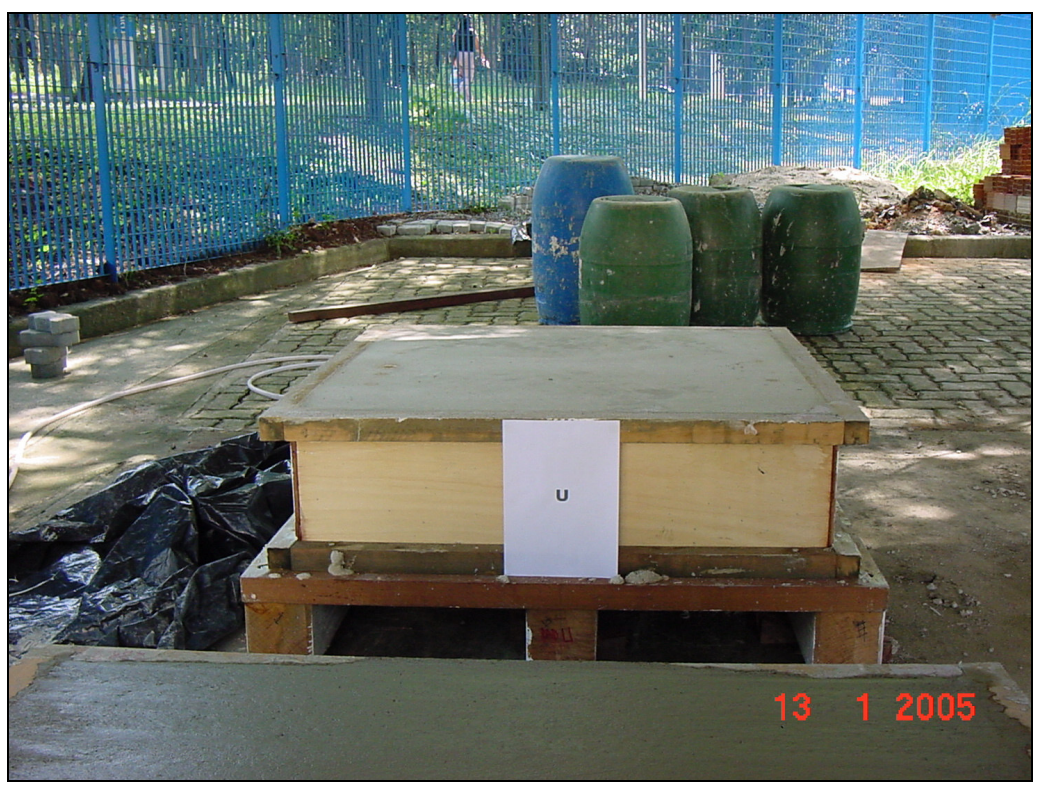

Figura 3.4.2 Bloco de $U$ em fase de cura. 


\section{Características Físicas dos Blocos Construídos}

\subsection{Densidade do Concreto em cada bloco}

A densidade do concreto utilizado na construção de cada um dos blocos de calibração foi estimada pela densidade das amostras coletadas com esse propósito durante o procedimento de envasamento descrito no Capítulo 3, seção 3.4.

As densidades foram medidas pelo método de Arquimedes. As medidas das massas foram feitas com uma balança eletrônica com carga máxima de $100 \mathrm{~kg}$ e com precisão de nominal de $0,020 \mathrm{~kg}$. O método de Arquimedes consiste em determinar o volume total da amostra através do valor do empuxo sofrido quando ela é imersa na água.

Inicialmente, as amostras tiveram a sua superfície impermeabilizada. $\mathrm{O}$ impermeabilizante da superfície lateral da amostra foi a parede do tubo de PVC, que tem uma espessura de 2-3 mm e a impermeabilização das faces superior e inferior foi feita com parafina.

O procedimento consiste em se medir, inicialmente, a massa $\left(P_{1}\right)$ da amostra. Em seguida, a amostra é mantida suspensa e totalmente imersa em um recipiente contendo água. Sendo $P_{2}$ a massa do recipiente contendo a água e $P_{3}$ a massa aparente do recipiente com água quando a amostra está totalmente imersa, pode-se escrever que a densidade aparente $\rho$ da amostra é dada por:

$$
\rho=\frac{P_{1}}{P_{2}-P_{3}}
$$

onde:

$P_{1}-$ massa da amostra

$P_{2}-$ massa do recipiente com água

$P_{3}$ - massa do recipiente com água mais a amostra suspensa 
$\mathrm{Na}$ forma em que foi escrita, a Equação 4.1.1 supõe que a densidade da água seja $1000 \mathrm{~kg} / \mathrm{m}^{3}$. O valor obtido pela equação acima deve ser corrigido levando em consideração a valor real da densidade da água.

A Tabela 4.1.1 apresenta quatro valores independentes da densidade aparente das amostras correspondentes a cada bloco de calibração, o valor médio e o desvio padrão. Os valores correspondem ao resultado da Equação 4.1.1, sem nenhuma correção. A temperatura da água utilizada na realização dessas medidas foi de $(21,0 \pm 0,1)^{\circ} \mathrm{C}$.

A Tabela 4.1.1 apresenta também uma estimativa da massa de cada bloco de calibração.

\begin{tabular}{|c|c|c|c|c|c|c|c|}
\hline Bloco & $\begin{array}{c}\mathbf{D 1} \\
\left(\mathbf{g} / \mathbf{c m}^{\mathbf{3}}\right)\end{array}$ & $\begin{array}{c}\mathbf{D 2} \\
\left(\mathbf{g} / \mathbf{c m}^{\mathbf{3}}\right)\end{array}$ & $\begin{array}{c}\mathbf{D 3} \\
\left(\mathbf{g} / \mathbf{c m}^{\mathbf{3}}\right)\end{array}$ & $\begin{array}{c}\mathbf{D 4} \\
\left(\mathbf{g} / \mathbf{c m}^{\mathbf{3}}\right)\end{array}$ & $\begin{array}{c}\text { Média } \\
\left(\mathbf{g} / \mathbf{c m}^{\mathbf{3}}\right)\end{array}$ & Desvio padrão & Massa $(\mathbf{k g})$ \\
\hline BKG1 & 2,196 & 2,196 & 2,192 & 2,196 & 2,195 & 0,002 & $658 \pm 5$ \\
\hline $\boldsymbol{K 1}$ & 1,974 & 1,974 & 1,974 & 1,978 & 1,975 & 0,002 & $593 \pm 3$ \\
\hline $\boldsymbol{U}$ & 2,195 & 2,195 & 2,204 & 2,195 & 2,197 & 0,004 & $659 \pm 9$ \\
\hline $\boldsymbol{T H}$ & 2,251 & 2,251 & 2,251 & 2,251 & 2,252 & 0,002 & $676 \pm 4$ \\
\hline $\boldsymbol{B} \boldsymbol{K} \mathbf{2}$ & 2,202 & 2,214 & 2,214 & 2,214 & 2,211 & 0,005 & $663 \pm 12$ \\
\hline $\boldsymbol{M 1}$ & 2,242 & 2,257 & 2,257 & 2,257 & 2,254 & 0,006 & $676 \pm 14$ \\
\hline $\boldsymbol{M} \mathbf{2}$ & 2,149 & 2,130 & 2,140 & 2,140 & 2,140 & 0,007 & $642 \pm 14$ \\
\hline $\boldsymbol{M 3}$ & 2,211 & 2,211 & 2,211 & 2,224 & 2,213 & 0,006 & $664 \pm 13$ \\
\hline
\end{tabular}

Tabela 4.1.1 Valores das densidades de cada bloco. Com a utilização dos valores de densidade foi possível estimar a massa de cada bloco, adotando-se um volume nominal de $0,3 \mathrm{~m}^{3}$ para todos os blocos. Obs. D1=primeira medida de densidade e assim por diante.

\subsection{Distribuição do Fluxo de radiação gama proveniente dos blocos de calibração}

Os blocos destinados à calibração de espectrômetros gama portáteis e aerotransportados devem representar, da melhor maneira possível, fontes de radiação gama semi-infinitas na direção vertical e que se estendam indefinidamente nas direções horizontais. Além disso, para que se possa determinar com precisão as constantes de calibração dos espectrômetros, as blocos têm que possuir concentrações de potássio, urânio e tório constantes em todo o seu volume e com valores bem conhecidos. 
Os blocos de calibração podem ser construídos com dimensões físicas muito variáveis, mas sempre finitas, de forma que, pelo menos em princípio, fatores de correção geométrica devem ser introduzidas para simular, matematicamente, fontes indefinidamente extensas.

A magnitude das heterogeneidades na distribuição dos elementos radioativos no volume de um bloco de calibração fica estabelecida durante a sua construção e, por isso, são tomados cuidados especiais na preparação da massa de concreto. No entanto, o resultado final é desconhecido e é necessário avaliar a amplitude das variações da concentração no concreto.

Uma das formas de se avaliar as variações na distribuição dos elementos radioativos no volume do concreto é colher, durante a sua confecção, amostras para serem analisadas em laboratório. Esse procedimento deve ser seguido, mas o número de amostras e o volume das amostras é sempre limitado. Uma técnica complementar, que pode ser aplicada, consiste em se avaliar a distribuição do fluxo de radiação gama proveniente da superfície do bloco, tal como foi feito por Grasty e colaboradores (1991).

O procedimento consiste em medir, com um espectrômetro gama portátil, o fluxo de radiação total de radiação gama em diferentes pontos da superfície do bloco de concreto. Como a radiação gama é penetrante, o detector acaba sendo sempre sensibilizado por todo o volume do bloco. Se, no entanto, o detector for blindado lateralmente, o seu registro passa a ser representativo de um volume limitado do concreto que, em primeira aproximação é definido pelo ângulo sólido com que o detector enxerga a superfície do concreto. As blindagens não são perfeitas de forma que, mesmo blindado, o detector recebe um fluxo parcialmente atenuado de radiação de todo o volume do concreto. No entanto, quanto melhor for a blindagem, maior é a participação da radiação emitida dentro desse ângulo sólido, e na direção do detector, sobre o seu registro, e menor é a influência do restante do bloco.

As leis que regem o fenômeno do decaimento radioativo permitem prever, e de fato se constata experimentalmente, que se um detector de radiação observa, sob um ângulo sólido 
fixo, uma fonte de radiação de intensidade constante, o número de contagens que é registrado em intervalos de tempo de mesma duração, varia aleatoriamente seguindo uma distribuição de Poisson bem definida pelo seu valor médio.

Em uma fonte de radiação gama semi-infinita, com concentração constante ao longo do seu volume e fixa no tempo, não seria possível se distinguir um ponto de observação na sua superfície de nenhum outro. Como os pontos de observação seriam, neste caso, indistinguíveis, os registros de um detector de radiação feitos em intervalos de tempo de mesma duração em diferentes pontos da superfície da fonte, sob o mesmo ângulo sólido, também deveriam se comportar como extrações de uma mesma distribuição de Poisson.

Quando se aplica o procedimento descrito a um bloco de calibração finito, registrando-se o fluxo de radiação total em pontos distantes da sua borda, o máximo que se pode esperar é que os registros sigam uma distribuição de Poisson. No entanto, existe neste caso um fator adicional que deve ser considerado que é a radiação de fundo.

A radiação de fundo tem origem no ambiente em que as medidas são realizadas e pode ser separado em duas componentes: uma de intensidade constante, que é devida as estruturas fixas em torno do local onde as medidas são realizadas e outra, de intensidade que pode variar, associada, principalmente, a variações de concentração de radônio e de seus descendentes de meia-vida curta na atmosfera. A blindagem que envolve o detector atenua o efeito da radiação de fundo, mas, ainda assim, a sua influência pode, eventualmente, ser percebida.

Quando a radiação de fundo mantém a sua intensidade constante durante o processo de aquisição de dados, as contagens totais brutas (fonte + fundo) devem se comportar como extrações de uma distribuição de Poisson. Se a intensidade da radiação de fundo variar essa suposição perde a validade. 
Uma forma de se observar eventuais flutuações na radiação de fundo é repetir, em um mesmo ponto do laboratório, medidas feitas com o detector blindado. Sendo o ponto de observação fixo, as contagens registradas deveriam se distribuir seguindo a estatística de Poisson, enquanto a intensidade da radiação atmosférica permanecesse constante.

Uma forma prática de se realizar esse controle é adotar, como ponto de observação das flutuações da radiação de fundo, o centro de um dos blocos que não contém minerais radioativos e manter esse bloco em posição fixa durante a aquisição de dados.

A verificação se um conjunto de registros pode ou não ser considerados como escolhas ao acaso de valores pertencentes a uma distribuição de Poisson definida pelo valor médio dessas contagens, é feita aplicando-se um teste de hipótese nula (ver por exemplo Davis, 1986). Se a hipótese de que os registros pertençam à distribuição de Poisson (hipótese nula do teste) não puder ser rejeitada, considerando um nível de significância pré-estabelecido, conclui-se que não se pode afirmar que a fonte de radiação seja heterogênea. Por outro lado, se a hipótese nula for rejeitada, pode-se afirmar, com uma probabilidade máxima de erro correspondente ao nível de significância, que a fonte é heterogênea. 


\subsubsection{A blindagem lateral do detector}

A blindagem utilizada para determinar a distribuição da intensidade do fluxo de radiação gama proveniente da superfície dos blocos de calibração consistiu de um conjunto de três anéis de chumbo (Figura 4.2.1.1) com $125 \mathrm{~mm}$ de altura, $140 \mathrm{~mm}$ de diâmetro interno e 240 mm de diâmetro externo. A massa aproximada de cada anel é $42 \mathrm{~kg}$.

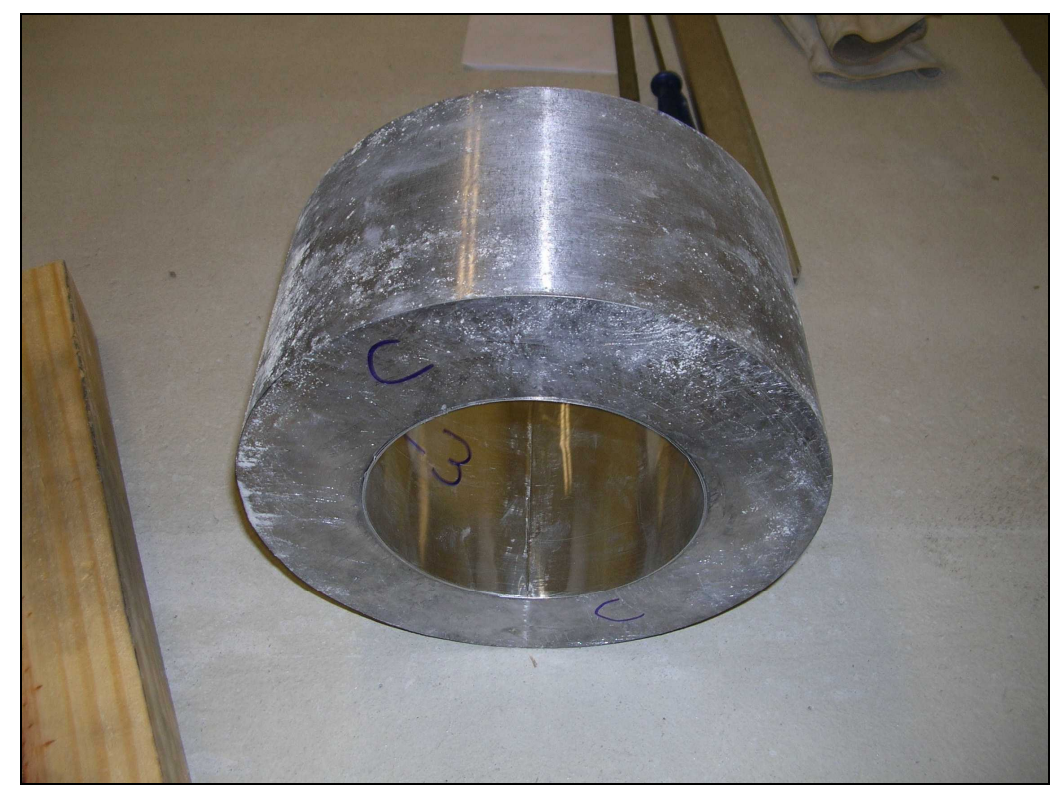

Figura 4.2.1.1 Anel de chumbo utilizado como blindagem lateral. 
Para atenuar a radiação gama originada no espalhamento Compton no volume dos anéis de chumbo, seis folhas de alumínio com $1 \mathrm{~mm}$ de espessura foram fixadas nas paredes internas dos anéis de chumbo (Figuras 4.2.1.2 e 4.2.1.3).

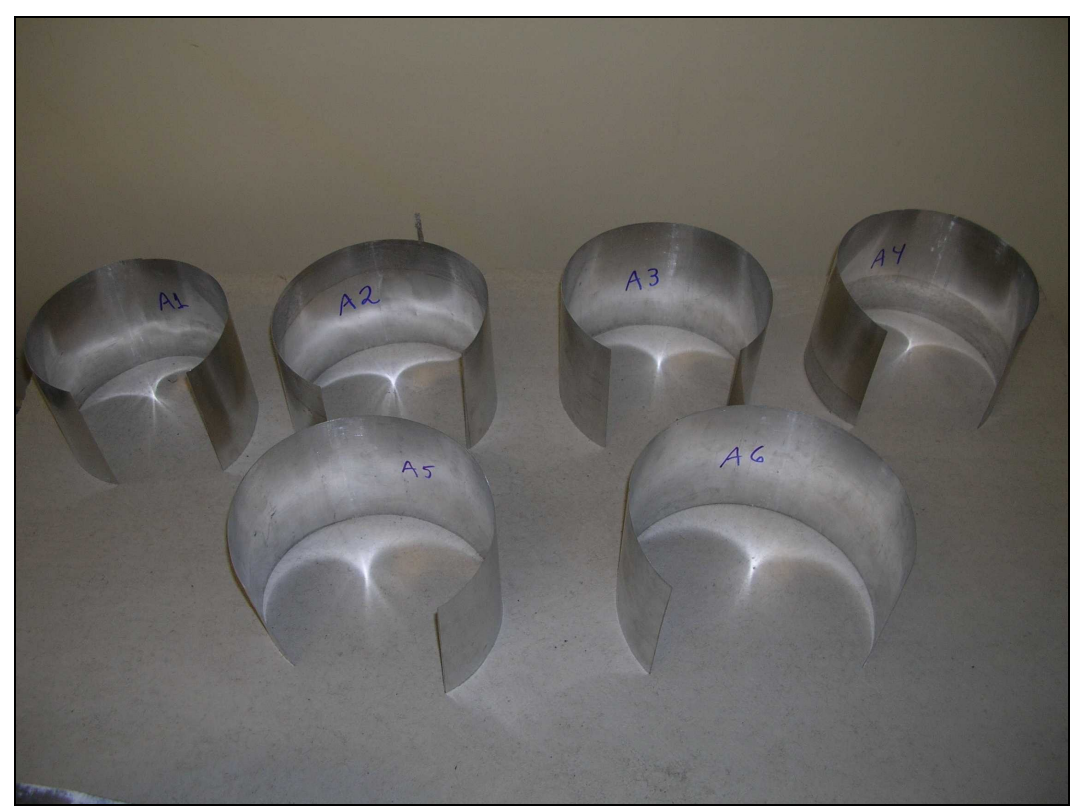

Figura 4.2.1.2 As folhas de alumínio foram introduzidas nos diâmetros internos dos anéis de chumbo.

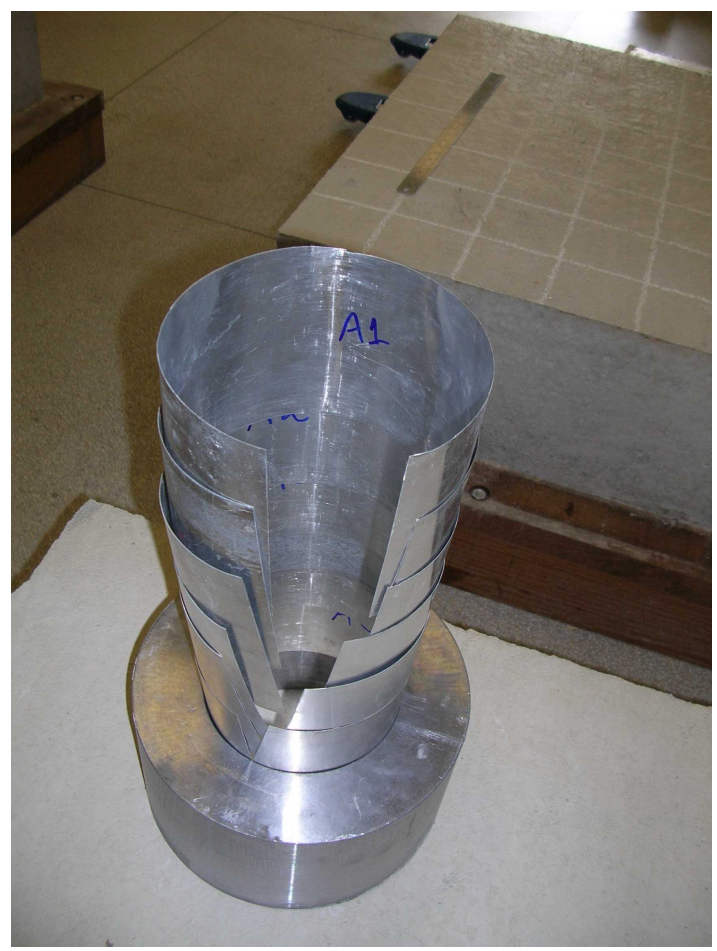

Figura 4.1.2.3 As várias camadas de alumínio foram montadas aos anéis de chumbo de modo a obter-se uma blindagem mais efetiva da radiação. 
O cristal do espectrômetro gama portátil foi sempre posto a altura correspondente ao anel central da blindagem de fundo (Figura 4.2.1.4).

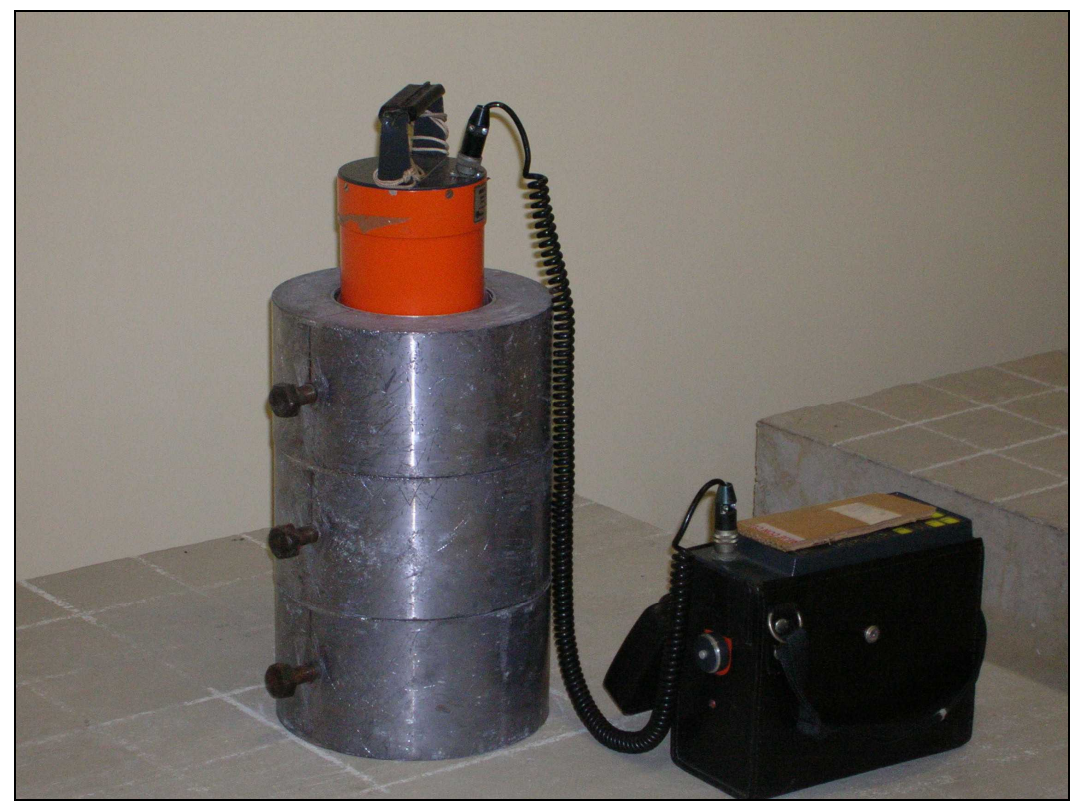

Figura 4.2.1.4 Apresenta a montagem da blindagem durante as medidas sobre a superfície dos blocos de calibração.

A posição foi mantida apoiando-se o detector sobre um segmento de tubo de PVC de $125 \mathrm{~mm}$ de altura. Com essa montagem, o ângulo sólido com que o detector enxerga a superfície do concreto fica limitado, praticamente, ao ângulo definido pela abertura do anel de chumbo. 


\subsubsection{Verificação da homogeneidade da distribuição da intensidade do fluxo de radiação gama proveniente da superfície do concreto}

Sobre a superfície dos oito blocos de concreto radioativo foi traçada uma malha regular quadrada com $125 \mathrm{~mm}$ de espaçamento. Como os blocos têm 1,0 m de lado, formou-se um reticulado de $8 \times 8$ elementos. Dois eixos perpendiculares foram definidos de forma que as intersecções (nós) do reticulado ficassem perfeitamente identificados por um par de coordenadas $(\mathrm{x}, \mathrm{y})$.

As medidas de intensidade do fluxo de radiação gama foram realizadas colocando-se o centro dos anéis sobre os nós do retículo traçado sobre os blocos. A incerteza da posição da blindagem em torno da posição do nó foi estimada em $10 \mathrm{~mm}$ nas duas direções. Para evitar a influência das bordas dos blocos utilizou-se apenas os 25 nós mais internos das malhas (Figura 4.2.2.1).

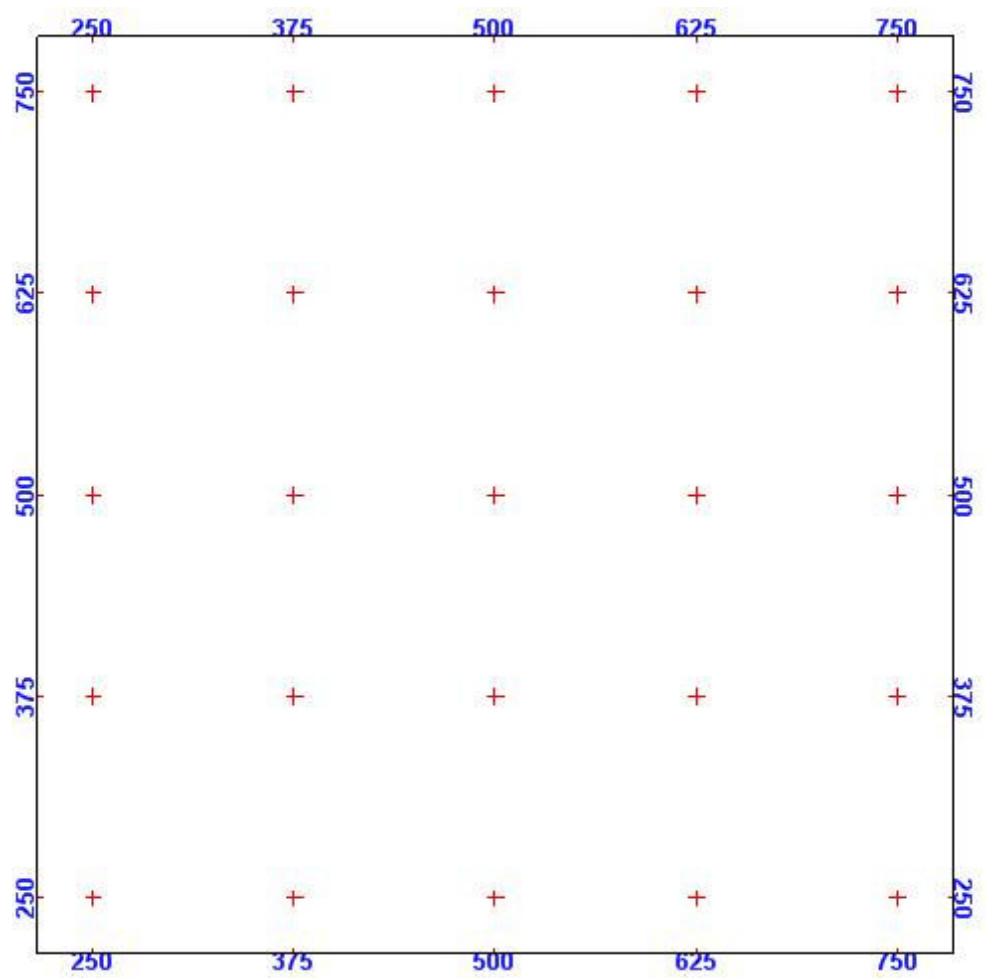

Figura 4.2.2.1. Pontos de medidas da radiação gama. 
Uma vez que os anéis de chumbo têm um diâmetro interno de $140 \mathrm{~mm}$, pode-se considerar que a fração da superfície dos blocos de concreto que é investigado através deste procedimento corresponde as coordenadas x e y contidas entre $125 \mathrm{~mm}$ e $875 \mathrm{~mm}$. Em termos relativos, a área investigada corresponde a $56,25 \%$ da superfície total do bloco.

$\mathrm{O}$ procedimento de medida começou sempre com uma observação da radiação de fundo. $\mathrm{O}$ bloco BKG2 foi escolhido e mantido em uma posição fixa durante as medidas de fluxo de radiação de cada um dos blocos de concreto, inclusive o bloco BKG1. A observação do fundo foi feita colocando-se o detector blindado no centro do bloco e acumulando-se as contagens por 10 minutos.

Após a primeira observação de fundo, o detector blindado era transferido para o bloco a ser analisado começando pelo nó na posição $(250,750)$. Depois de um período de acúmulo de contagens de 10 minutos, o detector blindado era transferido para o nó seguinte na posição $(250,625)$, onde as contagens eram acumuladas por 10 minutos. O processo se repetia até se atingir $(250,250)$. Após o período de contagem de 10 minutos, o detector blindado era transferido para o centro do bloco BKG2 para mais dez minutos de observação do fundo. $\mathrm{O}$ processo era então recomeçado pelo nó na posição $(375,250)$ subindo até o início da posição $(375,750)$. Nova observação da radiação de fundo era feita e o processo prosseguia até a última observação sobre o bloco analisado no nó da posição $(750,250)$. Uma última observação da radiação de fundo fechava o procedimento.

No caso da análise da homogeneidade do bloco BKG2, feita depois de todas os outros blocos terem sido analisados, as observações de fundo foram feitas no centro do bloco BKG1, que foi mantido em posição fixa durante todo o procedimento descrito acima.

A Tabela 4.2.2.1 apresenta as observações da radiação de fundo realizadas durante as análises de todos os blocos. Cada coluna da tabela corresponde ao período de análise de um dos 
blocos. As contagens apresentadas cobrem o intervalo de energia entre $410 \mathrm{keV}$ e $2810 \mathrm{keV}$ (Contagem Total).

A Tabela 4.2.2.2 apresenta as observações da intensidade de fluxo de radiação proveniente da superfície dos blocos de calibração. Cada coluna na tabela corresponde a observação da intensidade do fluxo de radiação de um dos blocos em todos os 25 nós selecionados da malha. As contagens apresentadas correspondem as contagens brutas, sem a remoção da influência das contagens de fundo.

\begin{tabular}{|c|c|c|c|c|c|c|c|c|}
\hline Bloco & BKG1 & BKG2 & K1 & $\boldsymbol{U}$ & TH & M1 & M2 & M3 \\
\hline OBS & & & & & & & & \\
\hline $\mathbf{1}$ & 6120 & 6045 & 6040 & 6034 & 5989 & 5940 & 5992 & 6018 \\
\hline $\mathbf{2}$ & 6055 & 6087 & 5919 & 5976 & 5935 & 6107 & 6050 & 6035 \\
\hline $\mathbf{3}$ & 6199 & 6063 & 6137 & 5914 & 5866 & 6119 & 6039 & 6158 \\
\hline $\mathbf{4}$ & 5963 & 6019 & 6023 & 6001 & 5828 & 6031 & 6094 & 5957 \\
\hline $\mathbf{5}$ & 6058 & 6022 & 6098 & 6122 & 5980 & 6138 & 6130 & 6019 \\
\hline $\mathbf{6}$ & 6078 & 6101 & 6099 & 6028 & 5888 & 6015 & 6008 & 6013 \\
\hline $\mathbf{7}$ & & & & & & & 6142 & \\
\hline Média & $\mathbf{6 0 7 9}$ & $\mathbf{6 0 5 6}$ & $\mathbf{6 0 5 3}$ & $\mathbf{6 0 1 3}$ & $\mathbf{5 9 1 4}$ & $\mathbf{6 0 5 8}$ & $\mathbf{6 0 6 5}$ & $\mathbf{6 0 3 3}$ \\
\hline Desvio-Padrão & $\mathbf{7 8}$ & $\mathbf{3 4}$ & $\mathbf{7 8}$ & $\mathbf{6 9}$ & $\mathbf{6 4}$ & $\mathbf{7 6}$ & $\mathbf{5 8}$ & $\mathbf{6 7}$ \\
\hline$\chi^{2}$ & $\mathbf{5 , 0 2 6}$ & $\mathbf{0 , 9 3 8}$ & $\mathbf{4 , 9 9 3}$ & $\mathbf{3 , 9 5 9}$ & $\mathbf{3 , 4 6 3}$ & $\mathbf{4 , 7 6 7}$ & $\mathbf{3 , 3 7 6}$ & $\mathbf{3 , 6 8 4}$ \\
\hline
\end{tabular}

Tabela 4.2.2.1 Valores das medidas da radiação de fundo para cada bloco de calibração. 


\begin{tabular}{|c|c|c|c|c|c|c|c|c|c|c|}
\hline nó & $\boldsymbol{X}$ & $\boldsymbol{y}$ & $\boldsymbol{B K G 1}$ & $\boldsymbol{B K G 2}$ & $\boldsymbol{K 1}$ & $\boldsymbol{U}$ & $\boldsymbol{T H}$ & $\boldsymbol{M 1}$ & $\boldsymbol{M} \mathbf{2}$ & $\boldsymbol{M 3}$ \\
\hline 9 & 250 & 750 & 6026 & 6229 & 7896 & 14096 & 16034 & 9758 & 13126 & 10712 \\
\hline 10 & 250 & 625 & 6048 & 6081 & 7833 & 14320 & 15961 & 9634 & 12991 & 10797 \\
\hline 11 & 250 & 500 & 6053 & 6049 & 7808 & 14286 & 16006 & 9760 & 13212 & 10686 \\
\hline 12 & 250 & 375 & 6096 & 6098 & 7878 & 13958 & 16052 & 9500 & 13263 & 10585 \\
\hline 13 & 250 & 250 & 5913 & 6157 & 7732 & 14056 & 15594 & 9632 & 13119 & 10461 \\
\hline 16 & 375 & 250 & 5960 & 6020 & 7804 & 14246 & 15728 & 9688 & 13429 & 10622 \\
\hline 17 & 375 & 375 & 5886 & 6056 & 7893 & 14343 & 16274 & 9670 & 13105 & 10739 \\
\hline 18 & 375 & 500 & 5892 & 5957 & 7922 & 14575 & 16262 & 9843 & 13540 & 10826 \\
\hline 19 & 375 & 625 & 5937 & 6094 & 7940 & 14113 & 16223 & 9692 & 13350 & 10829 \\
\hline 20 & 375 & 750 & 6121 & 6267 & 7811 & 14353 & 15949 & 9872 & 13328 & 10812 \\
\hline 23 & 500 & 750 & 6242 & 6027 & 7923 & 13982 & 15816 & 9665 & 13070 & 10768 \\
\hline 24 & 500 & 625 & 6159 & 6054 & 7695 & 14283 & 16187 & 9822 & 13367 & 10803 \\
\hline 25 & 500 & 500 & 6069 & 6032 & 7625 & 14332 & 16263 & 9700 & 13395 & 10701 \\
\hline 26 & 500 & 375 & 6197 & 6104 & 7871 & 14298 & 16059 & 9722 & 13372 & 10748 \\
\hline 27 & 500 & 250 & 5944 & 6106 & 7687 & 14173 & 15967 & 9601 & 13340 & 10431 \\
\hline 30 & 625 & 250 & 6077 & 6104 & 8018 & 14162 & 15758 & 9845 & 13192 & 10757 \\
\hline 31 & 625 & 375 & 5951 & 5937 & 7934 & 14193 & 15990 & 9654 & 13563 & 10825 \\
\hline 32 & 625 & 500 & 6052 & 6089 & 8018 & 14146 & 16166 & 9964 & 13561 & 10704 \\
\hline 33 & 625 & 625 & 6138 & 6085 & 7973 & 14779 & 15911 & 9899 & 13304 & 10933 \\
\hline 34 & 625 & 750 & 6032 & 6187 & 8049 & 14110 & 15414 & 9809 & 13076 & 10820 \\
\hline 37 & 750 & 750 & 6172 & 6118 & 7966 & 13920 & 15742 & 9831 & 13334 & 10576 \\
\hline 38 & 750 & 625 & 6107 & 6029 & 7897 & 14331 & 15901 & 9793 & 13328 & 10767 \\
\hline 39 & 750 & 500 & 5947 & 6183 & 7843 & 14490 & 16177 & 9897 & 13167 & 10655 \\
\hline 40 & 750 & 375 & 6060 & 6275 & 7893 & 14409 & 15801 & 9617 & 13406 & 10569 \\
\hline 41 & 750 & 250 & 6082 & 6025 & 7676 & 13878 & 15791 & 9978 & 13244 & 10554 \\
\hline & & media & $\mathbf{6 0 5 3}$ & $\mathbf{6 0 9 5}$ & $\mathbf{7 8 6 3}$ & $\mathbf{1 4 2 3 3}$ & $\mathbf{1 5 9 6 1}$ & $\mathbf{9 7 5 8}$ & $\mathbf{1 3 3 2 8}$ & $\mathbf{1 0 7 3 9}$ \\
\hline & desvpad & $\mathbf{9 8}$ & $\mathbf{8 5}$ & $\mathbf{1 1 3}$ & $\mathbf{2 0 8}$ & $\mathbf{2 2 1}$ & $\mathbf{1 1 5}$ & $\mathbf{1 5 6}$ & $\mathbf{1 2 4}$ \\
\hline & quiquadrado & $\mathbf{3 8 , 0 8 0}$ & $\mathbf{2 8 , 4 5 0}$ & $\mathbf{3 8 , 9 7 4}$ & $\mathbf{7 2 , 9 5 3}$ & $\mathbf{7 3 , 4 4 1}$ & $\mathbf{3 2 , 5 8 7}$ & $\mathbf{4 3 , 8 2 2}$ & $\mathbf{3 4 , 3 6 3}$ \\
\hline
\end{tabular}

Tabela 4.2.2.2 Valores das medidas das taxas de contagens do canal de contagem total para os blocos de calibração.

Para o conjunto de valores de observação da radiação de fundo correspondente a cada bloco e para o conjunto de valores da intensidade do fluxo de radiação proveniente da superfície de cada bloco calcula-se o valor médio:

$$
\bar{x}=\frac{1}{N} \sum_{i=1}^{N} x_{i}
$$

E a sua variância amostral

$$
s^{2}=\frac{1}{N-1} \sum_{i=1}^{N}\left(x_{i}-\bar{x}\right)^{2}
$$


Um terceiro parâmetro pode ser calculado na forma:

$$
\chi_{\text {calculado }}^{2}=\frac{1}{-} \sum_{i=1}^{N}\left(x_{i}-\bar{x}\right)^{2}
$$

Usando as equações 4.2.2.1 e 4.2.2.2, pode-se escrever:

$$
\chi_{\text {calculado }}^{2}=(N-1) \frac{s^{2}}{-}
$$

Em uma distribuição de Poisson, ou o seu valor esperado é igual à sua variância. Se a distribuição da qual os $N$ valores $x_{i}$ são extraídos fosse uma distribuição de Poisson e se o seu valor esperado e a variância fossem conhecidos e substituídos na Equação 4.2.2.4 o resultado seria:

$$
\chi_{\text {calculado }}^{2}=(N-1)
$$

Quando, no entanto, se utiliza estimativas $\bar{x}$ e $s^{2}$ obtidas a partir de $N$ valores, a Equação 4.2.2.4 fornece um valor de uma variável aleatória contínua, que tem como função de densidade de probabilidade a função $\chi^{2} \operatorname{com}(N-1)$ graus de liberdade (Knoll, 1988).

Quando o valor calculado pela equação 4.2.2.4, a partir de um conjunto de $N$ valores aproxima de $(N-1)$, imagina-se que os valores individuais de $x_{i}$ possam ter sido extraídos de uma distribuição de Poisson. Por outro lado, à medida que o $\chi^{2}$ calculado se afasta de $(N-1)$, essa hipótese parece menos provável.

O teste de hipótese a ser aplicado aos valores listados nas colunas das Tabelas 4.2.2.1 e 4.2.2.2 se baseia nesse raciocínio. Formalmente, trata-se de uma aplicação do critério do $\chi^{2}$, descrito, por exemplo em Davis (1986), Bevington (1969) e Vuolo (1996), onde se rejeitam 
valores de $\chi^{2}$ calculado com probabilidade igual ou inferior a um limite pré-estabelecido (nível de significância $\alpha$ ) de pertencerem à distribuição $\chi^{2} \operatorname{com}(N-1)$ graus de liberdade.

A Tabela 4.2.2.1 apresenta, para cada coluna o valor médio, o seu desvio padrão amostral e o valor da variável $\chi^{2}$ calculada pela equação 4.2.2.2. O número de graus de liberdade, nesse caso, é cinco, e rejeitam-se os valores de $\chi^{2}$ calculado, assumindo um nível de significância de 0,05, quando (Spiegel, 1976):

$$
\chi_{\text {calculado }}^{2}<0,831 \quad \text { ou } \quad \chi_{\text {calculado }}^{2}>12,8
$$

Nenhum dos valores $\chi^{2}$ calculados satisfaz as condições acima e, portanto, não se rejeitou a hipótese de que as observações da radiação de fundo, correspondentes a cada bloco de calibração, tenham sido escolhidas ao acaso de distribuições de Poisson.

A conclusão é que não há evidência de que a intensidade da radiação de fundo tenha variado nos intervalos de tempo em que foi observada. A Tabela 4.2.2.2 apresenta, para cada coluna, o valor médio, o seu desvio padrão amostral e valor da variável $\chi^{2}$ calculada pela equação 4.2.2.2. O número de graus de liberdade, neste caso, é 24 , é rejeitam-se os valores de $\chi^{2}$ calculado, assumindo um nível de significância de 0,05, quando (Spiegel, 1976):

$$
\chi_{\text {calculado }}^{2}<12,4 \quad \text { ou } \quad \chi_{\text {calculado }}^{2}>39,4
$$

No caso dos blocos de U, TH e M2, rejeitou-se a hipótese de que os valores da intensidade do fluxo de radiação gama sejam extraídos de distribuições de Poisson. Uma vez que a radiação de fundo manteve a sua intensidade durante os intervalos de tempo de medida da intensidade do fluxo proveniente dos blocos, conclui-se que os blocos U, TH e M2 são heterogêneos. No 
caso dos demais blocos, não há evidência de heterogeneidades do ponto de vista da intensidade do fluxo de radiação gama proveniente da superfície do concreto.

\subsubsection{Uma segunda forma de verificar a homogeneidade da distribuição da intensidade do fluxo de radiação gama proveniente da superfície do concreto}

Uma segunda maneira de se avaliar a distribuição da intensidade da radiação gama emitida pelos blocos consiste em ajustar uma superfície polinomial de grau baixo aos valores de fluxo de radiação observados nos nós das malhas traçadas sobre os blocos. Essa segunda avaliação, além de indicar a presença de heterogeneidades, fornece uma imagem aproximada da sua forma.

Neste procedimento, as observações consistem, no caso dos blocos com minerais radioativos adicionados, dos valores listados nas colunas da Tabela 4.2.2.2, como valor médio da radiação de fundo subtraído, (z), e dos pares de coordenadas (x,y) dos pontos da malha. No caso dos blocos destinados a observação da radiação de fundo foram utilizados os valores brutos.

Inicialmente, às observações correspondentes a cada bloco foi ajustada uma superfície de primeiro grau:

$$
z=a+b x+c y
$$

Onde os coeficientes $a, b$ e $c$ são determinados pelo método dos mínimos quadrados, ponderados levando-se em consideração as incertezas tanto na variável dependente (z), quanto nas variáveis independentes (x e y) (Wolberg, 1968).

A Tabela 4.2.3.1 apresenta os resultados desses ajustes. Essa tabela apresenta os coeficientes $a, b$ e $c$, com as respectivas incertezas e o valor do $\chi^{2}$ do ajuste, definido, neste caso, por (Wolberg,1968): 


$$
\chi^{2}=\sum_{i=1}^{N} \frac{\left(z_{i}-\left(a+b x_{i}+c y_{i}\right)\right)^{2}}{\sigma_{i}^{2}}
$$

Onde

$$
\sigma_{i}^{2}=\sigma_{z i}^{2}+b^{2} \sigma_{x i}^{2}+c^{2} \sigma_{y i}^{2}
$$

Valores muito altos de $\chi^{2}$ fornecidos pela Equação 4.2.3.2 sugerem que, ou o modelo utilizado no ajuste (Equação 4.2.3.1, neste caso) não representa adequadamente os dados, ou as incertezas das observações estão muito subestimadas. Por outro lado, valores muito baixos $\chi^{2}$ sugerem que as incertezas das observações estão muito superestimadas. Formalmente, trata-se de uma aplicação do critério do $\chi^{2}$ (Davis, 1986; Bevington, 1969; Vuolo, 1996). O número de graus de liberdade, neste caso é $(N-3)$. O critério foi sempre aplicado utilizando-se um nível de significância de 0,05.

\begin{tabular}{|c|c|c|c|c|}
\hline Bloco & $\mathbf{a} \pm \Delta \mathbf{a}$ & $\mathbf{b} \pm \Delta \mathbf{b}$ & $\mathbf{c} \pm \Delta \mathbf{c}$ & $\boldsymbol{\chi}^{\mathbf{2}}$ \\
\hline K1 & $1633 \pm 89$ & $0,14 \pm 0,12$ & $0,21 \pm 0,12$ & 18,4 \\
\hline $\mathbf{U}$ & $8150 \pm 178$ & $0,06 \pm 0,24$ & $0,08 \pm 0,24$ & 50,6 \\
\hline TH & $1016 \pm 186$ & $-0,27 \pm 0,25$ & $0,04 \pm 0,25$ & 51,2 \\
\hline M1 & $3445 \pm 87$ & $0,33 \pm 0,12$ & $0,17 \pm 0,12$ & 15,5 \\
\hline M2 & $7195 \pm 126$ & $0,24 \pm 0,17$ & $-0,18 \pm 0,17$ & 26,6 \\
\hline M3 & $4483 \pm 89$ & $0,00 \pm 0,12$ & $0,38 \pm 0,12$ & 15,3 \\
\hline BKG1 & $6035 \pm 71$ & $0,005 \pm 0,098$ & $0,111 \pm 0,098$ & 26,8 \\
\hline BKG2 & $5857 \pm 73$ & $0,15 \pm 0,10$ & $0,23 \pm 0,10$ & 28,3 \\
\hline
\end{tabular}

Tabela 4.2.3.1 Valores dos coeficientes ajustados com base nos dados da Tabela 4.2.2.2.

Sendo o número de graus de liberdade $(N-3)$ igual a 22 , rejeita-se o valor do $\chi^{2}$ dado pela equação 4.2.3.2 quando (Spiegel, 1976):

$$
\chi_{\text {calculado }}^{2}<11,7 \quad \text { ou } \quad \chi_{\text {calculado }}^{2}>38,1
$$


O resultado apresentado na Tabela 4.2.3.1 mostra que, com exceção dos blocos de U e TH, não se pode afirmar que o modelo utilizado (Equação 4.2.3.1) seja inadequado para representar a distribuição dos valores de fluxo de radiação gama sobre a superfície dos blocos. Além disso, não há indicação de que as incertezas desses valores tenham sido mal estimadas. $\mathrm{Na}$ realidade, a própria natureza estatística dos valores (distribuição de Poisson) indica a forma correta de se estimar essas incertezas.

As Figuras 4.2.3.1 a 4.2.3.3 apresentam as superfícies de tendência calculadas pela equação 4.2.3.1, utilizando os valores de $a, b$ e $c$ dados na Tabela 4.2.3.1, para os blocos BKG2, K1 e M2, respectivamente. Nessas figuras, a escala de cores representa o afastamento relativo dos valores calculados por:

$$
\text { afastamento relativo }=\frac{\text { valor } \text { calculado }- \text { valor } \text { médio }}{\text { valor médio }}
$$

Onde:

$$
\text { valor médio }=\frac{1}{\Delta x \Delta y} \int_{0}^{\Delta y \Delta x} \int_{0}(a+b x+c y) d x d y
$$

Com $\Delta \mathrm{x}$ e $\Delta \mathrm{y}$ sendo iguais a $1000 \mathrm{~mm}$. 


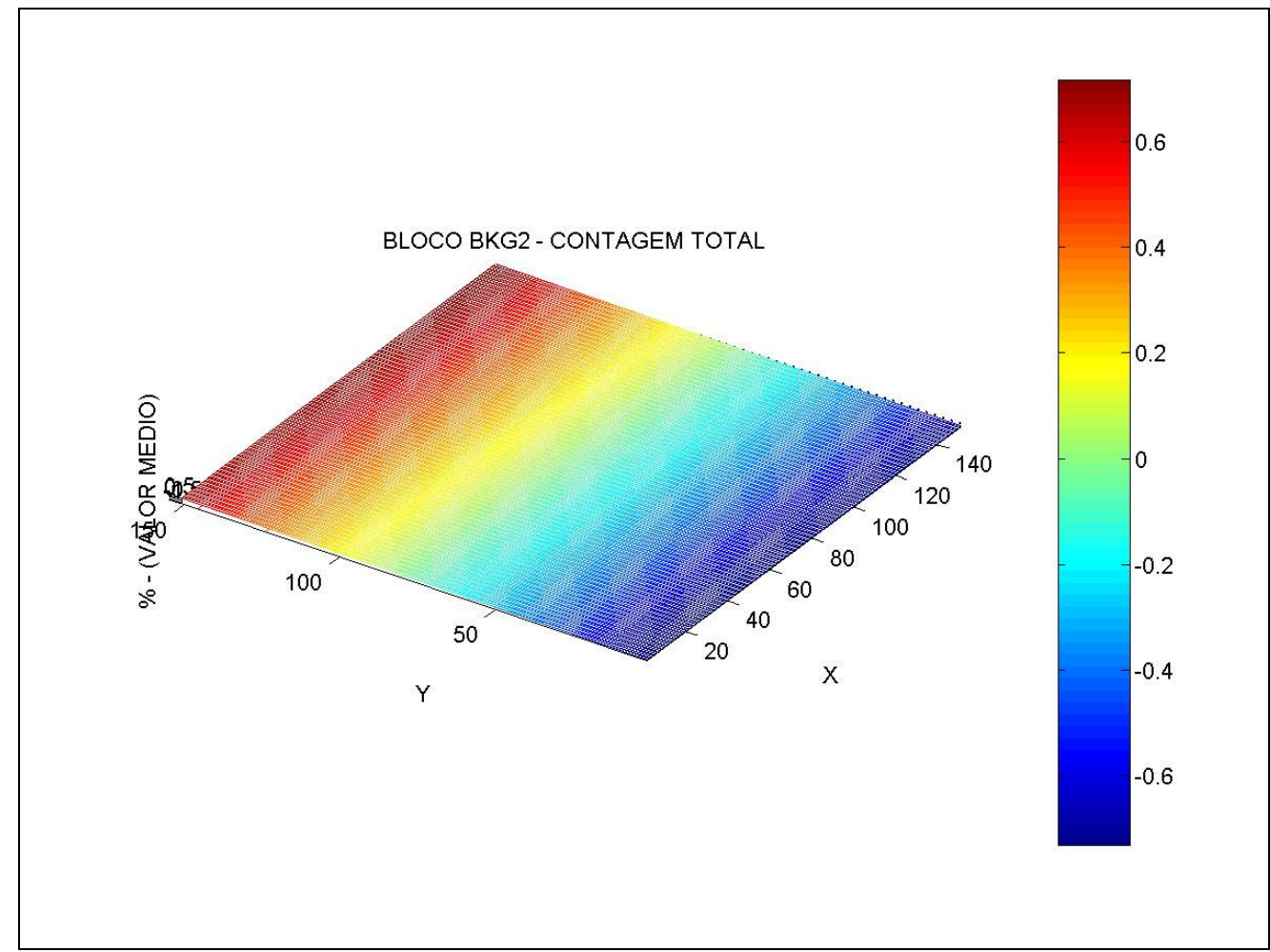

Figura 4.2.3.1 Medidas do bloco de background 2 - BKG2. Os dados foram ajustados a uma superfície planar. Note a variação percentual das medidas na escala de cores (aproximadamente $\pm 0,6 \%$ ).

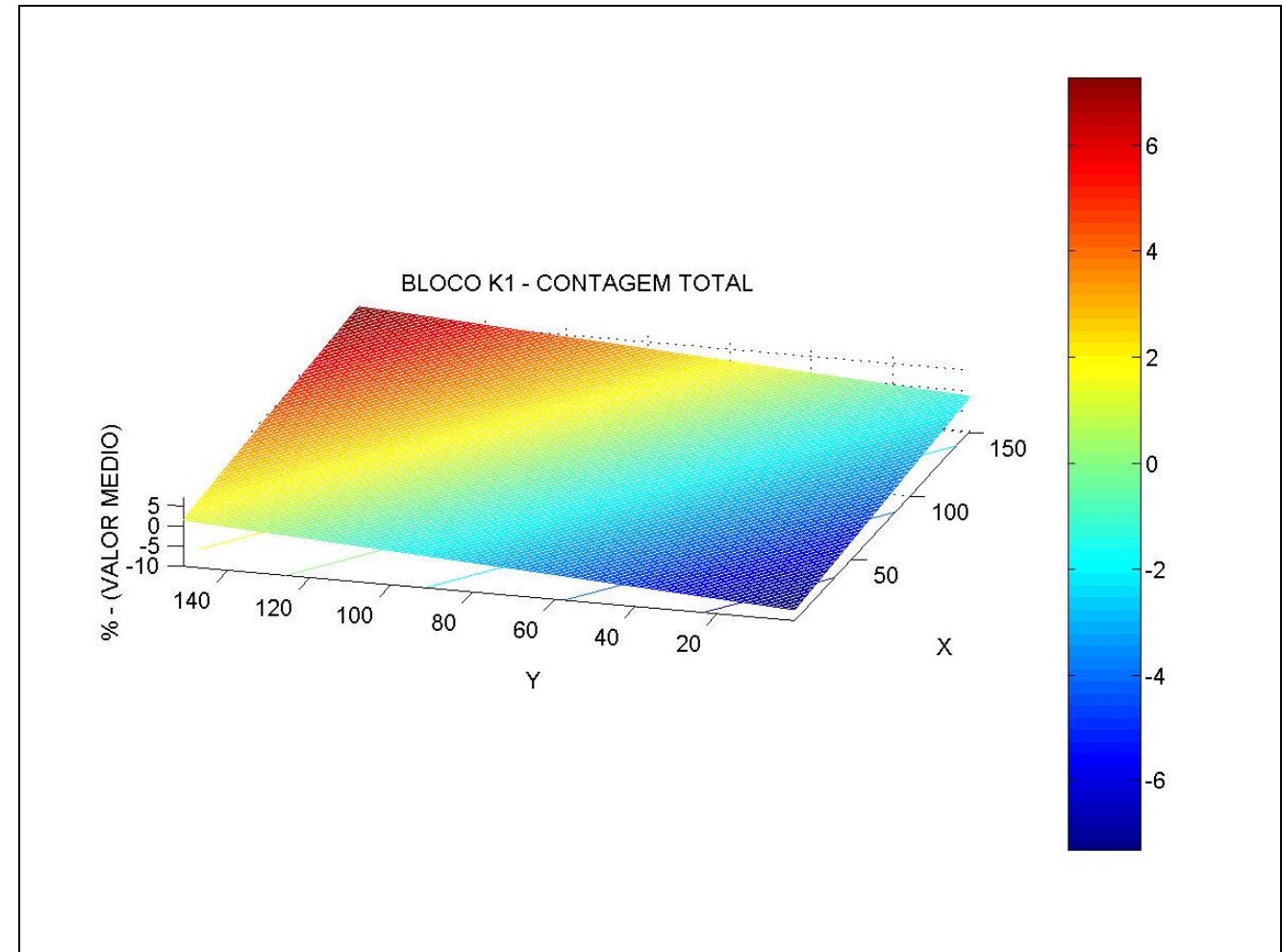

Figura 4.2.3.2 Medidas do bloco de potássio - K1. Os dados foram ajustados a uma superfície planar. Note a variação percentual das medidas na escala de cores (aproximadamente $\pm 6 \%$ ). 


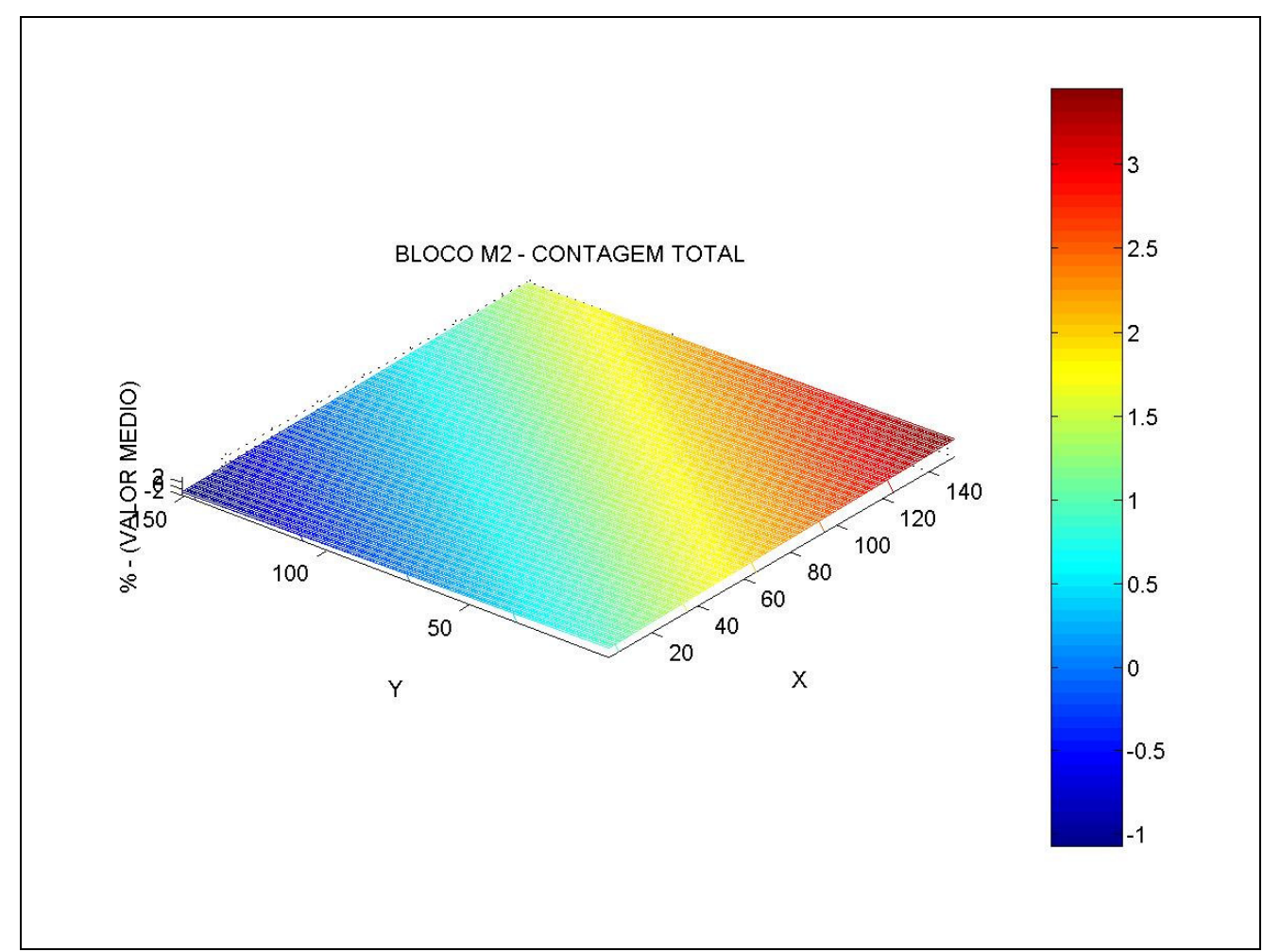

Figura 4.2.3.3 Medidas do bloco mista 2 - M2. Os dados foram ajustados a uma superfície planar. Note a variação percentual das medidas na escala de cores (aproximadamente +3 e $-1 \%$ ).

As Figuras 4.2.3.4 a 4.2.3.6 apresentam as superfícies de tendência calculadas utilizando os valores obtidos para os blocos BKG1, M1 e M3. 


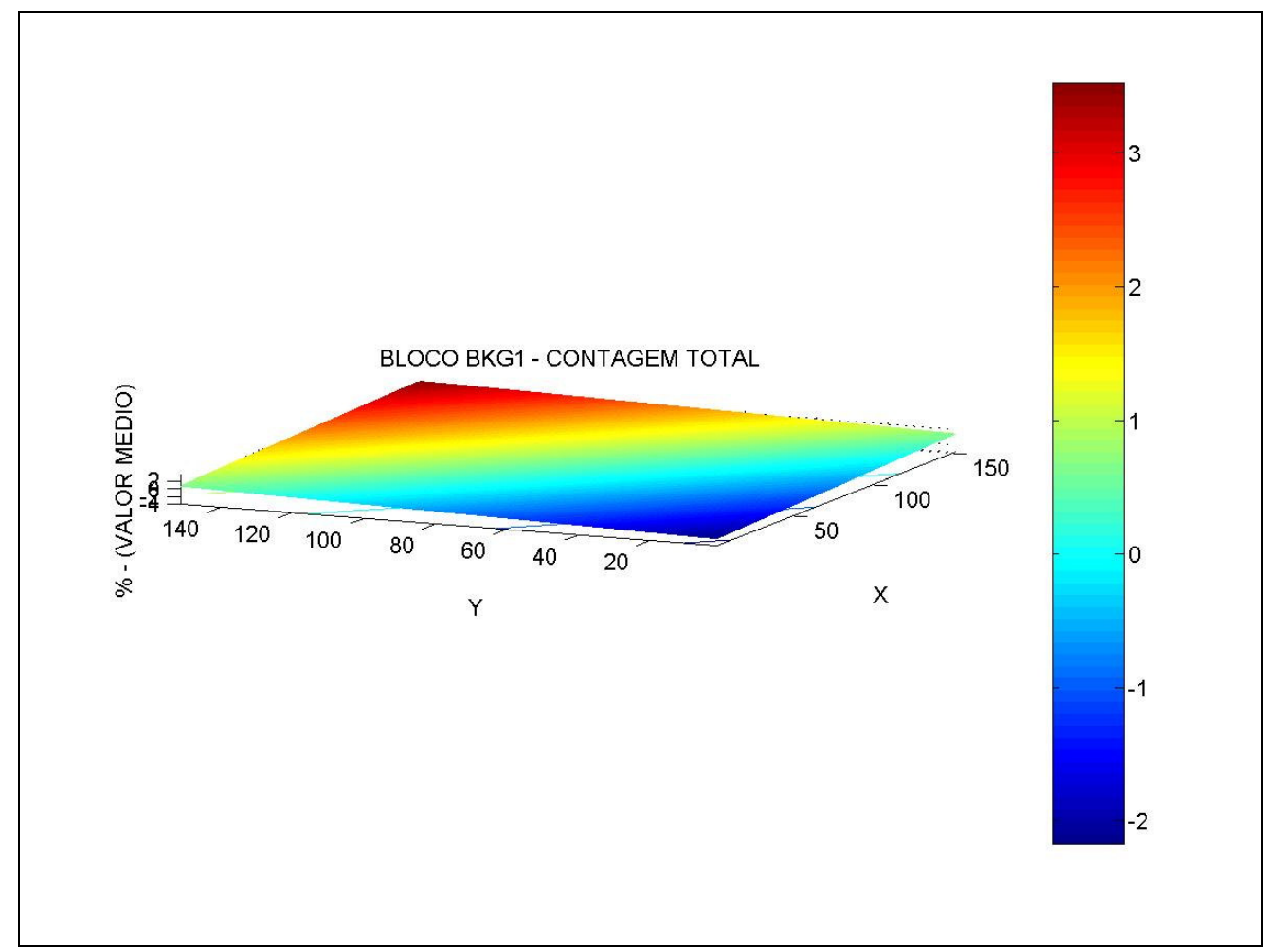

Figura 4.2.3.4. Medidas do bloco de background 1 - BKG1. Os dados foram ajustados a uma superfície planar. Note a variação percentual das medidas na escala de cores (aproximadamente +3 e -2 ).

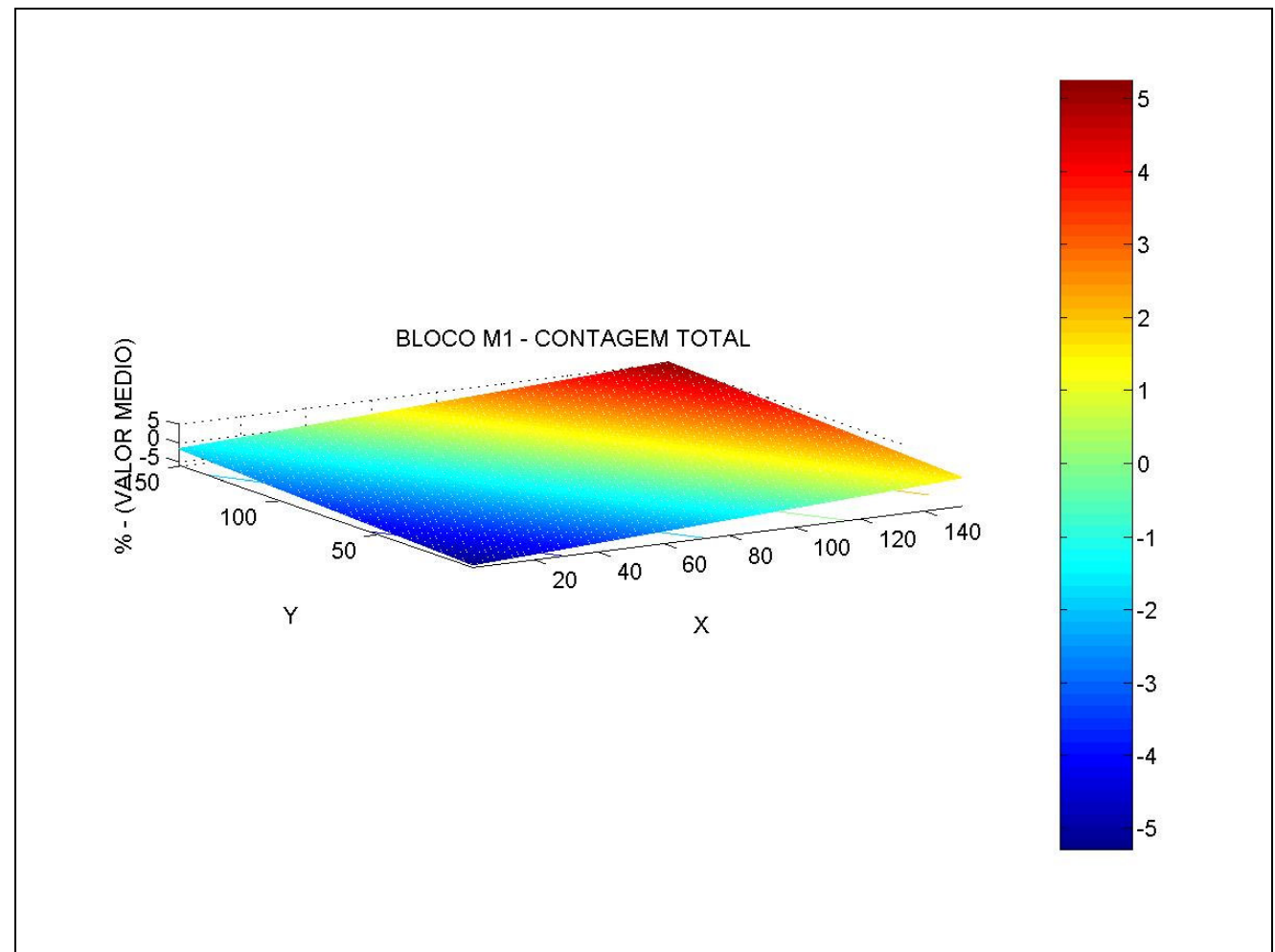

Figura 4.2.3.5 Medidas do bloco mista 1 - M1. Os dados foram ajustados a uma superfície planar. Note a variação percentual das medidas na escala de cores (aproximadamente $\pm 5 \%$ ). 


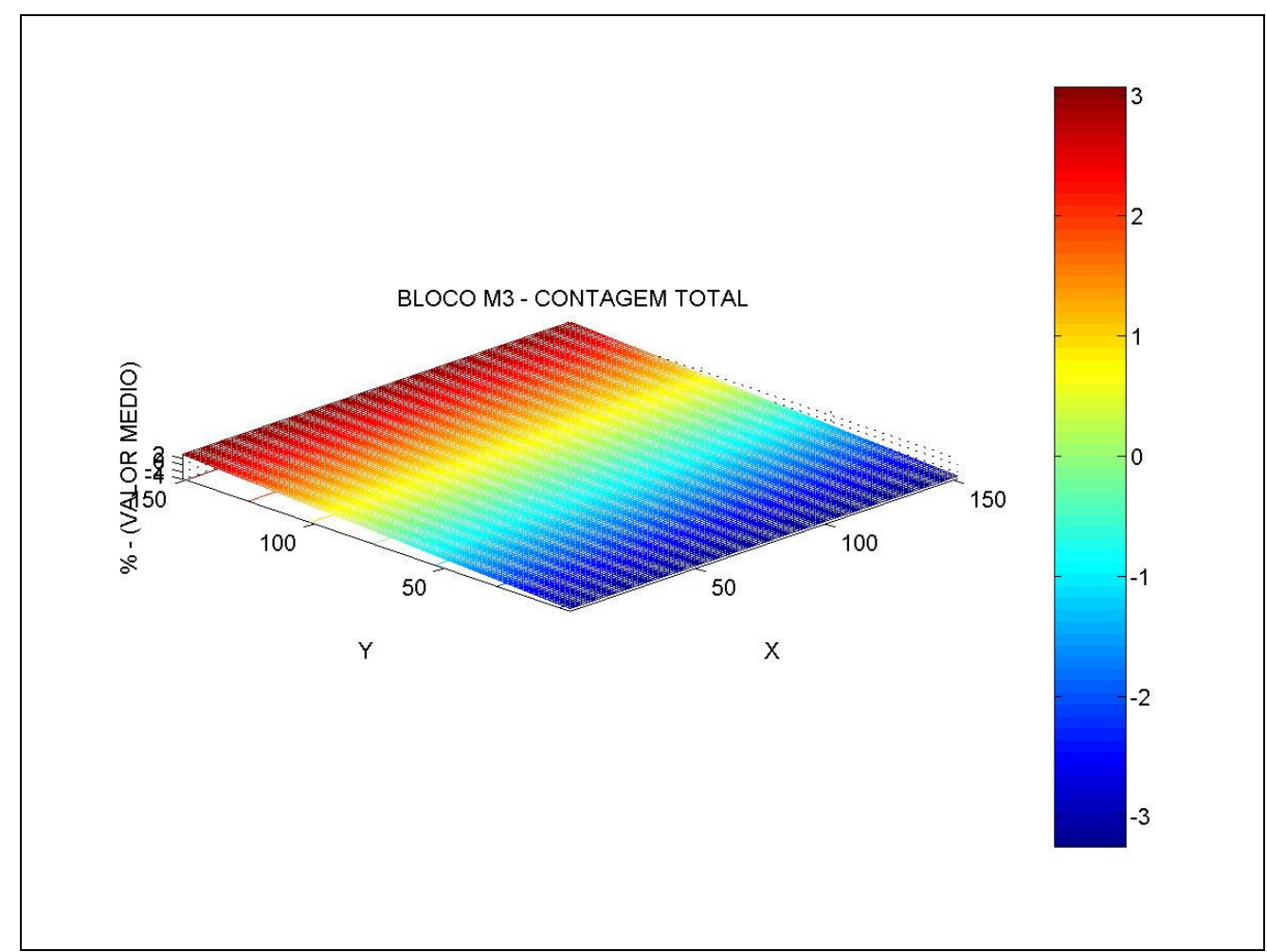

Figura 4.2.3.6 Medidas do bloco mista 3 - M3. Os dados foram ajustados a uma superfície planar. Note a variação percentual das medidas na escala de cores (aproximadamente $\pm 3 \%$ ).

De uma forma geral, as Figuras 4.2.3.1 a 4.2.3.6 sugerem que, com a exceção do bloco BKG2, todos os demais apresentam alguma tendência e que, por isso, seriam, em maior ou menor grau, heterogêneas. Convém, no entanto, analisar o significado estatístico dos coeficientes listados na Tabela 4.2.3.1.

Uma vez conhecidos $a$ e $\sigma_{a}, b$ e $\sigma_{b}$ e $c$ e $\sigma_{c}$, pode-se definir o intervalo de confiança desses coeficientes na forma (Wolberg, 1968):

$$
a-\sigma_{a} t_{\frac{\alpha}{2}, v}<a<\mathrm{a}+\sigma_{\mathrm{a}} t_{\frac{\alpha}{2}, v}
$$

com inequações equivalentes para $b$ e $c$, que define o intervalo em torno da estimativa do coeficiente $a$, onde existe uma probabilidade $(1-\alpha)$ de se encontrar o seu valor real.

Na inequação 4.2.3.6 $t_{\frac{\alpha}{2}, v}$ representa a variável t-student para um nível de significância $\alpha / 2$ e para $\vee$ graus de liberdade. 
Sendo neste caso, $v$ igual a 22 e escolhendo o nível de significância $\alpha / 2$ como 0,025 da variável t-student é 2,06 (Spiegel, 1976).

Observando a Tabela 4.2.3.1, pode-se notar que os intervalos de confiança de $95 \%$ dos coeficientes $b$ e $c$, das superfícies correspondentes aos blocos K1, M2 e BKG2 incluem o valor zero. Isso significa que os coeficientes $b$ e $c$ podem ser nulos. Por outro lado, os intervalos de confiança de $95 \%$, ou do coeficiente b ou do coeficiente $\mathrm{c}$, das superfícies correspondentes aos blocos M1, M3 e BKG1 não incluem o valor zero. Isso significa que se pode afirmar, com probabilidade máxima de erro de 0,05 que pelo menos um dos coeficientes não é nulo.

A conclusão a que se pode afirmar, com uma probabilidade máxima de erro de 0,05 , que os blocos M1, M3 e BKG1 são heterogêneas. Nada, nesse sentido, pode ser afirmado em relação às demais.

No caso dos blocos U e TH, os valores de $\chi^{2}$ calculados pela equação 4.2.3.2 e apresentados na Tabela 4.2.3.1 permitem afirmar, com um nível de significância de 0,05, que o modelo representado pela equação 4.2.3.1 não ajusta os valores observados do fluxo de radiação proveniente da superfície do concreto.

Os valores do fluxo de radiação proveniente da superfície dos blocos $\mathrm{U}$ e $\mathrm{TH}$ foram ajustados a um segundo modelo, definido por:

$$
z=a+b \cdot x+c \cdot y+d \cdot x \cdot y+e \cdot x^{2}+f \cdot y^{2}
$$

A Tabela 4.2.3.2 apresenta os coeficientes calculados, as suas incertezas e o valor de $\chi^{2}$ calculado por:

$$
\chi^{2}=\sum_{i=1}^{N} \frac{\left(z_{i}-\left(a+b x_{i}+c y_{i}+d x_{i} y_{i}+e x_{i}^{2}+f y_{i}^{2}\right)\right)^{2}}{\sigma_{i}^{2}}
$$

onde: 


$$
\sigma_{i}^{2}=\sigma_{z i}^{2}+\left(b+d y_{i}+2 x_{i}\right)^{2} \sigma_{x i}^{2}+\left(c+d x_{i}+2 f y_{i}^{2}\right) \sigma_{y i}^{2}
$$

E o número de graus de liberdade é 19 . O valor calculado da variável $\chi^{2}$ é rejeitado quando (Spiegel, 1976):

$$
\chi^{2}<8,91 \text { ou quando } \chi^{2}>32,9
$$

\begin{tabular}{|c|c|c|c|c|c|c|l|}
\hline Bloco & $\mathbf{a} \pm \boldsymbol{\Delta a}$ & $\mathbf{b} \pm \Delta \mathbf{b}$ & $\mathbf{c} \pm \Delta \mathbf{c}$ & $\mathbf{d} \pm \boldsymbol{\Delta \mathbf { d }}$ & $\mathbf{e} \pm \Delta \mathbf{e}$ & $\mathbf{f} \pm \Delta \mathbf{f}$ & $\chi^{2}$ \\
\hline $\mathbf{U}$ & $6811 \pm 469$ & $1,7 \pm 1,4$ & $4,5 \pm 1,5$ & $-0,00020 \pm 0,00010$ & $-0,0015 \pm 0,0014$ & $-0,0043 \pm 0,0014$ & 32,4 \\
\hline $\mathbf{T H}$ & $7980 \pm 350$ & $2,6 \pm 1,1$ & $6,9 \pm 1,1$ & $-0,0017 \pm 0,0001$ & $-0,0020 \pm 0,0011$ & $-0,0060 \pm 0,0011$ & 16,5 \\
\hline
\end{tabular}

Tabela 4.2.3.2 Valores dos coeficientes ajustados para uma biquadrática para os blocos $\mathrm{U}$ e TH.

Os resultados mostram que não se pode rejeitar, com nível de significância $\alpha$ de 0,05 , a hipótese de que o modelo definido pela equação 4.2.3.8 represente os valores do fluxo de radiação proveniente da superfície dos blocos U e TH.

Observando-se a Tabela 4.2.3.2, pode-se notar que os intervalos de confiança de 0,95 dos coeficientes $c$ e $f$, no caso do bloco de $\mathrm{U}$ e $b, c$ e $f$, no caso do bloco TH, não incluem o valor zero. Isso significa que pode-se afirmar, com uma probabilidade máxima de erro de 0,05 , que os termos $c y$ e $f y^{2}$, no caso do bloco U, e $b x, c y$ e $f y^{2}$, no caso do bloco TH, não são nulos.

As Figuras 4.2.3.7 e 4.2.3.8 apresentam as superfícies definidas pelos coeficientes listados na Tabela 4.2.3.2. A escala de cores corresponde ao afastamento relativo dado pela equação 4.2.3.4, neste caso:

$$
\text { valor médio }=\frac{1}{\Delta x \Delta y} \int_{0}^{\Delta y \Delta x} \int_{0}^{\Delta}\left(a+b x+c y+d x y+e x^{2}+f y^{2}\right) d x d y
$$




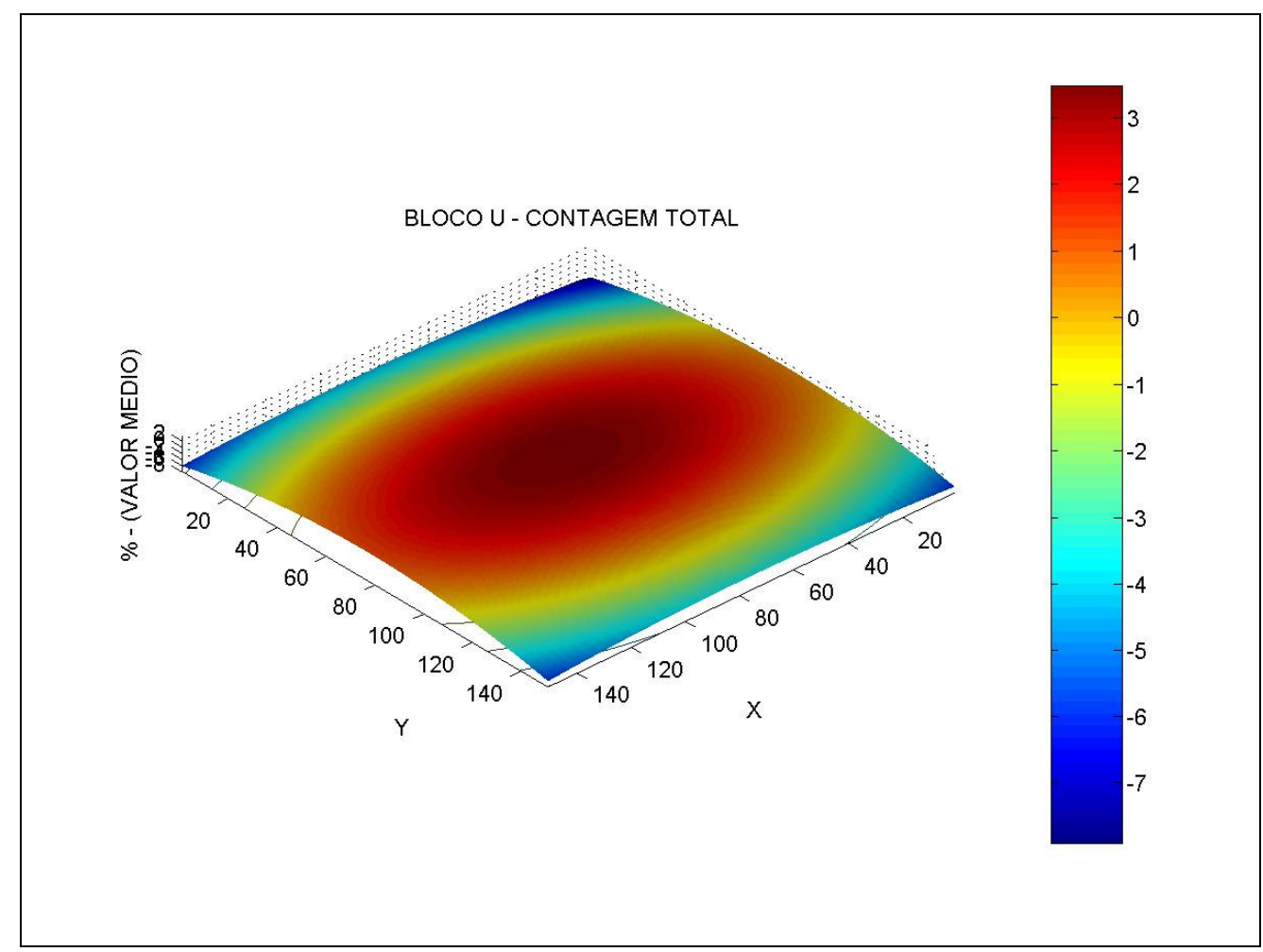

Figura 4.2.3.7. Medidas do bloco de urânio - U. Os dados foram ajustados a uma superfície biquadrática. Note que o mapa de isolinhas não está centralizado, sugerindo um escape preferencial de radônio para a direita do eixo $X$.

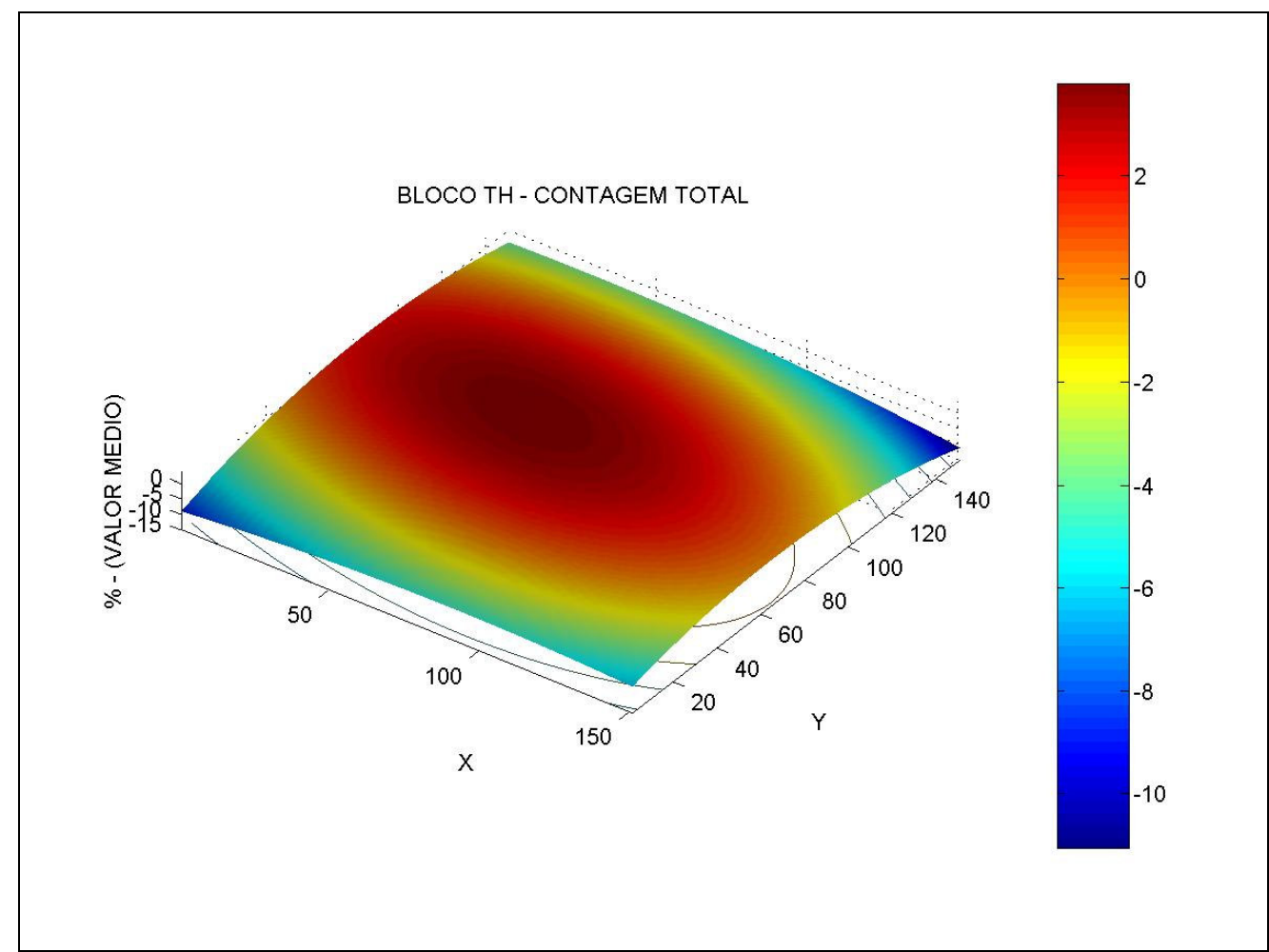

Figura 4.2.3.8. Medidas do bloco de tório - TH. Os dados foram ajustados a uma superfície biquadrática. Note que o mapa de isolinhas não está centralizado, sugerindo um escape preferencial de radônio obliquamente e a esquerda do eixo $\mathrm{X}$. 
As heterogeneidades na distribuição do fluxo de radiação proveniente da superfície dos blocos U e TH, bem como dos blocos M1, M3 e BKG1 são, provavelmente associadas a heterogeneidades na distribuição dos elementos radioativos do seu interior. Embora não se tenha adicionado minerais radioativos ao bloco BKG1, os materiais de construção possuem potássio e traços de urânio e de tório em na sua composição.

Existe, no entanto, principalmente no caso do bloco de U, a possibilidade de escape de radônio $\left({ }^{222} \mathrm{Rn}\right)$ através dos poros e pequenas fissuras que conectem o interior do bloco à sua superfície. $\mathrm{O}$ escape de radônio simula uma diminuição na concentração de urânio próximo à superfície do concreto, porque induz desequilíbrio radioativo entre ${ }^{226} \mathrm{Ra}$ e seus descendentes gama emissores de meia-vida curta da série do urânio, o ${ }^{214} \mathrm{~Pb}$ e o ${ }^{214} \mathrm{Bi}$.

O escape de radônio pode ser limitado impermeabilizando-se a superfície do concreto. No caso dos oito blocos construídos, tomou-se a decisão de impermeabilizar a superfície do concreto, não somente para evitar o escape de radônio, que não foi observado diretamente, mas também para diminuir variações de umidade e proteger os blocos de eventuais exposições ao tempo. De qualquer forma, verificou-se o efeito da impermeabilização sobre o fluxo da radiação proveniente da superfície do concreto, no caso dos blocos $\mathrm{U}$ e TH. 


\subsection{O acabamento dos blocos}

As superfícies dos blocos foram impermeabilizadas com uma seqüência de aplicações de uma mão de um fundo preparador de paredes e duas mãos de tinta. Tanto a base quanto a tinta têm água como solvente. $\mathrm{O}$ fundo preparador é um co-polímero acrílico. A tinta utilizada se destina a pintura de quadras poliesportivas, resistente e tem alta aderência ao concreto.

\subsubsection{O efeito do acabamento sobre o fluxo de radiação gama proveniente da superfície dos blocos U e TH.}

Vinte e cinco dias após a aplicação da camada impermeabilizadora, repetiu-se o processo de coleta de valores de fluxo de radiação gama emitida pelas superfícies dos blocos U e TH. A Tabela 4.3.1.1 apresenta as observações da radiação de fundo tomadas sobre o bloco BKG2.

\begin{tabular}{|c|c|c|}
\hline Bloco & $\mathbf{U}$ & TH \\
\hline OBS & $\mathbf{C T}$ & $\mathbf{C T}$ \\
\hline $\mathbf{1}$ & 6032 & 5999 \\
\hline $\mathbf{2}$ & 5839 & 5867 \\
\hline $\mathbf{3}$ & 5995 & 6125 \\
\hline $\mathbf{4}$ & 6082 & 5934 \\
\hline $\mathbf{5}$ & 5898 & 6118 \\
\hline $\mathbf{6}$ & 5999 & 6101 \\
\hline Média & 5974 & 6024 \\
\hline Desvio-Padrão & 90 & 108 \\
\hline $\boldsymbol{\chi}^{\mathbf{2}}$ & 6,711 & 9,685 \\
\hline
\end{tabular}

Tabela 4.3.1.1 Valores da radiação de fundo do canal de contagem total, medido sobre a superfície dos blocos U e TH, após a impermeabilização dos mesmos. 
A Tabela 4.3.1.2 apresenta os valores observados sobre os nós das malhas traçados sobre os blocos.

\begin{tabular}{|c|c|c|c|c|}
\hline nó & $\mathrm{x}$ & $\mathrm{y}$ & $\mathbf{U}$ (CT) & TH (CT) \\
\hline 9 & 250 & 750 & 14067 & 15723 \\
\hline 10 & 250 & 625 & 14496 & 15859 \\
\hline 11 & 250 & 500 & 14508 & 15852 \\
\hline 12 & 250 & 375 & 14033 & 15777 \\
\hline 13 & 250 & 250 & 13974 & 15573 \\
\hline 16 & 375 & 250 & 13943 & 16149 \\
\hline 17 & 375 & 375 & 14363 & 16052 \\
\hline 18 & 375 & 500 & 14309 & 16191 \\
\hline 19 & 375 & 625 & 14130 & 16094 \\
\hline 20 & 375 & 750 & 14014 & 15912 \\
\hline 23 & 500 & 750 & 14044 & 16067 \\
\hline 24 & 500 & 625 & 14111 & 16382 \\
\hline 25 & 500 & 500 & 14343 & 15882 \\
\hline 26 & 500 & 375 & 14301 & 16075 \\
\hline 27 & 500 & 250 & 14076 & 16086 \\
\hline 30 & 625 & 250 & 14111 & 16010 \\
\hline 31 & 625 & 375 & 14183 & 15798 \\
\hline 32 & 625 & 500 & 14352 & 16136 \\
\hline 33 & 625 & 625 & 14304 & 16139 \\
\hline 34 & 625 & 750 & 14145 & 16103 \\
\hline 37 & 750 & 750 & 13915 & 15615 \\
\hline 38 & 750 & 625 & 13934 & 15815 \\
\hline 39 & 750 & 500 & 14219 & 15811 \\
\hline 40 & 750 & 375 & 14173 & 15948 \\
\hline 41 & 750 & 250 & 13953 & 15668 \\
\hline & & media & 14160 & 15949 \\
\cline { 2 - 5 } & desvpad & 173 & 200 \\
\cline { 2 - 5 } & quiquadrado & 50,727 & 60,192 \\
\hline
\end{tabular}

Tabela 4.3.1.2 Valores do canal de contagem total dos blocos U e TH, após a impermeabilização da superfície.

No caso dos dois blocos, não foi rejeitada a hipótese de que as observações de fundo possam ser consideradas como extrações ao acaso de distribuições de Poisson. A hipótese de que os valores de fluxo de radiação, provenientes da superfície dos blocos $\mathrm{U}$ e $\mathrm{TH}$, possam ser consideradas como extrações de distribuições de Poisson foi, por sua vez, rejeitada nos dois casos, considerando-se um nível de significância de 0,05.

A Tabela 4.3.1.3 apresenta os coeficientes $a, b$ e $c$ e os seus respectivos desvios padrões do modelo, representado pela Equação 4.2.3.1, aplicado aos valores da Tabela 4.3.1.2. 


\begin{tabular}{|c|c|c|c|c|}
\hline Bloco & $\mathbf{a} \pm \Delta \mathbf{a}$ & $\mathbf{b} \pm \Delta \mathbf{b}$ & $\mathbf{c} \pm \Delta \mathbf{c}$ & $\boldsymbol{\chi}^{2}$ \\
\hline $\mathbf{U}$ & $8283 \pm 144$ & $-0,23 \pm 0,20$ & $0,03 \pm 0,20$ & 33,7 \\
\hline $\mathbf{T H}$ & $9884 \pm 171$ & $-0,00 \pm 0,24$ & $0,09 \pm 0,24$ & 43,4 \\
\hline
\end{tabular}

Tabela 4.3.1.3 Valores dos ajustes para os blocos U e TH, de uma função do primeiro grau.

No caso do bloco $\mathrm{U}$, os resultados mostram que não se pode rejeitar, com nível de significância de 0,05, a hipótese que o modelo descrito pela equação 4.2.3.1 represente os valores do fluxo de radiação gama. Além disso, os intervalos de confiança de 0,95 em torno dos coeficientes $b$ e $c$ mostram que não se pode afirmar que existam heterogeneidades na distribuição dos valores de fluxo de radiação.

No caso do bloco $\mathrm{TH}$, os resultados permitem afirmar, com probabilidade máxima de erro de 0,05, que o modelo representado pela equação 4.2.3.1 não representa os valores de fluxo de radiação gama. A aplicação do modelo representado pela equação 4.2.3.7 fornece:

$$
\begin{aligned}
& z=(8236 \pm 335)+(5,8 \pm 1,0) \cdot x+(1,8 \pm 1,0) \cdot y-(1,388 \pm 0,077) \cdot 10^{-4} x y- \\
& (0,0057 \pm 0,0010) \cdot x^{2}-(0,0016 \pm 0,0010) \cdot y^{2}
\end{aligned}
$$

com um valor de $\chi^{2}$ calculado pela equação 4.2.3.8 de 15,2.

O resultado indica que não se pode rejeitar a hipótese de que o modelo descrito pela equação 4.2.3.11 represente os valores de fluxo de radiação gama proveniente da superfície do bloco TH. Os intervalos de confiança de 0,95 em torno dos valores dos coeficientes ajustados mostram que se pode afirmar que os termos $b x, d x y$ e $e x^{2}$ não são nulos.

Em conclusão, a impermeabilização anulou as heterogeneidades observadas no bloco U. O bloco TH manteve parte das heterogeneidades anteriormente observadas. 


\subsection{Determinação das concentrações de potássio, urânio e tório nas amostras de concreto por espectrometria gama}

A técnica de medida de atividades foi a espectrometria gama, utilizando um detector semicondutor de germânio hiper-puro. A atividade de cada radionuclídeo foi determinada na comparação com padrões secundários de radioatividade, seguindo a metodologia descrita em Ribeiro e colaboradores (2001).

As amostras de concreto retiradas durante o envasamento dos blocos de calibração, como descrito no Capítulo 3, seção 3.5, foram preparadas para a determinação das concentrações de potássio, urânio e tório, através da técnica de espectrometria gama.

As amostras são identificadas pelo nome do bloco de calibração e pela posição de coleta indicada na Figura 3.5.1. Por exemplo, a amostra K1_5 corresponde ao material retirado do centro do bloco K1. A amostra TH_1 corresponde a amostra retirada da posição 1 do bloco TH.

A posição dos pontos de coleta foi sempre identificada e utilizada como referência. As malhas traçadas sobre a superfície dos blocos tem sua origem no vértice do bloco mais próximo do ponto de coleta 1 .

\subsubsection{Preparação das amostras}

Inicialmente, as amostras foram inteiramente britadas manualmente. Em seguida, a massa total de todas amostras foi seca e pulverizada em moinhos de disco, nos laboratórios da mina de urânio Ussamu Utsumi, das Indústrias Nucleares Brasileiras, em Poços de Caldas, Minas Gerais. A dimensão máxima dos grãos das amostras ficou inferior a 60 mesh. 
As amostras foram, então, quarteadas e uma alíquota do material pulverizado foi retirado e homogeneizado mecanicamente. A Tabela 4.4.1.1 apresenta as massas dessas alíquotas.

\begin{tabular}{|c|c|c|}
\hline Amostra & aliquota (g) & massa porta-amostras (g) \\
\hline 1BR_1 & 541,07 & 483,57 \\
\hline 1BR_2 & 629,84 & 473,58 \\
\hline 1BR_3 & 614,60 & 487,77 \\
\hline 1BR_4 & 578,33 & 491,61 \\
\hline 1BR_5 & 535,12 & 497,72 \\
\hline 2BR_1 & 585,67 & 498,03 \\
\hline 2BR_2 & 604,75 & 493,36 \\
\hline 2BR_3 & 616,96 & 500,70 \\
\hline 2BR 4 & 574,06 & 520,58 \\
\hline 2BR_5 & 586,60 & 497,67 \\
\hline K1_1 & 641,99 & 502,10 \\
\hline K1_2 & 625,90 & 484,57 \\
\hline K1_3 & 594,23 & 475,16 \\
\hline K1_4 & 595,41 & 462,88 \\
\hline K1_5 & 591,86 & 460,59 \\
\hline U_1 & 676,58 & 508,26 \\
\hline$\overline{U 2}$ & 684,99 & 496,11 \\
\hline $\mathbf{U} 3$ & 661,67 & 495,10 \\
\hline U_4 & 609,00 & 497,17 \\
\hline $\mathbf{U} 5$ & 661,90 & 494,27 \\
\hline TH 1 & 558,05 & 504,30 \\
\hline TH_2 & 654,51 & 492,05 \\
\hline TH_3 & 631,68 & 514,87 \\
\hline TH_4 & 615,15 & 513,77 \\
\hline TH_5 & 620,65 & 506,84 \\
\hline M1_1 & 630,27 & 496,57 \\
\hline M1_2 & 647,00 & 508,11 \\
\hline M1_3 & 591,36 & 521,19 \\
\hline M1_4 & 593,10 & 503,11 \\
\hline M1_5 & 631,92 & 506,56 \\
\hline M2_1 & 577,26 & 507,19 \\
\hline M2 2 & 597,88 & 498,92 \\
\hline M2 3 & 600,71 & 505,23 \\
\hline M2_4 & 577,37 & 501,79 \\
\hline M2_5 & 607,46 & 491,99 \\
\hline M3_1 & 660,22 & 512,65 \\
\hline M3_2 & 607,20 & 507,52 \\
\hline M3_3 & 632,41 & 502,12 \\
\hline M3_4 & 582,45 & 497,00 \\
\hline M3_5 & 685,92 & 497,55 \\
\hline
\end{tabular}

Tabela 4.4.1.1 Massas das alíquotas, que foram quarteadas e massas das amostras que foram seladas em porta-amostras, para medida da atividade. 
O restante do material foi reservado para análises futuras. O material homogeneizado, foi em seguida hermeticamente encerrado em porta amostras de poliestireno rígido, com dimensões internas de $46 \mathrm{~mm}$ de altura e $90 \mathrm{~mm}$ de diâmetro. A Tabela 4.4.1.1 apresenta as massas das amostras transferidas para o porta amostras.

O material permaneceu armazenado por, no mínimo, quarenta dias antes do início das análises, para garantir o equilíbrio radioativo secular entre o ${ }^{226} \mathrm{Ra}$ e os seus descendentes de meia-vida curta, o ${ }^{214} \mathrm{~Pb}$ e o ${ }^{214} \mathrm{Bi}$.

\subsubsection{Padrões de radioatividade}

As medidas de atividade de potássio, urânio e tório foram feitas por comparação com padrões de atividade secundários descritos em Ribeiro e colaboradores (2001). Esses padrões foram preparados diluindo-se, em quartzo em pó estéril, padrões primários com concentração certificada pelo New Brunswick Laboratory (NBL) do Departamento de Energia dos Estados Unidos. O padrão primário de urânio é o NBL\#3B, com concentração nominal de $(3,900 \pm 0,005) \%$ de $\mathrm{U}_{3} \mathrm{O}_{8}$, com o ${ }^{238} \mathrm{U}$ em equilíbrio radioativo secular com o ${ }^{226} \mathrm{Ra}$. O padrão primário de tório contém $(1,000 \pm 0,005) \%$ de tório e $(0,040 \pm 0,005) \%$ de urânio natural.

As atividades totais dos padrões secundários são $(61,500 \pm 0,086) \mathrm{Bq}$ de ${ }^{238} \mathrm{U}$, o que corresponde a uma concentração de $(46,566 \pm 0,069) \mu \mathrm{g} / \mathrm{g}$ de urânio natural e $(21,98 \pm 0,11) \mathrm{Bq}$ de ${ }^{232} \mathrm{Th}$, correspondendo a $(51,40 \pm 0,25) \mu \mathrm{g} / \mathrm{g}$ de tório.

$\mathrm{O}$ padrão de potássio é constituído de dicromato de potássio $\left(\mathrm{K}_{2} \mathrm{Cr}_{2} \mathrm{O}_{7}\right)$ com uma atividade de

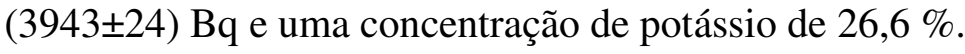

Todos os padrões são encerrados no mesmo tipo de porta-amostras utilizados com as amostras de concreto. 


\subsubsection{Aquisição e Análise dos Espectros}

\subsubsection{Equipamento Utilizado}

Os espectros gama das amostras e dos padrões foram adquiridos com um espectrômetro gama dotado de um detector coaxial de germânio hiper-puro (HPGe) com um volume de $253 \mathrm{~cm}^{3}$ e uma eficiência relativa de $70 \%$. A análise dos espectros foi realizada através do programa Genie-2000, fornecido pela Canberra Industries Inc.

\subsubsection{Radionuclídeos Analisados}

A Tabela 4.4.3.2.1 lista os diversos radionuclídeos utilizados para cada uma das séries radioativas naturais.

\begin{tabular}{|c|c|c|}
\hline Série & Elemento & Energia (keV) \\
\hline \multirow{4}{*}{ URÂAIO } & ${ }^{214} \mathrm{~Pb}$ & 295,4 \\
\cline { 2 - 3 } & ${ }^{214} \mathrm{~Pb}$ & 351,9 \\
\cline { 2 - 3 } & ${ }^{114} \mathrm{Bi}$ & 609,3 \\
\cline { 2 - 3 } & ${ }^{214} \mathrm{Bi}$ & 1120,3 \\
\cline { 2 - 3 } & ${ }^{214} \mathrm{Bi}$ & 1764,5 \\
\hline \multirow{4}{*}{ TÓRIO } & ${ }^{212} \mathrm{~Pb}$ & 238,6 \\
\cline { 2 - 3 } & ${ }^{212} \mathrm{Bi}$ & 727,3 \\
\cline { 2 - 3 } & ${ }^{208} \mathrm{Tl}$ & 583,2 \\
\cline { 2 - 3 } & ${ }^{208} \mathrm{Tl}$ & 860,3 \\
\cline { 2 - 3 } & ${ }^{228} \mathrm{Ac}$ & 911,2 \\
\cline { 2 - 3 } & ${ }^{228} \mathrm{Ac}$ & 968,9 \\
\hline & ${ }^{40} \mathrm{~K}$ & 1460,8 \\
\hline
\end{tabular}

Tabela 4.4.3.2.1 Radioelementos utilizados para cálculo das atividades do potássio, urânio e tório.

Da série do urânio, foram utilizados os picos do ${ }^{214} \mathrm{~Pb}(295,4 \mathrm{keV}$ e $351,9 \mathrm{keV})$ e do ${ }^{214} \mathrm{Bi}$ $(609,3 \mathrm{keV}, 1120,3 \mathrm{keV}$ e $1764,5 \mathrm{keV})$ para determinação da atividade do ${ }^{226} \mathrm{Ra}$.

Da série do tório, foram utilizados os picos de absorção total do ${ }^{228} \mathrm{Ac}(911,2 \mathrm{keV}$ e 968,9 $\mathrm{keV}$ ), para determinação da atividade do ${ }^{228} \mathrm{Ac}$. A atividade do ${ }^{228}$ Th foi determinada a partir dos picos de absorção total do ${ }^{212} \mathrm{~Pb}(238,6 \mathrm{keV})$, do ${ }^{212} \mathrm{Bi}(727,3 \mathrm{keV})$ e do ${ }^{208} \mathrm{Tl}(860,3 \mathrm{keV}$ e $583,2 \mathrm{keV})$.

A atividade do ${ }^{40} \mathrm{~K}$ foi determinada a partir do seu pico de absorção total de $1460,8 \mathrm{keV}$. 


\subsubsection{Limites de Detecção}

Um dos principais problemas da aplicação da espectrometria gama no estudo de materiais com radioatividade comparável a radioatividade do ambiente é o estabelecimento do nível mínimo de contagens no espectro que indica com segurança a presença de um gama emissor particular na amostra, ou seja, o estabelecimento do que poderia, em termos gerais, ser chamado de nível de detecção.

O problema da determinação de um nível de detecção para medidas de radioatividade tem sido discutido por diversos autores como, por exemplo, Currie (1968), Head (1972), Walford e Gilboy (1972) e Hurtgen e colaboradores (2000).

Nesse trabalho utilizou-se a metodologia proposta por Currie (1968), que definiu dois níveis de contagem acima da radiação de fundo para estabelecer de uma forma dotada de significado estatístico, o nível de detecção de um espectrômetro. O primeiro nível definido como nível crítico de decisão $\left(L_{c}\right)$, consiste do sinal líquido mínimo acima do valor médio das radiações de fundo para que se possa afirmar, com uma probabilidade $(\alpha)$ de erro pré-estabelecida que uma contagem bruta observada não seja devida a radiação de fundo.

Isso significa que sinais líquidos acima de $L_{c}$, permitem dizer que a radiação é proveniente de uma fonte diferente do fundo, considerando que existe uma probabilidade máxima de se errar ao fazer esta afirmação. Por outro lado, sinais líquidos abaixo de $L_{c}$ indicam que não há evidência de que o sinal seja proveniente de uma fonte diferente do fundo. No entanto, não fica estabelecida a probabilidade de se errar ao fazer essa afirmação.

Currie (1968) definiu também o limite de detecção $\left(L_{d}\right)$ como sendo o valor médio mínimo da distribuição de contagens produzidas por uma fonte radioativa diferente do fundo, para o qual a probabilidade de se obter uma contagem abaixo de $L_{c}$ fosse, no máximo, um valor $\beta$ préestabelecido. 
A definição formal do nível crítico de decisão e do limite de detecção é apresentada em detalhe no trabalho original de Currie (1968). Santos e colaboradores (2000) apresentam uma descrição do método.

\subsubsection{Os limites de decisão e detecção do Laboratório de Geofísica Nuclear do IAG/USP}

Para a determinação do nível de decisão e do limite de detecção do Laboratório de Geofísica

Nuclear foram estabelecidas as probabilidades $\alpha$ e $\beta$ em 0,05 .

\begin{tabular}{|c|c|c|c|c|}
\hline Nuclídeo & Energia (keV) & Contagens/hora & Lc (cont./h) & Ld (cont./h) \\
\hline${ }^{214} \mathbf{P b}$ & 295,4 & $49,6 \pm 2,1$ & 54,43 & 59,33 \\
\hline${ }^{214} \mathbf{P b}$ & 351,9 & $84,8 \pm 2,5$ & 90,51 & 96,29 \\
\hline${ }^{214} \mathbf{B i}$ & 609,3 & $65,0 \pm 1,9$ & 69,41 & 73,88 \\
\hline${ }^{214} \mathbf{B i}$ & 1120,3 & $15,9 \pm 1,5$ & 19,48 & 23,13 \\
\hline${ }^{\mathbf{2 1 4}} \mathbf{B i}$ & 1764,5 & $17,6 \pm 1,0$ & 20,00 & 22,43 \\
\hline${ }^{212} \mathbf{P b}$ & 238,6 & $182,1 \pm 3,5$ & 190,13 & 198,23 \\
\hline${ }^{\mathbf{2 1}} \mathbf{B i}$ & 727,3 & $14,4 \pm 1,7$ & 18,30 & 22,28 \\
\hline${ }^{\mathbf{2 0 8}} \mathbf{T l}$ & 583,2 & $59,8 \pm 2,0$ & 64,54 & 69,35 \\
\hline${ }^{\mathbf{2 0 8}} \mathbf{T l}$ & 860,3 & $7,4 \pm 1,2$ & 10,21 & 13,07 \\
\hline${ }^{228} \mathbf{A c}$ & 911,2 & $44,2 \pm 1,6$ & 47,90 & 51,69 \\
\hline${ }^{228} \mathbf{A c}$ & 968,9 & $25,2 \pm 1,8$ & 29,42 & 33,70 \\
\hline
\end{tabular}

Tabela 4.4.3.4.1 Valores dos níveis de decisão e dos limites de deteç̧ão para o padrão estéril com matriz de $\mathrm{SiO}_{2}$. 


\subsubsection{Cálculo das atividades}

As atividades dos emissores gama presentes nas amostras foram determinadas comparando-se as áreas líquidas dos picos de absorção total observados nos espectros das amostras $P_{a}$ e nos espectros dos padrões secundários de radioatividade $P_{p}$ (Carlos, 2002). Uma vez que a geometria de detecção é a mesma para os padrões e as amostras e assumindo que as atenuações da radiação gama sejam idênticas em ambos os casos, a atividade de um emissor gama $\left(A_{a}\right)$, medida a partir de um pico de absorção total isolado e produzido apenas por esse emissor é dada pela equação (Szöghy \& Kish, 1978):

$$
A_{a}=A_{p} \cdot \frac{P_{a} \cdot t_{p}}{P_{p} \cdot t_{a}}
$$

onde:

$A_{a}:$ atividade da amostra

$A_{p}$ : atividade do padrão

$P_{a}$ : área da amostra

$P_{p}$ : área do padrão

$t_{a}$ e $t_{p}$ : tempos de acumulação dos espectros da amostra e padrões, respectivamente.

As Tabelas 4.4.3.5.1 e 4.4.3.5.2 apresentam os valores das atividades para os radioisótopos das séries do ${ }^{238} \mathrm{U}$ e ${ }^{232} \mathrm{Th}$, respectivamente, medidas por espectrometria gama de alta resolução. 


\begin{tabular}{|c|c|c|c|c|c|c|c|c|c|c|c|c|}
\hline Amostra & massa (g) & $\begin{array}{c}\text { atividade } \\
{ }^{214} \mathrm{~Pb}(295,2 \\
\mathrm{keV}) \mathrm{Bq}\end{array}$ & incerteza & $\begin{array}{c}\text { atividade } \\
{ }^{214} \mathrm{~Pb}(351,9 \\
\mathrm{keV}) \mathrm{Bq}\end{array}$ & incerteza & $\begin{array}{c}\text { atividade } \\
\text { média }{ }^{214} \mathrm{~Pb}\end{array}$ & incerteza & $\chi^{2}$ & $\begin{array}{c}\text { atividade } \\
{ }_{214} \mathrm{Bi}(609,3 \\
\mathrm{keV}) \mathrm{Bq}\end{array}$ & incerteza & $\begin{array}{c}\text { atividade } \\
{ }^{214} \mathrm{Bi}(1120,3 \\
\mathrm{keV}) \mathbf{B q}\end{array}$ & incerteza \\
\hline 1BR_1 & 483,57 & 10,64 & 0,44 & 10,47 & 0,27 & 10,52 & 0,23 & 0,112 & 10,97 & 0,28 & 9,85 & 0,82 \\
\hline 1BR_2 & 473,58 & 9,70 & 0,43 & 10,45 & 0,27 & 10,24 & 0,23 & 2,127 & 11,31 & 0,28 & 11,71 & 0,88 \\
\hline 1BR_3 & 487,77 & 10,85 & 0,41 & 10,66 & 0,27 & 10,71 & 0,23 & 0,153 & 11,16 & 0,29 & 11,44 & 0,90 \\
\hline 1BR_4 & 491,61 & 11,67 & 0,46 & 10,75 & 0,28 & 11,00 & 0,24 & 2,977 & 10,88 & 0,29 & 11,0 & 1,0 \\
\hline 1BR_5 & 497,725 & 10,64 & 0,41 & 10,52 & 0,29 & 10,56 & 0,24 & 0,064 & 11,16 & 0,31 & 9,89 & 0,93 \\
\hline 2BR_1 & 498,035 & $\begin{array}{l}10,40 \\
\end{array}$ & 0,43 & $\begin{array}{l}10,70 \\
\end{array}$ & 0,26 & $\begin{array}{l}10,62 \\
\end{array}$ & 0,22 & 0,371 & 11,07 & 0,31 & 11,16 & 0,84 \\
\hline 2BR_2 & 493,365 & 10,93 & 0,44 & 11,54 & 0,29 & 11,36 & 0,25 & 1,327 & 11,67 & 0,30 & 12,68 & 0,83 \\
\hline 2BR_3 & 500,7 & $\begin{array}{l}12,08 \\
\end{array}$ & 0,44 & 12,45 & 0,31 & $\begin{array}{l}12,33 \\
\end{array}$ & 0,26 & 0,481 & 13,01 & 0,33 & 15,30 & 0,95 \\
\hline 2BR_4 & 520,58 & 9,95 & 0,48 & 10,75 & 0,27 & 10,55 & 0,24 & 2,080 & 11,37 & 0,29 & 10,18 & 0,85 \\
\hline 2BR_5 & 497,675 & 10,68 & 0,48 & 10,21 & 0,27 & 10,32 & 0,23 & 0,745 & 10,43 & 0,29 & 11,44 & 0,85 \\
\hline K1_1 & 502,105 & 3,09 & 0,78 & 3,24 & 0,52 & 3,19 & 0,43 & 0,026 & 3,04 & 0,46 & $<\mathrm{LD}$ & \\
\hline K1_2 & 484,575 & 2,91 & 0,66 & 2,30 & 0,42 & 2,47 & 0,35 & 0,593 & 2,93 & 0,46 & 2,7 & 1,9 \\
\hline K1_3 & 475,165 & 2,28 & 0,78 & 2,08 & 0,33 & 2,11 & 0,31 & 0,058 & 3,09 & 0,40 & 2,4 & 1,9 \\
\hline K1_4 & 462,885 & 2,73 & 0,75 & 2,98 & 0,40 & 2,92 & 0,35 & 0,087 & 2,35 & 0,46 & $<\mathrm{LD}$ & \\
\hline K1_5 & 460,59 & 2,99 & 0,73 & 2,86 & 0,38 & 2,88 & 0,34 & 0,027 & 3,31 & 0,49 & $<\mathrm{LD}$ & \\
\hline U_1 & 508,26 & 296,1 & 3,9 & 299,4 & 2,8 & 298,3 & 2,3 & 0,448 & 308,9 & 3,0 & 304,1 & 6,3 \\
\hline $\mathbf{U} \_2$ & 496,115 & 274,8 & 3,7 & 273,2 & 2,6 & 273,7 & 2,1 & 0,127 & 282,2 & 2,7 & 288,7 & 6,1 \\
\hline U_3 & 495,105 & 263,3 & 3,5 & 276,0 & 2,5 & 271,6 & 2,1 & 8,579 & 278,5 & 2,7 & 273,2 & 5,8 \\
\hline U_4 & 497,17 & 284,7 & 3,6 & 280,7 & 2,7 & 282,1 & 2,1 & 0,800 & 289,5 & 2,8 & 298,6 & 6,1 \\
\hline $\mathbf{U}+5$ & 494,275 & 281,4 & 3,6 & 282,6 & 2,6 & 282,1 & 2,1 & 0,070 & 284,6 & 2,7 & 295,8 & 6,6 \\
\hline TH_1 & 504,3 & 47,6 & 1,9 & 45,4 & 1,1 & 45,96 & 0,98 & 1,020 & 49,2 & 1,3 & 51,8 & 3,4 \\
\hline TH_2 & 492,055 & 44,3 & 1,9 & 44,1 & 1,3 & 44,2 & 1,1 & 0,005 & 45,2 & 1,1 & 53,1 & 3,2 \\
\hline TH_3 & 514,87 & 47,3 & 2,0 & 45,9 & 1,3 & 46,3 & 1,1 & 0,333 & 47,7 & 1,2 & 55,3 & 3,7 \\
\hline TH_4 & 513,775 & 42,0 & 1,8 & 45,8 & 1,1 & 44,87 & 0,91 & 3,272 & 47,4 & 1,1 & 44,5 & 3,1 \\
\hline TH_5 & 506,84 & 46,9 & 2,3 & 46,5 & 1,3 & $\begin{array}{l}46,6 \\
\end{array}$ & 1,1 & 0,029 & 48,1 & 1,3 & 52,5 & 3,2 \\
\hline M1_1 & 496,575 & 32,7 & 1,2 & 33,40 & 0,62 & 33,24 & 0,55 & 0,304 & 35,02 & 0,70 & 37,1 & 1,9 \\
\hline M1_2 & 508,11 & 37,51 & 0,96 & 36,44 & 0,63 & 36,76 & 0,53 & 0,865 & 38,49 & 0,71 & 39,0 & 2,4 \\
\hline M1_3 & 521,19 & 43,8 & 1,1 & 43,96 & 0,76 & 43,91 & 0,62 & 0,011 & 45,36 & 0,81 & 48,4 & 2,1 \\
\hline M1_4 & 503,115 & 33,2 & 1,1 & 37,09 & 0,73 & 35,94 & 0,61 & 8,507 & 38,73 & 0,70 & 40,7 & 1,9 \\
\hline M1_5 & 506,565 & 32,42 & 0,94 & 32,52 & 0,70 & 32,48 & 0,56 & 0,006 & 33,26 & 0,70 & 34,3 & 1,9 \\
\hline M2_1 & 507,195 & 83,7 & 1,5 & 81,7 & 1,0 & 82,35 & 0,85 & 1,197 & 85,8 & 1,1 & 83,2 & 2,6 \\
\hline M2_2 & 498,92 & 85,3 & 1,9 & 85,0 & 1,0 & 85,05 & 0,91 & 0,028 & 88,8 & 1,1 & 91,2 & 2,7 \\
\hline M2_3 & 505,23 & 82,9 & 1,6 & 80,8 & 1,1 & 81,45 & 0,93 & 1,128 & 84,0 & 1,1 & 86,7 & 2,7 \\
\hline M2_4 & 501,79 & 75,5 & 1,3 & 77,5 & 1,0 & $\begin{array}{l}76,73 \\
\end{array}$ & 0,83 & 1,399 & $\begin{array}{l}79,1 \\
\end{array}$ & 1,0 & 81,5 & 2,9 \\
\hline M2_5 & 491,99 & 80,4 & 1,4 & 80,8 & 1,1 & 80,63 & 0,84 & 0,043 & 82,1 & 1,1 & 79,0 & 2,7 \\
\hline M3_1 & 512,65 & 134,5 & 1,9 & 135,4 & 1,3 & 135,1 & 1,1 & 0,136 & 137,5 & 1,4 & 146,1 & 3,2 \\
\hline M3_2 & 507,52 & 129,6 & 1,7 & 127,5 & 1,3 & 128,2 & 1,0 & 0,983 & 129,6 & 1,3 & 133,4 & 3,2 \\
\hline M3_3 & 502,125 & 125,5 & 1,7 & 130,7 & 1,3 & 128,9 & 1,0 & 5,942 & 132,0 & 1,3 & 136,4 & 3,2 \\
\hline M3_4 & 497 & 136,2 & 1,8 & 136,4 & 1,3 & 136,3 & 1,0 & 0,006 & 138,1 & 1,4 & 142,5 & 3,3 \\
\hline M3_5 & 497,555 & 132,1 & 1,7 & 132,1 & 1,2 & 132,1 & 1,0 & 0,001 & 135,0 & 1,3 & 133,6 & 3,2 \\
\hline
\end{tabular}

Continua... 


\begin{tabular}{|c|c|c|c|c|c|c|c|}
\hline $\begin{array}{c}\text { atividade } \\
{ }^{214} \mathrm{Bi}(1764,5 \\
\mathrm{keV}) \mathrm{Bq}\end{array}$ & incerteza & $\begin{array}{c}\text { atividade } \\
\text { média }{ }^{214} \mathbf{B i}\end{array}$ & incerteza & $\chi^{2}$ & $\begin{array}{c}\text { atividade } \\
\text { média }{ }^{226} \mathrm{Ra}\end{array}$ & incerteza & $\chi^{2}$ \\
\hline 10,73 & 0,66 & 10,84 & 0,24 & 1,708 & 10,67 & 0,17 & 2,758 \\
\hline 12,01 & 0,74 & 11,42 & 0,25 & 0,892 & 10,77 & 0,17 & 15,097 \\
\hline 10,29 & 0,72 & 11,07 & 0,26 & 1,409 & 10,87 & 0,17 & 2,657 \\
\hline 11,29 & 0,71 & 10,94 & 0,26 & 0,285 & 10,97 & 0,17 & 3,283 \\
\hline 10,26 & 0,68 & 10,91 & 0,27 & 2,778 & 10,72 & 0,18 & 3,832 \\
\hline 11,04 & 0,68 & 11,07 & 0,27 & 0,014 & 10,80 & 0,17 & 2,067 \\
\hline 11,75 & 0,70 & 11,78 & 0,26 & 1,306 & 11,56 & 0,18 & 4,065 \\
\hline 12,17 & 0,74 & 13,10 & 0,29 & 6,989 & 12,66 & 0,19 & 11,419 \\
\hline 10,69 & 0,72 & 11,17 & 0,26 & 2,263 & 10,84 & 0,18 & 7,398 \\
\hline 12,02 & 0,65 & 10,76 & 0,25 & 5,698 & 10,52 & 0,17 & 8,057 \\
\hline 3,27 & 0,87 & 3,09 & 0,40 & 0,056 & 3,14 & 0,29 & 0,112 \\
\hline 3,40 & 0,87 & 3,02 & 0,40 & 0,257 & 2,72 & 0,26 & 1,902 \\
\hline 2,75 & 0,75 & 2,99 & 0,34 & 0,265 & 2,50 & 0,23 & 3,985 \\
\hline 2,4 & 1,1 & 2,36 & 0,42 & 0,004 & 2,69 & 0,27 & 1,149 \\
\hline 2,3 & 1,0 & 3,11 & 0,44 & 0,828 & 2,97 & 0,27 & 1,020 \\
\hline 294,3 & 5,9 & 305,7 & 2,4 & 4,931 & 301,7 & 1,7 & 10,321 \\
\hline 272,8 & 5,6 & 281,6 & 2,3 & 3,851 & 277,4 & 1,5 & 10,402 \\
\hline 283,2 & 6,0 & 278,4 & 2,3 & 1,453 & 274,7 & 1,5 & 14,926 \\
\hline 281,3 & 5,8 & 289,5 & 2,3 & 4,267 & 285,5 & 1,6 & 10,565 \\
\hline 283,9 & 5,9 & 285,9 & 2,3 & 2,643 & 283,9 & 1,6 & 4,145 \\
\hline 48,3 & 2,8 & 49,3 & 1,1 & 0,658 & 47,42 & 0,74 & 6,792 \\
\hline 45,1 & 3,1 & 46,0 & 1,0 & 5,610 & 45,16 & 0,74 & 7,046 \\
\hline 50,9 & 2,9 & 48,8 & 1,1 & 4,458 & 47,56 & 0,75 & 7,444 \\
\hline 47,0 & 3,0 & 47,0 & 1,0 & 0,733 & 45,83 & 0,68 & 6,480 \\
\hline 50,4 & 3,5 & 48,9 & 1,1 & 1,853 & 47,74 & 0,80 & 3,915 \\
\hline 35,4 & 1,6 & 35,29 & 0,61 & 1,085 & 34,17 & 0,41 & 7,651 \\
\hline 36,7 & 1,6 & 38,26 & 0,63 & 1,110 & 37,38 & 0,40 & 5,347 \\
\hline 44,2 & 1,6 & 45,47 & 0,68 & 2,558 & 44,61 & 0,46 & 5,405 \\
\hline 37,0 & 1,7 & 38,72 & 0,62 & 2,008 & 37,32 & 0,44 & 20,703 \\
\hline 32,5 & 1,5 & 33,24 & 0,60 & 0,606 & 32,84 & 0,41 & 1,451 \\
\hline 85,0 & 2,4 & 85,33 & 0,94 & 0,874 & 83,70 & 0,63 & 7,576 \\
\hline 88,0 & 2,5 & 88,98 & 0,95 & 0,821 & 86,94 & 0,66 & 9,796 \\
\hline 84,7 & 2,3 & 84,39 & 0,91 & 0,932 & 82,94 & 0,65 & 7,207 \\
\hline 81,4 & 2,3 & 79,68 & 0,88 & 1,337 & 78,11 & 0,60 & 8,718 \\
\hline 79,2 & 2,4 & 81,35 & 0,91 & 2,159 & 80,96 & 0,62 & 2,535 \\
\hline 138,9 & 2,9 & 138,8 & 1,1 & 6,023 & 136,88 & 0,79 & 11,404 \\
\hline 134,0 & 2,8 & 130,7 & 1,1 & 2,824 & 129,40 & 0,76 & 6,450 \\
\hline 132,1 & 2,9 & 132,5 & 1,1 & 1,669 & 130,57 & 0,75 & 13,456 \\
\hline 135,3 & 2,9 & 138,2 & 1,2 & 2,723 & 137,12 & 0,77 & 4,199 \\
\hline 134,0 & 2,9 & 134,7 & 1,1 & 0,231 & 133,27 & 0,76 & 3,088 \\
\hline
\end{tabular}

Tabela 4.4.3.5.1 Valores das atividades dos radioelementos da série do urânio. 


\begin{tabular}{|c|c|c|c|c|c|c|c|c|c|c|c|c|}
\hline Amostra & massa (g) & $\begin{array}{l}\text { atividade }{ }^{228} \mathrm{Ac} \\
(911,2 \mathrm{keV}) \mathrm{Bq}\end{array}$ & incerteza & $\begin{array}{c}\text { atividade }{ }^{228} \mathrm{Ac} \\
(968 \mathrm{keV}) \mathrm{Bq}\end{array}$ & incerteza & $\begin{array}{l}\text { atividade } \\
\text { média }{ }^{228} \mathrm{Ac}\end{array}$ & incerteza & $x^{2}$ & $\begin{array}{l}\text { atividade }{ }^{212} \mathrm{~Pb} \\
(238,6 \mathrm{keV}) \mathrm{Bq}\end{array}$ & incerteza & $\begin{array}{l}\text { atividade }{ }^{212} \mathrm{Bi} \\
(727,3 \mathrm{keV}) \mathrm{Bq}\end{array}$ & incerteza \\
\hline 1BR_1 & 483,57 & 18,32 & 0,93 & 16,6 & 1,2 & 17,7 & 1,3 & 1,238 & 17,43 & 0,35 & 18,6 & 1,6 \\
\hline 1BR_2 & 473,58 & 17,35 & 0,64 & 17,5 & 1,1 & 17,4 & 1,1 & 0,016 & 17,75 & 0,36 & 19,7 & 1,6 \\
\hline 1BR_3 & 487,77 & 18,64 & 0,86 & 18,1 & 1,9 & 18,5 & 1,0 & 0,078 & $\begin{array}{l}18,39 \\
\end{array}$ & 0,36 & 21,0 & 1,7 \\
\hline 1BR_4 & 491,61 & 17,22 & 0,61 & 18,5 & 1,3 & 17,4 & 1,0 & 0,766 & 17,43 & 0,35 & 17,7 & 1,6 \\
\hline 1BR_5 & 497,725 & 17,80 & 0,61 & 19,3 & 7,3 & 17,8 & 0,6 & 0,039 & 18,39 & 0,36 & 20,1 & 1,7 \\
\hline 2BR_1 & 498,035 & 16,51 & 0,81 & 18,8 & 1,4 & 17,1 & 0,7 & 2,140 & 18,87 & 0,36 & 19,7 & 1,5 \\
\hline 2BR_2 & 493,365 & 18,39 & 0,62 & 19,0 & 1,3 & 18,5 & 0,6 & 0,201 & 18,71 & 0,37 & 19,9 & 1,9 \\
\hline 2BR_3 & 500,7 & 22,3 & 1,5 & 21,3 & 1,3 & 21,7 & 1,0 & 0,224 & 21,74 & 0,40 & 22,9 & 1,9 \\
\hline 2BR_4 & 520,58 & 19,03 & 0,66 & 19,7 & 1,4 & 19,2 & 0,6 & 0,191 & 19,34 & 0,37 & 18,1 & 1,6 \\
\hline 2BR_5 & 497,675 & 17,35 & 0,60 & 16,4 & 1,7 & 17,2 & 0,6 & 0,276 & 16,79 & 0,35 & 19,0 & 1,7 \\
\hline K1_1 & 502,105 & 5,23 & 0,87 & $<\mathrm{LD}$ & & 5,2 & 0,9 & & 3,22 & 0,39 & 10,2 & 2,6 \\
\hline K1_2 & 484,575 & $<\mathrm{LD}$ & & 4,9 & 2,6 & 4,9 & 2,6 & & 4,56 & 0,43 & 6,8 & 2,7 \\
\hline K1_3 & 475,165 & 5,92 & $\begin{array}{l}0,89 \\
\end{array}$ & 4,6 & 1,2 & 5,4 & 0,7 & 0,766 & 2,67 & 0,41 & 4,1 & 2,7 \\
\hline K1_4 & 462,885 & 4,8 & 1,4 & $<\mathrm{LD}$ & & 4,8 & 1,4 & & 4,56 & 0,42 & 7,5 & 2,6 \\
\hline K1_5 & 460,59 & 4,43 & 0,99 & $<\mathrm{LD}$ & & 4,4 & 1,0 & & 3,98 & 0,41 & 6,9 & 2,6 \\
\hline U_1 & 508,26 & 70,0 & 2,5 & 63,5 & 4,5 & 68,5 & 2,2 & 1,574 & 71,0 & 1,3 & 52,1 & 5,6 \\
\hline U_2 & 496,115 & 54,6 & 2,4 & 45,1 & 3,1 & 51,1 & 1,9 & 5,899 & 40,6 & 1,1 & 48,4 & 5,2 \\
\hline U_3 & 495,105 & 53,4 & 2,4 & 49,4 & 15,1 & 53,3 & 2,3 & 0,066 & 52,3 & 1,1 & 56,4 & 6,0 \\
\hline U_4 & 497,17 & 55,4 & 2,4 & 54,2 & 4,3 & 55,1 & 2,1 & 0,057 & 57,3 & 1,1 & 56,2 & 5,8 \\
\hline $\mathbf{U} \mathbf{5}$ & 494,275 & 50,0 & 3,0 & 52,5 & 30,8 & 50,0 & 3,0 & 0,007 & 53,3 & 1,1 & 58,7 & 6,0 \\
\hline TH_1 & 504,3 & 280,4 & 6,5 & 284,4 & 10,9 & 281,5 & 5,6 & 0,098 & 283,3 & 3,6 & 304,6 & 13,9 \\
\hline TH_2 & 492,055 & 275,3 & 6,4 & 265,6 & 10,6 & 272,7 & 5,4 & 0,608 & 277,5 & 3,5 & 314,3 & 14,4 \\
\hline TH_3 & 514,87 & 275,3 & 6,5 & 270,4 & 9,9 & 273,8 & 5,4 & 0,165 & 273,7 & 3,5 & 285,4 & 13,3 \\
\hline TH_4 & 513,775 & 272,7 & 6,4 & 274,4 & 10,3 & 273,2 & 5,4 & 0,019 & 274,3 & 3,5 & 289,7 & 13,3 \\
\hline TH_5 & 506,84 & 283,0 & 7,3 & 286,1 & 11,2 & 283,9 & 6,1 & 0,054 & 283,9 & 3,6 & 286,2 & 13,4 \\
\hline M1_1 & 496,575 & 72,1 & 2,6 & 72,1 & 3,7 & 72,1 & 2,1 & 0,000 & 72,5 & 1,1 & 75,1 & 4,5 \\
\hline M1_2 & 508,11 & 73,3 & 1,9 & 74,1 & 3,4 & 73,5 & 1,7 & 0,034 & 73,2 & 1,1 & 76,4 & 4,2 \\
\hline M1_3 & 521,19 & 72,7 & 2,1 & 71,0 & 2,8 & 72,1 & 1,7 & 0,227 & 73,2 & 1,1 & 75,5 & 4,4 \\
\hline M1_4 & 503,115 & 75,0 & 2,0 & 72,5 & 3,1 & 74,3 & 1,7 & 0,450 & 74,1 & 1,1 & 79,0 & 4,4 \\
\hline M1_5 & 506,565 & 74,5 & 2,3 & 73,4 & 3,4 & 74,2 & 1,9 & 0,070 & 76,0 & 1,1 & 78,1 & 4,8 \\
\hline M2_1 & 507,195 & 134,6 & 3,9 & 133,4 & 4,1 & 134,0 & 2,8 & 0,052 & 134,2 & 1,7 & 148,7 & 7,4 \\
\hline M2_2 & 498,92 & 134,6 & 3,2 & 133,1 & 4,9 & 134,2 & 2,7 & 0,065 & 135,1 & 1,7 & 142,1 & 6,6 \\
\hline M2_3 & 505,23 & 133,3 & 3,2 & 140,5 & 5,4 & 135,2 & 2,8 & 1,318 & 136,1 & 1,7 & 141,2 & 6,8 \\
\hline M2 4 & 501,79 & 128,2 & 3,5 & 126,4 & 5,4 & 127,6 & 2,9 & 0,079 & 131,0 & 1,7 & 145,2 & 7,3 \\
\hline M2_5 & 491,99 & 130,8 & 3,6 & 128,6 & 4,8 & 130,0 & 2,9 & 0,135 & 131,3 & 1,7 & 149,6 & 7,2 \\
\hline M3_1 & 512,65 & 43,8 & 1,4 & 46,8 & 2,8 & 44,5 & 1,3 & 0,936 & 46,33 & 0,79 & 45,3 & 3,6 \\
\hline M3_2 & 507,52 & 43,2 & 1,8 & 46,2 & 2,9 & 44,0 & 1,5 & 0,788 & 44,73 & 0,77 & 52,3 & 4,1 \\
\hline M3_3 & 502,125 & 47,4 & 1,5 & 44,4 & 2,6 & 46,7 & 1,3 & 0,984 & 46,33 & 0,79 & 44,8 & 3,7 \\
\hline M3 4 & 497,00 & 44,8 & 2,1 & 46,4 & 2,7 & 45,4 & 1,6 & 0,216 & 46,33 & 0,79 & 45,7 & 3,7 \\
\hline M3_5 & 497,555 & 43,9 & 2,0 & 45,7 & 2,8 & 44,6 & 1,6 & 0,278 & 46,01 & 0,78 & 47,9 & 3,8 \\
\hline
\end{tabular}

Continua .... 
continuação

\begin{tabular}{|c|c|c|c|c|c|c|c|c|c|}
\hline $\begin{array}{c}\text { atividade }{ }^{208} \mathrm{Tl}(583,2 \\
\mathrm{keV}) \mathrm{Bq}\end{array}$ & incerteza & $\begin{array}{c}\text { atividade }{ }^{208} \mathrm{Tl}(860,6 \\
\text { keV) Bq }\end{array}$ & incerteza & $\begin{array}{c}\text { atividade média } \\
{ }^{208} \mathrm{Tl} \\
\end{array}$ & incerteza & $\chi^{2}$ & $\begin{array}{c}\text { atividade média } \\
{ }^{232} \mathrm{Th}\end{array}$ & incerteza & $\chi^{2}$ \\
\hline 18,31 & 0,49 & 17,3 & 2,3 & 18,27 & 0,48 & 0,169 & 17,749 & 0,281 & 2,424 \\
\hline 18,31 & 0,48 & 17,7 & 2,4 & 18,29 & 0,47 & 0,057 & 17,998 & 0,280 & 1,982 \\
\hline 19,02 & 0,52 & 18,0 & 2,1 & 18,96 & 0,50 & 0,231 & 18,650 & 0,288 & 3,090 \\
\hline 17,99 & 0,54 & 18,3 & 2,4 & 18,00 & 0,53 & 0,019 & 17,608 & 0,288 & 0,837 \\
\hline 18,45 & 0,48 & 21,5 & 2,3 & 18,58 & 0,47 & 1,651 & 18,504 & 0,285 & 2,636 \\
\hline 19,35 & 0,55 & 17,6 & 2,2 & 19,25 & 0,54 & 0,567 & 19,010 & 0,295 & 1,096 \\
\hline 18,31 & 0,51 & 22,7 & 2,3 & 18,52 & 0,50 & 3,468 & 18,669 & 0,291 & 3,988 \\
\hline 22,63 & 0,58 & 25,4 & 2,4 & 22,78 & 0,57 & 1,232 & 22,109 & 0,321 & 3,704 \\
\hline 19,96 & 0,52 & 16,1 & 2,1 & 19,74 & 0,50 & 3,104 & 19,440 & 0,294 & 4,187 \\
\hline 17,89 & 0,50 & 17,1 & 2,3 & 17,85 & 0,49 & 0,122 & 17,193 & 0,279 & 4,382 \\
\hline 5,57 & 0,73 & $<\mathrm{LD}$ & & 5,57 & 0,73 & & 5,898 & 0,700 & 2,870 \\
\hline$<\mathrm{LD}$ & & $<\mathrm{LD}$ & & & & & 4,874 & 0,424 & 1,068 \\
\hline 5,14 & 0,74 & $<\mathrm{LD}$ & & 5,14 & 0,74 & & 5,162 & 0,744 & 1,143 \\
\hline$<\mathrm{LD}$ & & $<\mathrm{LD}$ & & & & & 4,636 & 0,417 & 1,272 \\
\hline$<\mathrm{LD}$ & & $<\mathrm{LD}$ & & & & & 4,055 & 0,405 & 1,244 \\
\hline 70,6 & 3,0 & 55,5 & 9,0 & 69,2 & 2,8 & 2,530 & 69,9 & 1,1 & 13,420 \\
\hline 49,6 & 1,9 & 51,6 & 7,2 & 49,7 & 1,9 & 0,074 & 43,31 & 0,95 & 18,392 \\
\hline 53,1 & 2,4 & 62,1 & 11,0 & 53,5 & 2,3 & 0,638 & 52,59 & 0,95 & 1,301 \\
\hline 57,3 & 2,1 & 52,0 & 8,2 & 56,9 & 2,1 & 0,384 & 57,15 & 0,97 & 0,429 \\
\hline 53,9 & 2,3 & 64,5 & 9,6 & 54,4 & 2,2 & 1,152 & 53,65 & 0,95 & 2,110 \\
\hline 295,1 & 4,9 & 275,6 & 16,8 & 293,6 & 4,7 & 1,240 & 287,8 & 2,8 & 5,845 \\
\hline 285,7 & 4,9 & 269,6 & 17,6 & 284,6 & 4,7 & 0,775 & 281,3 & 2,7 & 7,688 \\
\hline 282,0 & 4,6 & 263,7 & 16,6 & 280,7 & 4,5 & 1,119 & 276,7 & 2,7 & 3,078 \\
\hline 282,0 & 4,7 & 286,0 & 17,4 & 282,2 & 4,6 & 0,049 & 277,7 & 2,7 & 2,790 \\
\hline 291,3 & 4,8 & 293,4 & 17,7 & 291,5 & 4,6 & 0,012 & 286,7 & 2,8 & 1,706 \\
\hline 74,0 & 1,5 & 77,6 & 5,9 & 74,2 & 1,5 & 0,342 & 73,18 & 0,85 & 1,380 \\
\hline 74,6 & 1,6 & 70,9 & 5,7 & 74,4 & 1,5 & 0,408 & 73,67 & 0,86 & 1,251 \\
\hline 76,0 & 1,7 & 77,6 & 5,9 & 76,1 & 1,6 & 0,060 & 74,16 & 0,88 & 2,566 \\
\hline 76,2 & 1,5 & 71,6 & 5,8 & 75,9 & 1,5 & 0,590 & 74,90 & 0,86 & 2,440 \\
\hline 77,4 & 1,5 & 79,8 & 7,1 & 77,5 & 1,5 & 0,113 & 76,60 & 0,87 & 0,820 \\
\hline 137,4 & 2,4 & 130,2 & 11,1 & 137,1 & 2,3 & 0,403 & 135,6 & 1,4 & 4,648 \\
\hline 141,2 & 2,4 & 132,4 & 8,8 & 140,6 & 2,3 & 0,914 & 137,2 & 1,4 & 4,985 \\
\hline 137,4 & 2,3 & 130,9 & 9,1 & 137,0 & 2,2 & 0,479 & 136,6 & 1,3 & 1,070 \\
\hline 131,8 & 2,3 & 126,5 & 8,6 & 131,4 & 2,2 & 0,354 & 131,6 & 1,3 & 3,919 \\
\hline 135,5 & 2,4 & 128,7 & 8,7 & 135,1 & 2,3 & 0,567 & 133,2 & 1,3 & 7,649 \\
\hline 44,9 & 1,1 & 50,8 & 5,7 & 45,1 & 1,1 & 1,043 & 45,87 & 0,62 & 1,947 \\
\hline 42,0 & 1,1 & 37,9 & 5,1 & 41,8 & 1,1 & 0,598 & 43,97 & 0,63 & 9,571 \\
\hline 48,4 & 1,5 & 48,3 & 5,3 & 48,4 & 1,5 & 0,000 & 46,74 & 0,69 & 1,853 \\
\hline 43,8 & 1,2 & 45,4 & 6,2 & 43,9 & 1,2 & 0,063 & 45,57 & 0,64 & 3,084 \\
\hline 46,3 & 1,5 & 50,9 & 7,9 & 46,4 & 1,5 & 0,330 & 46,16 & 0,68 & 0,617 \\
\hline
\end{tabular}

Tabela 4.4.3.5.2 Valores das atividades dos radioelementos da série do tório. 


\subsection{Concentrações de potássio, urânio e tório nas amostras de concreto}

A Tabela 4.4.3.5.1 apresenta a atividade do ${ }^{214} \mathrm{~Pb}$, medida através dos picos de absorção total com 295,2 keV e com 351,9 keV e ${ }^{214} \mathrm{Bi}$, medida através dos picos de absorção total com $609,3 \mathrm{keV}, 1120,3 \mathrm{keV}$ e $1764,5 \mathrm{keV}$. Essa mesma tabela apresenta também as atividades médias do ${ }^{214} \mathrm{~Pb}$ e do ${ }^{214} \mathrm{Bi}$, ponderadas pelo inverso das variâncias das estimativas individuais. A Tabela 4.4.3.5.1 apresenta ainda a atividade do ${ }^{226} \mathrm{Ra}$, estimada pela média ponderada das cinco estimativas fornecidas pelos picos de absorção total do ${ }^{214} \mathrm{~Pb}$ e do ${ }^{214} \mathrm{Bi}$.

Para verificar, em cada caso, se as médias ponderadas são representativas dos valores individuais, aplica-se o critério do $\chi^{2}$. A hipótese nula, neste caso é que os valores individuais são bem ajustados pelos valores médios. O nível de significância adotado foi de 0,05. A Tabela 4.4.3.5.1 apresenta o resultado da aplicação desse critério.

A Tabela 4.4.3.5.2 apresenta as atividades do ${ }^{228} \mathrm{Ac}$, medidas pelos picos de absorção total em 911,2 keV e $969 \mathrm{keV}$, do ${ }^{212} \mathrm{~Pb}$ em 238,6 keV, do ${ }^{212} \mathrm{Bi}$ em 727,3 keV e do ${ }^{208} \mathrm{Tl}$, medido pelos picos de absorção total com 583,2 keV e $860,3 \mathrm{keV}$. A Tabela 4.4.3.5.2 apresenta também as medidas das atividades do ${ }^{228} \mathrm{Ac}$ e do ${ }^{208} \mathrm{Tl}$, ponderadas pelo inverso das variâncias das estimativas individuais. A Tabela 4.4.3.5.2 apresenta ainda a atividade do ${ }^{232} \mathrm{Th}$, estimada pela média ponderada das estimativas fornecidas pelos picos de absorção total do ${ }^{228} \mathrm{Ac},{ }^{212} \mathrm{~Pb},{ }^{212} \mathrm{Bi}$ e ${ }^{208} \mathrm{Tl}$. Nessa estimativa, assume-se que a série do tório esteja em equilíbrio radioativo secular. Por fim, a Tabela 4.4.3.5.2 apresenta os resultados da aplicação do critério do $\chi^{2}$ sobre as médias ponderadas.

A Tabela 4.5.1 apresenta a concentração de potássio, expressa em porcentagem de massa, do urânio natural e do tório, expressas em partes por milhão (ppm) em massa, 
medidas nas cinco amostras coletadas durante o envasamento do bloco K1. A concentração de urânio natural é obtida considerando que o ${ }^{238} \mathrm{U}$ e o ${ }^{226} \mathrm{Ra}$ estejam em equilíbrio radioativo secular nessas amostras. A concentração de tório é obtida considerando que a série do tório esteja em equilíbrio radioativo secular nas amostras.

As Tabelas 4.5.2 a 4.5.8, apresentam os resultados correspondentes aos demais blocos. Finalmente, a Tabela 4.5.9 apresenta uma síntese das concentrações finais de todos os blocos de calibração.

\begin{tabular}{|c|c|c|c|}
\hline Bloco K1 & $\begin{array}{c}\text { CK } \\
(\%)\end{array}$ & $\begin{array}{c}\text { CU } \\
(p p m \text { eU) }\end{array}$ & $\begin{array}{c}\text { CTh } \\
(\text { ppm } \text { eTh })\end{array}$ \\
\hline K1_1 & $5,28 \pm 0,07$ & $0,22 \pm 0,54$ & $1,97 \pm 0,15$ \\
\hline K1_2 & $5,25 \pm 0,07$ & $0,00 \pm 0,00$ & $2,03 \pm 0,16$ \\
\hline K1_3 & $5,19 \pm 0,07$ & $0,44 \pm 0,54$ & $1,92 \pm 0,16$ \\
\hline K1_4 & $5,17 \pm 0,07$ & $0,57 \pm 0,59$ & $0,69 \pm 0,14$ \\
\hline K1_5 & $5,35 \pm 0,07$ & $0,00 \pm 0,00$ & $2,06 \pm 0,17$ \\
\hline media & $5,25 \pm 0,07$ & $0,25 \pm 0,26$ & $1,74 \pm 0,59$ \\
\hline
\end{tabular}

Tabela 4.5.1 Valores de concentração de cada amostra do bloco K1.

\begin{tabular}{|c|c|c|c|}
\hline Bloco $\boldsymbol{U}$ & $\begin{array}{c}\boldsymbol{C K} \\
(\boldsymbol{\%})\end{array}$ & $\begin{array}{c}\boldsymbol{C U} \\
(\boldsymbol{p p m} \boldsymbol{e U})\end{array}$ & $\begin{array}{c}\boldsymbol{C T h} \\
(\text { ppm } \boldsymbol{e T h})\end{array}$ \\
\hline U_1 & $0,67 \pm 0,04$ & $41,99 \pm 2,04$ & $33,73 \pm 0,51$ \\
\hline U_2 & $0,59 \pm 0,04$ & $44,75 \pm 2,37$ & $22,39 \pm 0,43$ \\
\hline U_3 & $0,66 \pm 0,05$ & $49,52 \pm 2,21$ & $26,27 \pm 0,45$ \\
\hline U_4 & $0,66 \pm 0,04$ & $45,94 \pm 2,03$ & $28,16 \pm 0,45$ \\
\hline U_5 & $0,64 \pm 0,04$ & $47,33 \pm 2,06$ & $26,62 \pm 0,47$ \\
\hline media & $0,65 \pm 0,03$ & $45,90 \pm 2,82$ & $27,43 \pm 4,11$ \\
\hline
\end{tabular}

Tabela 4.5.2 Valores de concentração de cada amostra do bloco $U$.

\begin{tabular}{|c|c|c|c|}
\hline Bloco TH & $\begin{array}{c}\text { CK } \\
\text { (\%) }\end{array}$ & $\begin{array}{c}\boldsymbol{C U} \\
(\boldsymbol{p p m} \boldsymbol{e U})\end{array}$ & $\begin{array}{c}\boldsymbol{C T h} \\
(\boldsymbol{p p m} \boldsymbol{e} \text { Th })\end{array}$ \\
\hline TH_1 & $0,85 \pm 0,03$ & $10,07 \pm 1,86$ & $140,26 \pm 1,35$ \\
\hline TH_2 & $0,75 \pm 0,03$ & $7,08 \pm 1,42$ & $140,25 \pm 1,36$ \\
\hline TH_3 & $0,81 \pm 0,03$ & $6,38 \pm 2,09$ & $132,24 \pm 1,27$ \\
\hline TH_4 & $0,78 \pm 0,03$ & $8,24 \pm 1,69$ & $132,78 \pm 1,28$ \\
\hline TH_5 & $0,76 \pm 0,03$ & $5,84 \pm 1,62$ & $139,42 \pm 1,35$ \\
\hline media & $0,79 \pm 0,04$ & $7,52 \pm 1,68$ & $136,99 \pm 4,11$ \\
\hline
\end{tabular}

Tabela 4.5.3 Valores de concentração de cada amostra do bloco $\mathbf{T H}$. 


\begin{tabular}{|c|c|c|c|}
\hline Bloco M1 & $\begin{array}{c}\boldsymbol{C K} \\
(\boldsymbol{\%})\end{array}$ & $\begin{array}{c}\boldsymbol{C U} \\
(\text { ppm } \boldsymbol{e U})\end{array}$ & $\begin{array}{c}\boldsymbol{C T h} \\
(\boldsymbol{p p m} \boldsymbol{e T h})\end{array}$ \\
\hline M1_1 & $2,54 \pm 0,03$ & $5,15 \pm 0,76$ & $36,30 \pm 0,42$ \\
\hline M1_2 & $2,64 \pm 0,04$ & $4,91 \pm 0,64$ & $35,80 \pm 0,40$ \\
\hline M1_3 & $2,62 \pm 0,04$ & $6,45 \pm 0,65$ & $34,87 \pm 0,40$ \\
\hline M1_4 & $2,67 \pm 0,04$ & $6,01 \pm 0,78$ & $36,71 \pm 0,41$ \\
\hline M1_5 & $2,60 \pm 0,04$ & $4,87 \pm 0,66$ & $37,10 \pm 0,41$ \\
\hline media & $2,61 \pm 0,05$ & $5,48 \pm 0,71$ & $36,15 \pm 0,87$ \\
\hline
\end{tabular}

Tabela 4.5.4 Valores de concentração de cada amostra do bloco M1.

\begin{tabular}{|c|c|c|c|}
\hline Bloco M2 & $\begin{array}{c}\text { CK } \\
\text { (\%) }\end{array}$ & $\begin{array}{c}\text { CU } \\
(\text { ppm } \text { eU) }\end{array}$ & $\begin{array}{c}\text { CTh } \\
(\text { ppm } \text { eTh })\end{array}$ \\
\hline M2_1 & $3,45 \pm 0,04$ & $14,05 \pm 0,93$ & $65,85 \pm 0,65$ \\
\hline M2_2 & $3,54 \pm 0,04$ & $16,18 \pm 1,16$ & $67,56 \pm 0,66$ \\
\hline M2_3 & $3,47 \pm 0,04$ & $13,76 \pm 1,11$ & $66,42 \pm 0,65$ \\
\hline M2_4 & $3,38 \pm 0,04$ & $11,87 \pm 1,00$ & $63,76 \pm 0,64$ \\
\hline M2_5 & $3,56 \pm 0,04$ & $13,16 \pm 1,04$ & $66,47 \pm 0,67$ \\
\hline media & $3,48 \pm 0,07$ & $13,81 \pm 1,57$ & $66,01 \pm 1,40$ \\
\hline
\end{tabular}

Tabela 4.5.5 Valores de concentração de cada amostra do bloco M2.

\begin{tabular}{|c|c|c|c|}
\hline Bloco M3 & $\begin{array}{c}\text { CK } \\
(\%)\end{array}$ & $\begin{array}{c}\boldsymbol{C U} \\
(\boldsymbol{p p m} \text { eU) }\end{array}$ & $\begin{array}{c}\text { CTh } \\
(\text { ppm } \boldsymbol{e} \text { Th })\end{array}$ \\
\hline M3_1 & $1,48 \pm 0,03$ & $21,13 \pm 1,07$ & $21,95 \pm 0,29$ \\
\hline M3_2 & $1,53 \pm 0,03$ & $19,67 \pm 1,01$ & $21,37 \pm 0,30$ \\
\hline M3_3 & $1,53 \pm 0,03$ & $23,67 \pm 1,15$ & $23,00 \pm 0,31$ \\
\hline M3_4 & $1,51 \pm 0,03$ & $23,54 \pm 1,15$ & $22,60 \pm 0,31$ \\
\hline M3_5 & $1,49 \pm 0,03$ & $21,78 \pm 1,23$ & $22,76 \pm 0,32$ \\
\hline media & $1,51 \pm 0,02$ & $21,96 \pm 1,69$ & $22,33 \pm 0,67$ \\
\hline
\end{tabular}

Tabela 4.5.6 Valores de concentração de cada amostra do bloco M3. 


\begin{tabular}{|c|c|c|c|c|}
\hline Bloco BKG1 & $\begin{array}{c}\boldsymbol{C K} \\
(\%)\end{array}$ & inc & $\begin{array}{c}\boldsymbol{C U} \\
(\text { ppm } \boldsymbol{e U})\end{array}$ & $\begin{array}{c}\boldsymbol{C T h} \\
(\text { ppm } \text { eTh })\end{array}$ \\
\hline 1BR_1 & $0,65 \pm 0,01$ & 0,01 & $1,17 \pm 0,32$ & $9,04 \pm 0,14$ \\
\hline 1BR_2 & $0,66 \pm 0,02$ & 0,02 & $1,41 \pm 0,30$ & $9,32 \pm 0,14$ \\
\hline 1BR_3 & $0,66 \pm 0,01$ & 0,01 & $1,37 \pm 0,35$ & $9,44 \pm 0,14$ \\
\hline 1BR_4 & $0,65 \pm 0,01$ & 0,01 & $1,05 \pm 0,28$ & $8,80 \pm 0,13$ \\
\hline 1BR_5 & $0,65 \pm 0,01$ & 0,01 & $1,48 \pm 0,29$ & $9,07 \pm 0,13$ \\
\hline media & $0,65 \pm 0,00$ & 0,00 & $1,30 \pm 0,18$ & $9,13 \pm 0,25$ \\
\hline
\end{tabular}

Tabela 4.5.7 Valores de concentração de cada amostra do bloco BKG1.

\begin{tabular}{|c|c|c|c|}
\hline Bloco BKG2 & $\begin{array}{c}\boldsymbol{C K} \\
(\boldsymbol{\%})\end{array}$ & $\begin{array}{c}\boldsymbol{C U} \\
(\boldsymbol{p p m} \boldsymbol{e U})\end{array}$ & $\begin{array}{c}\boldsymbol{C T h} \\
(\boldsymbol{p p m} \boldsymbol{e T h})\end{array}$ \\
\hline 2BR_1 & $0,66 \pm 0,01$ & $1,99 \pm 0,35$ & $9,29 \pm 0,14$ \\
\hline 2BR_2 & $0,64 \pm 0,01$ & $1,03 \pm 0,27$ & $9,33 \pm 0,13$ \\
\hline 2BR_3 & $0,65 \pm 0,01$ & $1,76 \pm 0,29$ & $10,87 \pm 0,16$ \\
\hline 2BR_4 & $0,66 \pm 0,01$ & $1,00 \pm 0,31$ & $9,19 \pm 0,13$ \\
\hline 2BR_5 & $0,66 \pm 0,01$ & $1,27 \pm 0,35$ & $8,52 \pm 0,13$ \\
\hline media & $0,65 \pm 0,01$ & $1,41 \pm 0,44$ & $9,44 \pm 0,87$ \\
\hline
\end{tabular}

Tabela 4.5.8 Valores de concentração de cada amostra do bloco BKG2.

\begin{tabular}{|c|c|c|c|}
\hline Blocos & $\boldsymbol{K}(\%)$ & $\boldsymbol{e U}(\boldsymbol{p p m})$ & $\boldsymbol{e T h}(\boldsymbol{p p m})$ \\
\hline $\boldsymbol{K} \boldsymbol{1}$ & $5,25 \pm 0,07$ & $0,25 \pm 0,26$ & $1,74 \pm 0,59$ \\
\hline $\boldsymbol{U}$ & $0,65 \pm 0,03$ & $45,90 \pm 2,82$ & $27,43 \pm 4,11$ \\
\hline $\boldsymbol{T H}$ & $0,79 \pm 0,04$ & $7,52 \pm 1,68$ & $136,99 \pm 4,11$ \\
\hline $\boldsymbol{B K G 1}$ & $0,65 \pm 0,00$ & $1,30 \pm 0,18$ & $9,13 \pm 0,25$ \\
\hline $\boldsymbol{B K G} \mathbf{2}$ & $0,65 \pm 0,01$ & $1,41 \pm 0,44$ & $9,44 \pm 0,87$ \\
\hline $\boldsymbol{M 1}$ & $2,61 \pm 0,05$ & $5,48 \pm 0,71$ & $36,15 \pm 0,87$ \\
\hline $\boldsymbol{M} 2$ & $3,48 \pm 0,07$ & $13,81 \pm 1,57$ & $66,01 \pm 1,40$ \\
\hline $\boldsymbol{M 3}$ & $1,51 \pm 0,02$ & $21,96 \pm 1,69$ & $22,33 \pm 0,67$ \\
\hline
\end{tabular}

Tabela 4.5.9 Valores das concentrações dos blocos obtidas das atividades determinadas por espectrômetro gama semicondutor de HPGe. 


\subsection{Sumário dos Resultados}

Os resultados descritos neste capítulo mostram que a maioria dos blocos de concreto, apresentam, dependendo da forma com que os dados são analisados, heterogeneidades na descrição dos elementos radioativos potássio, urânio e tório. Os valores de construção desses elementos, por sua vez, sugerem que essas irregularidades sejam pequenas de forma que elas podem ser utilizadas na calibração de espectrômetros gama portáteis e aerotransportados. 


\section{Calibração de Espectrômetros Gama Portáteis e Aerotransportados}

\subsection{Calibração de Espectrômetros Portáteis}

O procedimento de calibração necessita que os intervalos de energia ou janelas espectrais sejam definidas ao redor dos picos de absorção total do ${ }^{40} \mathrm{~K},{ }^{214} \mathrm{Bi} \mathrm{e}{ }^{208} \mathrm{Tl}$. O critério para ajuste dessas janelas estão bem descritas na literatura por Lфvborg e colaboradores (1976) e estas são escolhidas para corresponder a frações significativas das áreas dos picos, assim como para minimizar a interferência dos picos vizinhos no espectro.

Além disso, a janela de contagem total é definida entre dois limites largamente espaçados, cobrindo a maior parte do intervalo de energia correspondente aos espectros dos elementos radioativos naturais.

As três janelas espectrais dos elementos radioativos acumulam, tanto, as contagens que pertencem aos correspondentes picos de absorção total, quanto as contagens de outros picos de interferência, além do contínuo Compton e das contagens que pertencem a radiação de fundo.

As taxas de contagens devido a radiação de fundo tem que ser independentemente estimadas e diretamente subtraídas das taxas de contagens em cada janela espectral.

No método dos fatores de stripping, as equações de calibração são escritas assumindo que a interferência de um espectro sobre as outras duas janelas espectrais é proporcional as taxas de contagens, livres de qualquer interferência, em sua própria janela espectral. Então:

$$
\begin{aligned}
& \left(N_{K}\right)_{\text {liquido }}=N_{K}-\beta \cdot\left(N_{T h}\right)_{\text {liquido }}-\gamma \cdot\left(N_{U}\right)_{\text {liquido }} \\
& \left(N_{U}\right)_{\text {liquido }}=N_{U}-\alpha \cdot\left(N_{T h}\right)_{\text {liquido }}-g \cdot\left(N_{K}\right)_{\text {liquido }} \\
& \left(N_{T h}\right)_{\text {corr }}=N_{T h}-a \cdot\left(N_{U}\right)_{\text {liquido }}-b \cdot\left(N_{K}\right)_{\text {liquido }}
\end{aligned}
$$


Onde $N_{T h}, N_{U}, N_{K}$ são as taxas de contagens medidas nas janelas espectrais, com as correspondentes taxas de radiação de fundo subtraídas, e $\left(N_{\text {Th }}\right)_{\text {líquido }},\left(N_{U}\right)_{\text {líquido }}$, $\left(N_{K}\right)_{\text {liquido }}$ são as taxas de contagens livres de qualquer interferência, ou taxas de contagens líquidas. As constantes $\alpha, \beta, \gamma, a, b$ e $g$ são as constantes de stripping e estão descritas na Tabela 2.6.6.1.

Uma vez que o potássio tem um espectro gama monoenergético com pico de absorção total de energia muito menor que as as energias encontradas nos picos de ${ }^{214} \mathrm{Bi} \mathrm{e}{ }^{208} \mathrm{Tl}$, espera-se que as constantes $b$ e $g$ sejam iguais a zero.

A conversão das taxas de contagens para concentrações de potássio $\left(C_{K}\right)$, urânio $\left(C_{U}\right)$ e tório $\left(C_{T h}\right)$ é dada pelas constantes de sensibilidade das janelas espectrais $S_{K}, S_{U}$ e $S_{T h}$, na forma:

$$
\begin{aligned}
C_{K} & =\frac{\left(N_{K}\right)_{\text {liquido }}}{S_{K}} \\
\mathrm{C}_{\mathrm{U}} & =\frac{\left(N_{U}\right)_{\text {liquido }}}{S_{U}} \\
\mathrm{C}_{\mathrm{Th}} & =\frac{\left(N_{T h}\right)_{\text {liquido }}}{S_{\text {Th }}}
\end{aligned}
$$

As equações de calibração pelo método da matriz inversa pode ser facilmente derivado do método dos fatores de stripping na forma:

$$
\left[\begin{array}{c}
N_{K} \\
N_{U} \\
N_{T h}
\end{array}\right]=\left[\begin{array}{lll}
\alpha_{K, K} & \alpha_{K, U} & \alpha_{K, T h} \\
\alpha_{U, K} & \alpha_{U, U} & \alpha_{U, T h} \\
\alpha_{T h, K} & \alpha_{T h, U} & \alpha_{T h, T h}
\end{array}\right] \cdot\left[\begin{array}{c}
C_{K} \\
C_{U} \\
C_{T h}
\end{array}\right]
$$

onde o sistema sistema de matriz representa os coeficientes de interferência entre as janelas espectrais. Das equações 5.1.1 a 5.1.6 são encontradas as relações: 


$$
\begin{aligned}
& \alpha=\frac{\alpha_{U, T h}}{\alpha_{T h, T h}} \\
& \beta=\frac{\alpha_{K, T h}}{\alpha_{T h, T h}} \\
& \gamma=\frac{\alpha_{K, U}}{\alpha_{U, U}} \\
& \mathrm{a}=\frac{\alpha_{T h, U}}{\alpha_{U, U}} \\
& \mathrm{~b}=\frac{\alpha_{T h, K}}{\alpha_{K, K}} \\
& \mathrm{~g}=\frac{\alpha_{U, K}}{\alpha_{K, K}} \\
& \mathrm{~S}_{\mathrm{K}}=\alpha_{K, K} \\
& \mathrm{~S}_{\mathrm{U}}=\alpha_{U, U} \\
& \mathrm{~S}_{\mathrm{Th}}=\alpha_{T h, T h}
\end{aligned}
$$

Das equações 5.1.12 e 51.13, $\alpha_{T h, K}$ e $\alpha_{U, K}$ são esperados serem nulos.

O sistema de matrizes Equação 5.1.7 é uma forma conveniente de obter os fatores de stripping e as sensibilidades das janelas quando blocos mistos de calibração são utilizados para tal objetivo. Uma alternativa para o uso desses fatores e sensibilidades é escrever formalmente o sistema inverso (Equação 5.1.7), na forma:

$$
\left[\begin{array}{l}
C_{K} \\
C_{U} \\
C_{T h}
\end{array}\right]=\left[\begin{array}{lll}
\beta_{K, K} & \beta_{K, U} & \beta_{K, T h} \\
\beta_{U, K} & \beta_{U, U} & \beta_{U, T h} \\
\beta_{T h, K} & \beta_{T h, U} & \beta_{T h, T h}
\end{array}\right] \cdot\left[\begin{array}{c}
N_{K} \\
N_{U} \\
N_{T h}
\end{array}\right]
$$

Embora:

$$
\left[\begin{array}{lll}
\beta_{K, K} & \beta_{K, U} & \beta_{K, T h} \\
\beta_{U, K} & \beta_{U, U} & \beta_{U, T h} \\
\beta_{T h, K} & \beta_{T h, U} & \beta_{T h, T h}
\end{array}\right]=\left[\begin{array}{lll}
\alpha_{K, K} & \alpha_{K, U} & \alpha_{K, T h} \\
\alpha_{U, K} & \alpha_{U, U} & \alpha_{U, T h} \\
\alpha_{T h, K} & \alpha_{T h, U} & \alpha_{T h, T h}
\end{array}\right]^{-1}
$$

É mais prático usar diretamente o sistema 5.1.17, quando os fatores de stripping e sensibilidades não são utilizados. Espera-se que os coeficientes $\beta_{T h, K}$ e $\beta_{U, K}$ também sejam nulos. 


\subsubsection{Exemplo Calibração}

Um espectrômetro gama portátil marca Geofysica, modelo GS512 foi calibrado utilizando os blocos de concreto construídos.

A Tabela 5.1.1.1 apresenta a diferença entre as concentrações de potássio, urânio e tório $\left(C_{K}, C_{U}\right.$ e $\left.C_{T h}\right)$ contidas nos blocos K1, U, TH, M1, M2 e M3 e o bloco para observação da radiação de fundo, BKG2. Os valores negativos obtidos no caso do bloco K1 indicam que o concreto utilizado nesse bloco tem menor concentração de urânio e tório do que o bloco BKG2.

\begin{tabular}{|c|c|c|c|c|c|c|}
\hline Janela & $\boldsymbol{K 1}$ & $\boldsymbol{U}$ & $\boldsymbol{T H}$ & $\boldsymbol{M 1}$ & $\boldsymbol{M 2}$ & $\boldsymbol{M 3}$ \\
\hline $\boldsymbol{K}$ & $4,60 \pm 0,07$ & $0,00 \pm 0,03$ & $0,14 \pm 0,04$ & $1,96 \pm 0,05$ & $2,85 \pm 0,07$ & $0,86 \pm 0,02$ \\
\hline $\boldsymbol{U}$ & $-1,16 \pm 0,51$ & $44,5 \pm 2,8$ & $6,1 \pm 1,8$ & $4,07 \pm 0,84$ & $12,4 \pm 1,7$ & $20,5 \pm 1,8$ \\
\hline $\boldsymbol{T h}$ & $-7,7 \pm 1,1$ & $18,0 \pm 4,1$ & $127,6 \pm 4,1$ & $26,7 \pm 1,2$ & $56,6 \pm 1,6$ & $12,9 \pm 1,1$ \\
\hline
\end{tabular}

Tabela 5.1.1.1 Valores das concentrações líquidas dos blocos, medidos por espectrometria gama de alta resolução.

Essa diferença é devida à diferença de materiais utilizados. Enquanto que o BKG2 foi construído com materiais comuns, areia de construção e brita de basalto, enquanto o bloco K1 substituiu esse material por feldspato potássico. Em função desses valores negativos o bloco K1 não foi utilizado nesse procedimento de calibração.

A Tabela 5.1.1.2 apresenta as taxas de contagem líquidas $\left(N_{K}, N_{U}\right.$ e $\left.N_{T h}\right)$, contagens por minuto, observadas sobre os blocos de concreto nas janelas espectrais do espectrômetro GS512.

\begin{tabular}{|c|c|c|c|c|c|c|}
\hline Janela & $\boldsymbol{K 1}$ & $\boldsymbol{U}$ & $\boldsymbol{T H}$ & $\boldsymbol{M 1}$ & $\boldsymbol{M 2}$ & $\boldsymbol{M 3}$ \\
\hline $\boldsymbol{K}$ & $895 \pm 17$ & $728 \pm 16$ & $539 \pm 15$ & $438 \pm 15$ & $1082 \pm 17$ & $634 \pm 16$ \\
\hline $\boldsymbol{U}$ & - & $976 \pm 12$ & $667 \pm 11$ & $184,3 \pm 8,5$ & $521 \pm 10$ & $529 \pm 10$ \\
\hline $\boldsymbol{T h}$ & - & $132,9 \pm 7 \pm 2$ & $861 \pm 11$ & $183,5 \pm 7,6$ & $423,9 \pm 9,0$ & $115,1 \pm 7,1$ \\
\hline
\end{tabular}

Tabela 5.1.1.2 Valores das taxas de contagens (cpm) líquidas dos blocos, medidas com espectrômetro gama portátil. 
Os valores contidos nas Tabelas 5.1.1.1 e 5.1.1.2 foram ajustados ao sistema de Equações 5.1.7, seguindo o procedimento descrito em Ribeiro e colaboradores (2005). No caso da equação do potássio o resultado obtido foi:

$$
N_{K}=(190 \pm 46) \cdot C_{K}+(17,4 \pm 4,5) \cdot C_{U}+(3,3 \pm 1,3) \cdot C_{T h}
$$

O $\chi^{2}$ obtido nesse ajuste foi de 37,88 e a matriz de covariância entre os coeficientes $\alpha_{K, K}, \alpha_{K, U}$ e $\alpha_{K, T h}$ é:

$$
\operatorname{cov}\left(\alpha_{K, K}, \alpha_{K, U}, \alpha_{K, T h}\right)=\left[\begin{array}{ccc}
2,0713 & -0,0582 & -0,0255 \\
-0,0582 & 0,0207 & -0,0015 \\
-0,0025 & -0,0015 & 0,0018
\end{array}\right] \cdot 10^{3}
$$

O coeficiente $\alpha_{K, K}$ é o único que pode ser obtido utilizando os valores correspondentes ao bloco K1. A estimativa desse coeficiente, nesse caso é:

$$
\alpha_{K, K}=194,6 \pm 4,7 \mathrm{cpm} / \% \mathrm{~K}
$$

No caso da equação do urânio, o resultado obtido é:

$$
N_{U}=(21,3 \pm 1,0) \cdot C_{U}+(4,20 \pm 0,27) \cdot C_{T h}
$$

Com um valor de $\chi^{2}$ de 2,2383. A matriz de covariância entre os coeficientes $\alpha_{U, U} \mathrm{e}$ $\alpha_{U, T h}$ é:

$$
\operatorname{cov}\left(\alpha_{U, U}, \alpha_{U, T h}\right)=\left[\begin{array}{cc}
1,0042 & -0,1201 \\
-0,1201 & 0,0730
\end{array}\right]
$$

No caso da equação para o potássio, o resultado obtido foi:

$$
N_{K}=(7,14 \pm 0,25) \cdot C_{T h}
$$

Com um valor de $\chi^{2}$ de 9,5364 .

Os resultados mostram que, no caso das equações correspondentes a $N_{U}$ e $N_{T h}$, não se pode rejeitar a hipótese de que os modelos adotados (Equação 5.1.7) representem os valores experimentais. Além disso, os resultados sugerem que as incertezas das variáveis envolvidas foram bem estimadas. 
No caso da equação correspondente a $N_{K}$, o $\chi^{2}$ observado sugere que as incertezas nas concentrações de potássio estão muito subestimadas.

A Tabela 5.1.1.3 apresenta os valores dos coeficientes de interferência $\alpha, \beta$ e $\gamma$ e das sensibilidades $S_{K}, S_{U}$ e $S_{T h}$ calculadas através das equações 5.1.8 a 5.1.16.

\begin{tabular}{|c|c|}
\hline Coeficientes e sensibilidades & Valores \\
\hline $\boldsymbol{\alpha}$ & $0,588 \pm 0,043$ \\
\hline $\boldsymbol{\beta}$ & $0,462 \pm 0,183$ \\
\hline $\boldsymbol{\gamma}$ & $0,816 \pm 0,214$ \\
\hline $\boldsymbol{S}_{\boldsymbol{K}}(\boldsymbol{c p m} / \boldsymbol{\%} \boldsymbol{K})$ & $190 \pm 46$ \\
\hline $\boldsymbol{S}_{\boldsymbol{U}}(\mathbf{c p m} / \mathbf{p p m} \boldsymbol{U})$ & $21,3 \pm 1,0$ \\
\hline $\boldsymbol{S}_{\boldsymbol{T h}}(\mathbf{c p m} / \boldsymbol{p p m} \boldsymbol{T h})$ & $7,14 \pm 0,25$ \\
\hline
\end{tabular}

Tabela 5.1.1.3 Valores das constantes de espalhamento Compton e janelas de sensibilidades do espectrômetro gama portátil do IAG/USP. 


\subsection{Calibração de Espectrômetros Aerotransportados}

A teoria é basicamente a mesma apresentada na seção 5.1, porém com algum detalhe de operação do equipamento. Geralmente em aerolevantamentos utiliza-se a expressão 2,5 conjuntos de cristais. Onde temos duas caixas de cristais com detectores apontados para baixo (downward looking) e meio pacote de cristais apontados para cima (upward looking).

As medidas são tomadas para cada conjunto de cristais, separadamente, depois para todo o conjunto. Após a coleta dos dados os valores das constantes de stripping são calculadas através de um programa chamado PADWIN, desenvolvido por Lфvborg (1981). Esse programa leva em consideração os valores de correções geométricas para cada energia dos elementos radioativos de interesse.

$\mathrm{Na}$ conversão das taxas de contagens da janela de um espectrômetro aerotransportado para níveis de concentrações de solo, existem três fatores adicionais que devem ser considerados e que não aparecem em espectrômetros portáteis (IAEA, 1989):

1. as razões de stripping variam com a altitude, acima do solo

2. as três janelas de contagem variam com a altitude, acima do solo

3. as janelas de sensibilidades são necessárias na altitude nominal de vôo e não podem ser determinadas de medidas no solo em grandes blocos de calibração com concentrações conhecidas de potássio, urânio e tório.

O próprio espalhamento no ar, das razões de stripping $\alpha, \beta$ e $\gamma$ aumentam com a altitude acima do solo. Em levantamentos aerogamaespectrométricos é uma prática padrão medir as três razões de stripping no solo, com a utilização de grandes blocos de calibração ou através de blocos transportáveis para calibração e então calcular o aumento nas razões de stripping com relação a altitude. Nenhuma correção é aplicada as 
razões de stripping reversas $a, b$ e $g$, pois são muito pequenas e podem ser desconsideradas.

As razões de stripping são uma boa medida da qualidade de um sistema espectrométrico. Abaixo (Tabela 5.2.1) são apresentados alguns valores de um sistema com boa calibração e um sistema considerado com uma pobre calibração (IAEA, 1991).

\begin{tabular}{|c|c|c|}
\hline Coeficientes de espalhamento & Sistema bom & Sistema ruim \\
\hline $\boldsymbol{\alpha}$ & 0,25 & 0,38 \\
\hline $\boldsymbol{\beta}$ & 0,40 & 0,43 \\
\hline $\boldsymbol{\gamma}$ & 0,81 & 0,92 \\
\hline $\boldsymbol{a}$ & 0,06 & 0,09 \\
\hline $\boldsymbol{b}$ & 0 & 0,01 \\
\hline $\boldsymbol{g}$ & 0,003 & 0,06 \\
\hline
\end{tabular}

Tabela 5.2.1 Exemplos de valores de coeficientes de espalhamento Compton para dois sistemas de detecção gamaespectrométricos. 


\section{Conclusão}

A técnica que foi utilizada permitiu a construção de blocos transportáveis de concreto radioativo para a calibração de espectrômetros gama portáteis e aerotransportados. Os blocos obtidos apresentam resistência mecânica adequada a sua finalidade, são fáceis de movimentar e possuem concentrações de potássio, urânio e tório que permitem calibrações precisas e relativamente rápidas.

A distribuição do fluxo de radiação gama proveniente da superfície dos blocos de concreto foi analisada e a conclusão final é que a maioria deles apresenta pequenas heterogeneidades na distribuição dos elementos radioativos no seu interior. Essas heterogeneidades são menos evidentes nos resultados de medida de concentração de potássio, concentração equivalente de urânio e concentração equivalente de tório feitas em laboratório.

Os resultados das medidas feitas em laboratório e do exemplo de aplicação dos blocos de concreto na calibração de um espectrômetro gama portátil sugere a existência de imprecisões na determinação das concentrações de potássio e nas concentrações equivalentes de urânio.

A presença dessas imprecisões é indicado, no caso do urânio, pelo ajuste insatisfatório, em algumas amostras, da estimativa média da atividade do ${ }^{226} \mathrm{Ra}$ dos valores individuais das estimativas fornecidas pelo pico de absorção total do ${ }^{214} \mathrm{~Pb}$ e ${ }^{214} \mathrm{Bi}$.

No caso das concentrações de potássio, os resultados de exemplo de aplicação sugerem que as incertezas dessa concentração tenham sido subestimadas. 


\section{Referências Bibliográficas}

AGSO (Australian Geological Survey Organization). A Guide to the Technical Specifications for Airborne Gamma-Ray Surveys. Record 1995/60, 1995

BARretTo, P. M. C., AUSTERlitZ, C., MAlheiros, T. AND LØVBORG, L. Radioactive concrete sources at IRD/CNEN, Brazil, for the calibration of uranium exploration and environmental field instruments. IRD/DEX-3/CNEN, Instituto de Radioproteção e Dosimetria, Comissão Nacional de Energia Nuclear, Rio de Janeiro, 1986

BEVInGtON, P. R. Data Reduction and Error Analysis for the Physical Sciences (NY: McGraw-Hill Book Company), 1969.

BRISTOW, Q. Airborne Gamma-ray Spectrometry in Uranium Exploration Principles and Current Practice; Nuclear Geophysics, Ed. G.G. Clayton, Pergamon press, $31 \mathrm{pp}, 1983$.

CARLOS, D. U. Distribuição Vertical de U, Th e K nas Formações Iratí e Corumbataí na Região de Limeira - SP. Trabalho de Graduação, 27 pp, 2002.

CURRIE, L. A. Limits for Qualitative Detection and Quantitative Determination Aplication to Radiochemistry. Analytical Chemistry, 40:3:586-593, 1968.

DARNLEY, A. G., FLEET M. Evaluation of airborne gamma-ray spectrometry in the Bancroft and Elliot Lake areas of Ontario, Canada, In Proc. $5^{\text {th }}$ Symp. Remote Sensing of the Environment. Pp.833-853. University of Michigan, Ann Arbor, 1968.

DARNLEY, A. G., GRASTY, R.L. Mapping from the air by gamma-ray spectrometry. In Geochemical Exploration, Proc. $3^{\text {rd }}$ International Geochemical Exploration Symposium,pp. 485-500. CIM Spec. Vol. 11, Montreal, 1971. 
DARNLEY, A. G. The Development of Airborne Gamma-ray Spectrometry: Case Study in Technological Innovation and Acceptance, Nuclear Geophysics, Vol. 5, No. 4, pp.377-402, 1991.

DAVIS, J. C. Statistics and Data Analysis in Geology. Ed. John Wiley \& Sons, 1986.

GRASTY, R.L. The design, construction and application of airborne gamma-ray spectrometer calibration pads - Thailand; Geological Survey of Canada, Paper 8710, 34p, 1987.

GRASTY, R.L., HOLMAN, P.B. AND BLANCHARD, Y.B. Transportable Calibration Pads for Ground and Airborne Gamma-ray Spectrometers; Geological Survey of Canada, Paper 90-23, 25 p, 1991.

GRASTY, R.L. Recent Developments in Airborne Gamma Ray Surveying. In $7^{\text {th }}$ International Congress of the Brazilian Geophysical Society, 1999.

HEAD, J. H. Minimum detectable photopeak area in Ge(Li) spectra. Nuclear Instruments and Methods, 98, 419-428, 1972.

HURTGEN, C., JEROME, S., WOODS, M. Revisiting Currie - How low can you go? Applied Radiation and Isotopes 53(1-2), 45-50, 2000.

IAEA (INTERNATIONAL ATOMIC ENERGY AGENCY), Construction and Use of Calibration Facilities for Radiometric Field Equipment. Technical Report Series, $\mathrm{n}^{\circ}$ 309, Vienna, IAEA, 84 p, 1989.

IAEA (INTERNATIONAL ATOMIC ENERGY AGENCY), Airborne gamma-ray spectrometer surveying. Technical Report Series, n 323, Vienna, IAEA, 97 p, 1991.

IAEA (INTERNATIONAL ATOMIC ENERGY AGENCY) Guidelines for radioelement mapping using gamma ray spectrometry data, IAEA-TECDOC-1363, 2003. 
KILLEEN, P.G. Gamma-ray Spectrometric Methods in Uranium Exploration Application and Interpretation, p. 163-230, In Geophysics and Geochemistry in the Search for Metallic Ores, edited by P.J. Hood, Geological Survey of Canada, Economic Geology Report 31, 811 p, 1979.

KNOLL, G. F. Radiation Detection and Measurement. Ed. John Wiley \& Sons, 1988.

LØVBORG, L., KIRKEGAARD, P., CHRISTIANSEN, E.M. Design of NaI(TI) scintillation detectors for use in gamma ray surveys of geological sources. In: Exploration for Uranium Ore Deposits (Vienna: IAEA) pp. 127-148, 1976.

LØVBORG, L., BØTTER-JENSEN, L. AND KIRKEGAARD, P. Experience with concrete calibration sources for radiometric field instruments. Geophysics $43, n^{\circ} 3$, 543-549, 1978.

LØVBORG, L., CHRISTIANSEN, E. M., BØTTER-JENSEN, L. AND KIRKEGAARD, P. Pads facility for the calibration of gamma-ray measurements of rocks. Ris $\emptyset$ Report n R-454, 43 p, 1981.

LØVBORG, L., MOSE, E. Counting statistics in radioelement assaying with a portable spectrometer. Geophysics, vol. 52, no.4, p555-563, 1987.

MINTY, B.R.S. Fundamentals of airborne gamma-ray spectrometry. AGSO Journal of Australian Geology and Geophysics, 17 (2): 39-50, 1997.

MULTALA, J. The construction of gamma-ray spectrometer calibration pads. Geoexploration 19, 33-46, 1981.

RIBEIRO, F. B., ROQUE, A. Vertical Distribution of Uranium, Thorium and Potassium and of volumetric Heat Production Rates in the Sediments of the São Francisco Basin, Central Brazil, Applied Radiation and Isotopes 55, 393-405, 2001. 
RIBEIRO, F. B., CARLOS, D. U., HIODO, F. Y., STROBINO, E. F. A least squares procedure for calculating the calibration constants of a portable gamma-ray spectrometer. Radiation Protection Dosimetry 113(3):251-265, 2005.

SANTOS, R. N., MARQUES, L. S., RIBEIRO, F. B. Estudo do Desequilíbrio Radioativo das Séries do ${ }^{238} \mathrm{U} \mathrm{e}^{232}$ Th em Rochas Vulcânicas das Ilhas de Trindade e de Martin Vaz. Geochimica Brasiliensis, 14(1):135-153, 2000.

SPIEGEL, M. R. Estatística. Ed. Mcgraw-Hill, São Paulo, Rio de Janeiro, 1976.

STROMSWOLD, D.C. Monitoring of the airport calibration pads at Walker Field, Grand Junction, Colorado for long term radiation variations; U.S. Department of Energy, Grand Junction Office Report no. GJBX-99(78), 1978.

SZÖGHY, I. M., KISH L. (1978) Determination of Radioactive Disequilibrium in Uranium - Bearing Rocks. Canadian Journal of Earth Sciences 15, 35-44

VUOLO, J. H. Fundamentos da Teoria dos Erros, $2^{\text {a }}$ ed, Editora Edgard Blucher Ltda, São Paulo, 1996.

WALFORD, G. V., GILBOY, W. B. Fundamentals of Sensitivity Limits in Low Level Counting. In: Adams, J. A. S.; Lowder, W. M. \& Gesell, T. F. (eds); The Natural Radiation Environment, II, v. 1135-1154, 1972.

WARD, D.L. Construction of calibration pads facility, Walker Field, Grand Junction, Colorado, Bendix Field Engineering Corporation, GJBX-37(78). U.S. Department of Energy, Grand Junction, CO, 16pp, 1978.

WOlBerG, J. R. Prediction Analysis. Princeton, CA: D. Van Nostrand Company, Inc., 1968. 